\title{
Timber Bridge Pile Splicing with Fiber Reinforced Polymer Wraps
}

Drew L. Damich

West Virginia University, dldamich@mix.wvu.edu

Follow this and additional works at: https://researchrepository.wvu.edu/etd

Part of the Civil Engineering Commons, Mechanics of Materials Commons, Structural Engineering Commons, and the Structural Materials Commons

\section{Recommended Citation}

Damich, Drew L., "Timber Bridge Pile Splicing with Fiber Reinforced Polymer Wraps" (2021). Graduate Theses, Dissertations, and Problem Reports. 8291.

https://researchrepository.wvu.edu/etd/8291

This Thesis is protected by copyright and/or related rights. It has been brought to you by the The Research Repository @ WVU with permission from the rights-holder(s). You are free to use this Thesis in any way that is permitted by the copyright and related rights legislation that applies to your use. For other uses you must obtain permission from the rights-holder(s) directly, unless additional rights are indicated by a Creative Commons license in the record and/ or on the work itself. This Thesis has been accepted for inclusion in WVU Graduate Theses, Dissertations, and Problem Reports collection by an authorized administrator of The Research Repository @ WVU. For more information, please contact researchrepository@mail.wvu.edu. 


\title{
Timber Bridge Pile Splicing with Fiber Reinforced Polymer Wraps
}

\author{
Drew Damich
}

\author{
Thesis submitted to the \\ College of Engineering and Mineral Resources at \\ West Virginia University in \\ partial fulfillment of the requirements \\ for the degree of
}

\section{Master of Science \\ in \\ Civil Engineering}

\author{
Hota V.S. GangaRoa, Ph.D., P.E., Chair \\ Udaya B. Halabe, PhD., P.E. \\ Hung-Liang (Roger) Chen, PhD., P.E.
}

Department of Civil and Environmental Engineering

\author{
Morgantown, West Virginia \\ 2021
}

Keywords: Fiber Reinforced Polymer, Timber, Pile, Splice, Wrapping

Copyright 2021 Drew Damich 


\title{
ABSTRACT \\ Timber Bridge Pile Splicing with Fiber Reinforced Polymer Wraps
}

\author{
Drew Damich \\ Constructed Facilities Center, West Virginia University
}

Timber pile repair using splicing is widely used but little research has been done to determine their strength capacity after repair using this method. Current timber pile splicing mechanisms utilize various steel or wooden components. Fiber Reinforced Polymer (FRP) wraps can be utilized as replacement to conventional materials in splicing of timber piles. This study evaluated the strength capacities of traditional splicing mechanisms in relation to FRP wrap splice mechanisms. Traditional splicing mechanisms consisted of flat steel plate, C-channel steel plate, and wooden plate splices. The FRP wrap splice consisted of unidirectional glass/epoxy composite with three layers of fabric as well as bidirectional FRP wraps, where the fabrics were reinforcing wooden pieces in both the longitudinal and hoop direction. These four mechanisms were tested and compared under shear, bending, and axial loading scenarios. Of the three traditional splicing methods the C-channel was the strongest for each loading scenario. The FRP warp method was the strongest under axial loading conditions, however it lacked in bending capacity compared to the traditional methods. Bending failure in FRP splicing mechanism occurred due to the lack of fiber reinforcement in the hoop direction of the pile. To account for improving the capacity along the hoop direction, another design was utilized using the same three-layer unidirectional glass/epoxy composite with longitudinal dominant fiber orientation and three additional layers with hoop dominant fiber orientation. This new design was tested under shear and bending loading scenarios. Results of the six-layer wrap design showed significant improvement in bending and shear capacities from the original three-layer FRP composite wrap design. Virgin timber piles were 
tested under bending to determine the bending strength capacity for each of the splice mechanisms. This comparison provided that splicing a timber pile with splice mechanisms tested in this program decreased the bending capacity of piles (30-60 percent).

A theoretical analysis was performed to determine the shear, axial, and bending capacities of timber piles spliced with FRP wrap using design equations that were developed in this program. Theoretical stress values were compared with experimental stress values gained through laboratory testing to determine the reliability of the design equations. Shear and bending equations had low variability in theoretical versus experimental stress values. For axial analysis, when assuming failure occurs by compression of FRP large variability in theoretical versus experimental data was noted, meaning failure did not occur from compression in FRP. A new design equation was developed using Euler's Buckling equation for axial failure due to buckling. This equation provided much lower variability in theoretical versus experimental data, meaning failure in axial compression occurred in all three test specimens due to buckling followed by de-bond. The design methodology proposed herein for FRP wrap splices should be adapted as a common practice. 


\section{ACKNOWLEDGEMENTS}

I would like to express my deepest gratitude to my advisor and committee chairman, Dr. Hota V.S. GangaRao, P.E., for his inestimable guidance throughout this research. I also express deep gratitude to Dr. Roger Chen, P.E., and Dr. Udaya Halabe, P.E., for their assistance in revisions to this thesis. I would also like to express my sincerest thanks to Mr. Mark Skidmore and Mr. Joshua Wilt for their immense assistance in laboratory testing.

I thank Andrew Kenney, and Christopher Klocke for their assistance in laboratory experimentation. I would also like to thank Leslie VanZant for her administrative assistance. I thank the Louisiana Department of Transportation and Development for providing the financial support for Project 15-3ST, through the Constructed Facilities Center. 


\section{TABLE OF CONTENTS}

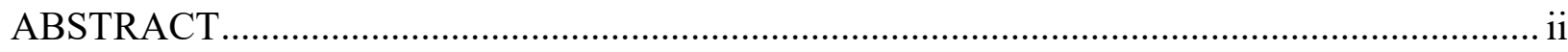

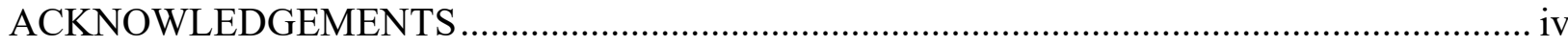

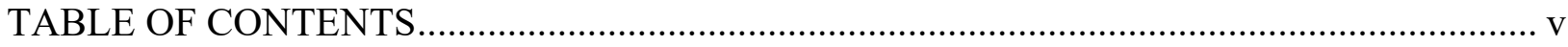

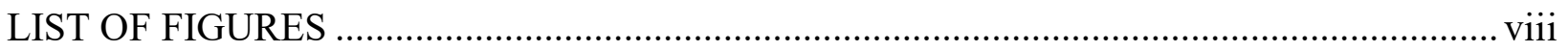

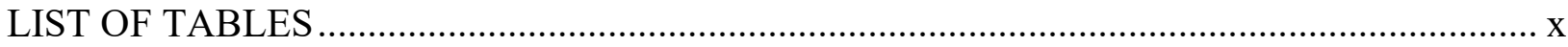

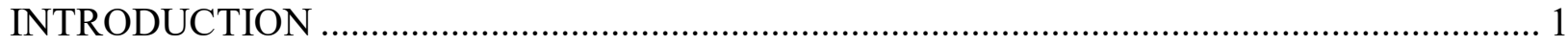

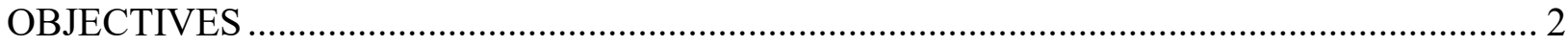

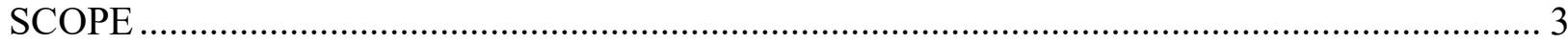

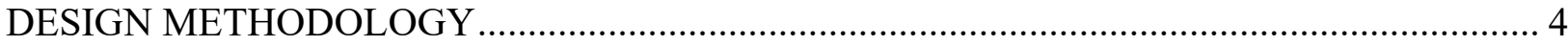

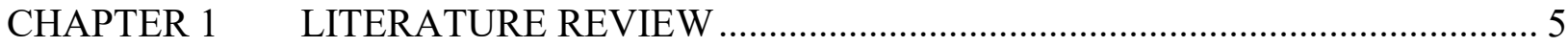

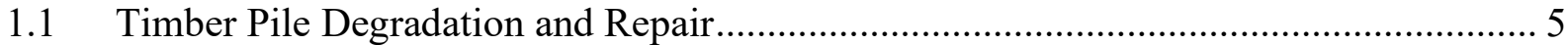

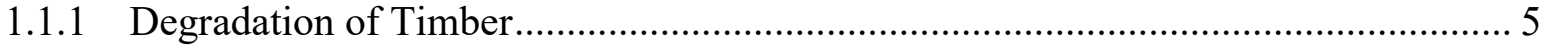

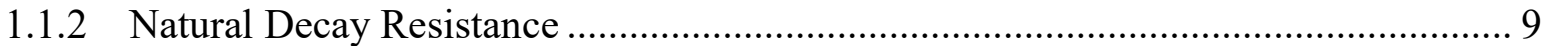

1.1.3 Induced Decay Resistance with Preservatives........................................................ 9

1.1.4 Timber Pile Repair Methods............................................................................. 10

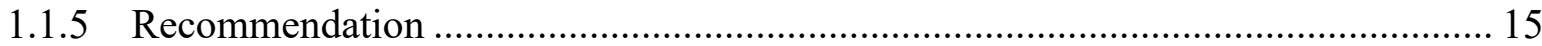

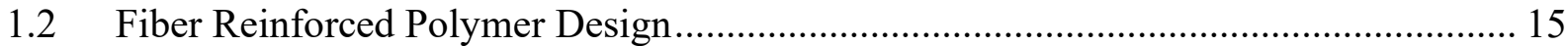

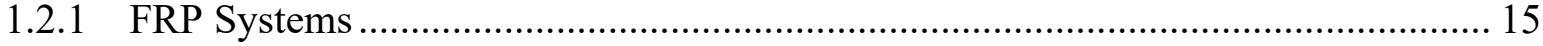

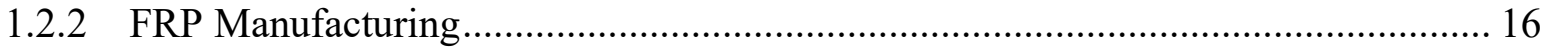

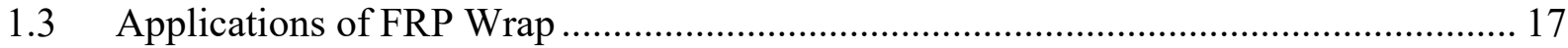

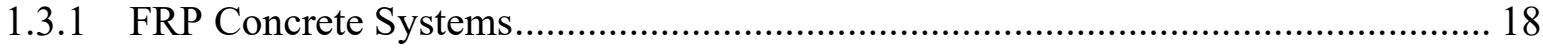

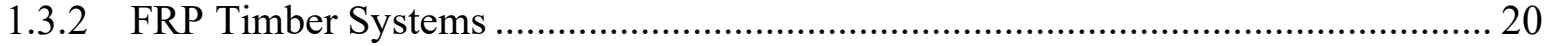

1.3.3 Conclusions from FRP Wrap Applications.......................................................... 23

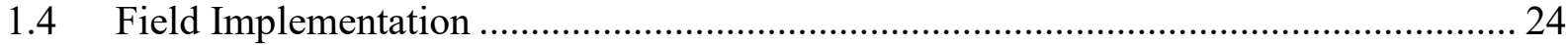

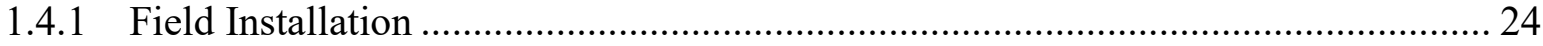

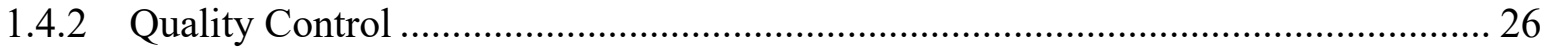

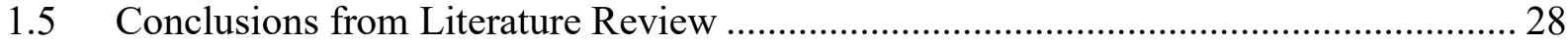

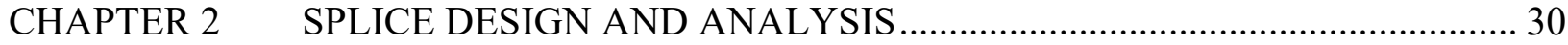

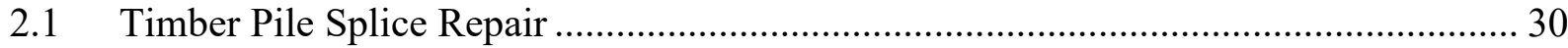

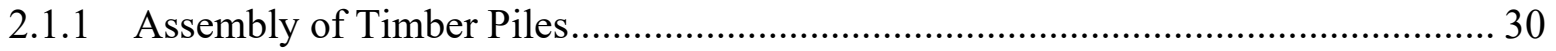


2.2 Timber Pile Repair Using Fiber Reinforced Polymers .................................................... 33

2.2.1 Assembly of Fiber Reinforced Polymer Splicing .................................................... 34

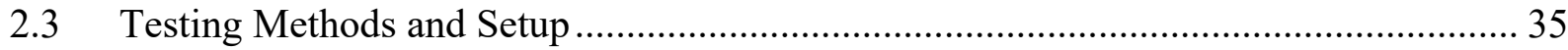

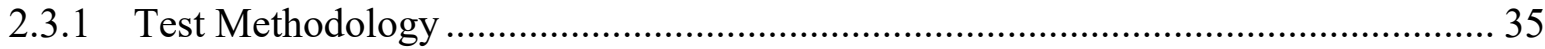

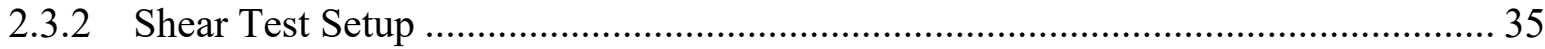

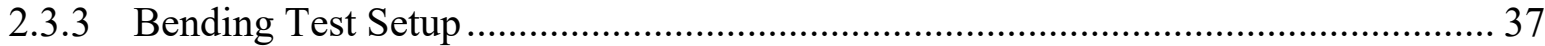

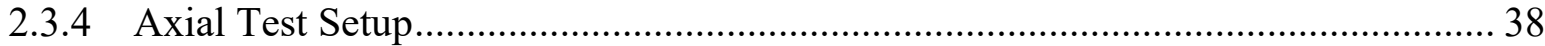

2.4 Test Results and Data Analysis for Traditional Splicing ………………........................ 39

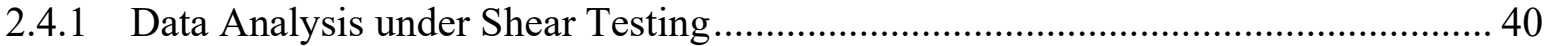

2.4.2 Data Analysis under Bending Testing ..................................................................... 45

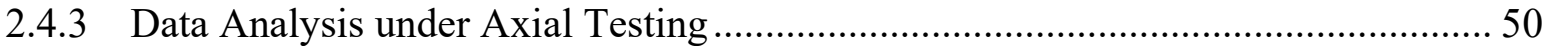

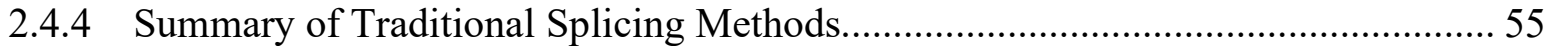

2.5 Test Results and Data Analysis for FRP Splicing ....................................................... 56

2.5.1 Data Analysis of FRP Splicing under Shear Testing …………………………..... 56

2.5.2 Data Analysis of FRP Splicing under Bending Testing ………………………..... 58

2.5.3 Data Analysis of FRP Splicing under Axial Testing ……………………………........ 60

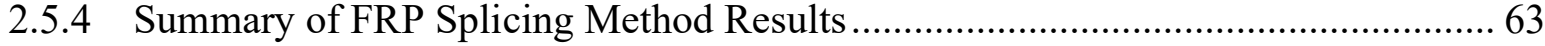

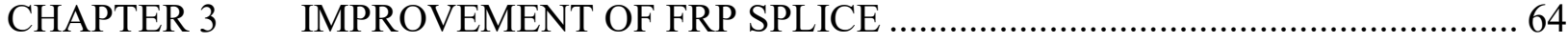

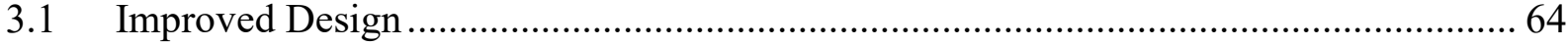

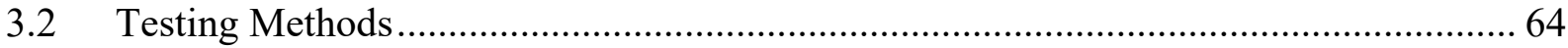

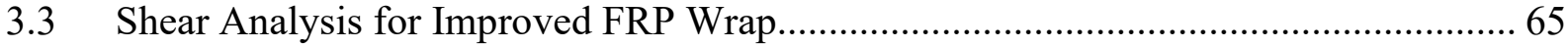

3.3.1 Summary and Failure Modes of Six-Layer FRP Wrap Under Shear......................... 66

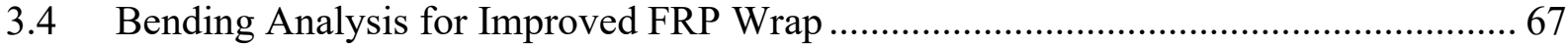

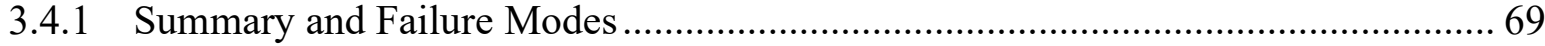

3.5 Conclusions from Improved FRP Splice................................................................... 71

CHAPTER 4 BENDING CAPACITY OF TIMBER PILES …………………………….... 73

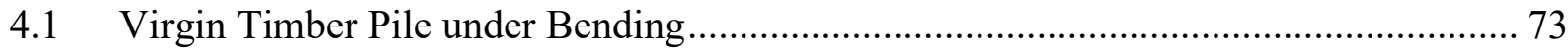

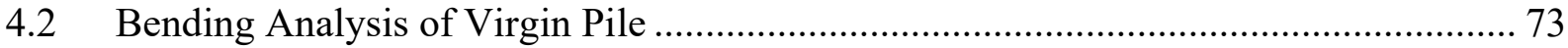

4.2.1 Discussion of Failure Modes in Virgin Pile......................................................... 74

4.3 Summary for Virgin Timber Pile Bending Analysis................................................ 75

CHAPTER 5 THEORETICAL ANALYSIS OF FRP SPLICE ………………………....... 76

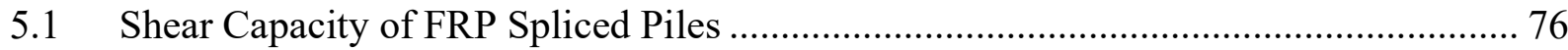

5.1.1 Shear Capacity with Three Layers of FRP Wrap.................................................. 76

5.1.2 Shear Capacity with Six Layers of FRP Wrap......................................................... 77 
5.1.3 Conclusions from Theoretical Shear Analysis..................................................... 78

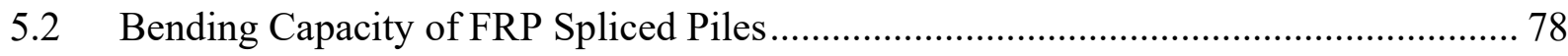

5.2.1 Bending Capacity with Three Layers of FRP Wrap .............................................. 79

5.2.2 Bending Capacity with Six Layers of FRP Wrap ……………………………........ 79

5.2.3 Conclusions from Theoretical Bending Analysis .................................................. 80

5.3 Axial Capacity of FRP Spliced Piles - Compression Failure ………………….......... 81

5.3.1 Axial Capacity of FRP Wrapped Piles - Compression Failure ………………….... 81

5.3.2 Conclusion from Theoretical Axial Analysis - Compression Failure ……………... 82

5.4 Axial Capacity of FRP Spliced Piles - Non-Compression Failure................................ 82

5.4.1 Axial Capacity of FRP Wrapped Piles - Non-Compression Failure......................... 84

5.4.2 Conclusions from Theoretical Axial Analysis - Non-Compression Failure ............. 85

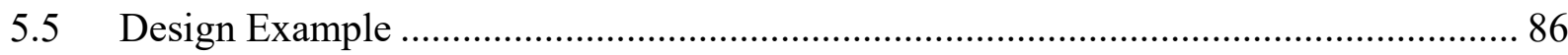

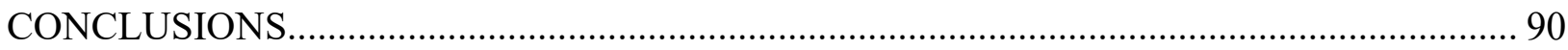

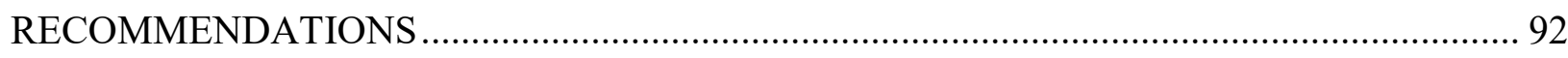

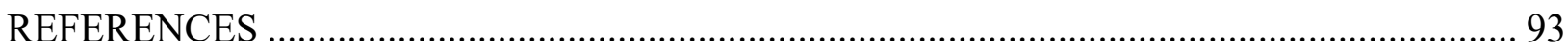

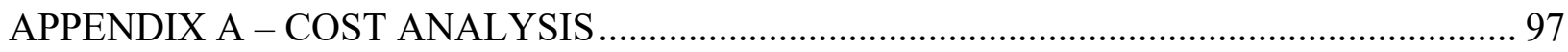




\section{LIST OF FIGURES}

Figure 1-1 - Timber Pile Decay at Ground Surface [5] ...................................................... 6

Figure 1-2 - Bacterial Decay of Timber Piles [6] ................................................................ 7

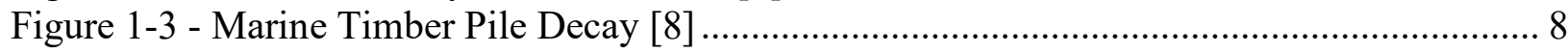

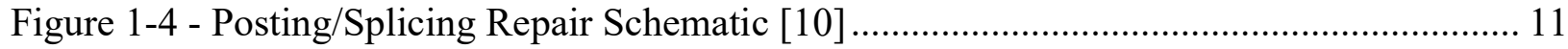

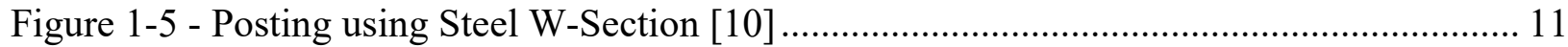

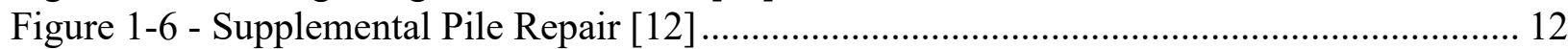

Figure 1-7 - Jacketing Flexible and Split Fiberboard Forms [12] ........................................... 13

Figure 1-8 - Polyvinyl Chloride Wrapping [12] ................................................................. 14

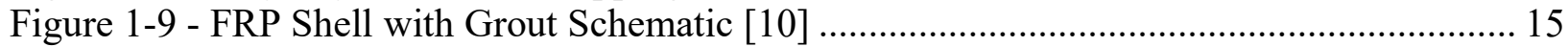

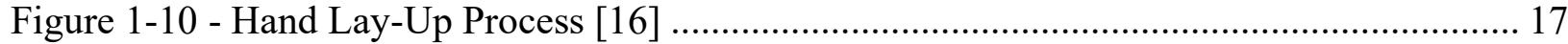

Figure 1-11 - FRP Wrap for Strengthening of Concrete Column [18] .................................. 18

Figure 1-12 - Full Depth FRP U-Shaped Shear Reinforcement [20] .................................... 20

Figure 1-13 - Timber Column Confinement Types [22] ..................................................... 21

Figure 1-14 - Strength of Timber Beams with U-Shaped FRP [21] ...................................... 22

Figure 1-15 - U-Shaped GFRP Wrap Reinforcement [23] ............................................. 23

Figure 1-16 - Pile Excavation and Removal of Debris ....................................................... 24

Figure 1-17 - Sanding of Pile in Field.................................................................................. 25

Figure 1-18 - Rubber Banding of Pile ......................................................................... 26

Figure 1-19 - Infrared Thermography of Concrete AASHTOH Girder Wrapped with FRP [29] 27

Figure 1-20 - Digital Tap Hammer ...................................................................................... 28

Figure 2-1 - C-Channel Splice Detail ............................................................................... 31

Figure 2-2 - C-Channel and Flat Steel Plate Detail ............................................................. 32

Figure 2-3 - Steel Splice Specimen Constructed in WVU-CFC Lab..................................... 32

Figure 2-4 - Unidirectional FRP Composite Orientation [31] .......................................... 33

Figure 2-5 - Completed Fiber Reinforced Polymer Splice ................................................... 35

Figure 2-6 - Shear Test Schematic..................................................................................... 36

Figure 2-7 - Shear Test Setup with Wooden Splice............................................................ 37

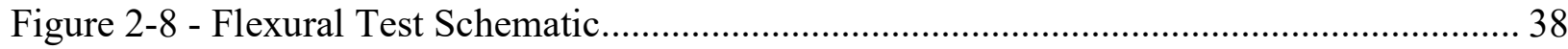

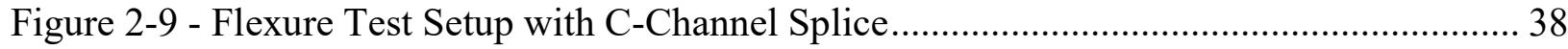

Figure 2-10 - Axial Compression Test Schematic ................................................................... 39

Figure 2-11 - Axial Test Setup with C-Channel Splice .......................................................... 39

Figure 2-12 - Shear Stress vs Deflection for Steel Plate Splice............................................... 41

Figure 2-13 - Shear Stress vs Deflection for C-Channel Splice ............................................... 42

Figure 2-14 - Shear Stress vs Deflection for Wood Splice.................................................. 43

Figure 2-15 - Yielding of Top and Bottom Plates in Steel Splicing ....................................... 44

Figure 2-16 - Yielding of Bolts in C-Channel Splicing .................................................. 45

Figure 2-17 - Cracking of Top and Bottom Plates in Wood Splicing ..................................... 45

Figure 2-18 - Bending Stress vs Deflection for Steel Splice ................................................... 47

Figure 2-19 - Bending Stress vs Deflection for C-Channel Splice........................................ 48

Figure 2-20 - Bending Stress vs Deflection for Wood Splicing ............................................. 48

Figure 2-21 - Steel Splice Yielding During Bending Test................................................ 49

Figure 2-22 - Steel Splice Cracked Pile .............................................................................. 50

Figure 2-23 - Wood Splicing Crack during Bending Test...................................................... 50

Figure 2-24 - Axial Stress vs Deflection for Flat Steel Plate Splice......................................... 52

Figure 2-25 - Axial Stress vs Deflection for C-Channel Splice.............................................. 52 
Figure 2-26 - Axial Stress vs Deflection for Wood Splice ......................................................... 53

Figure 2-27 - Cracking of Steel Splice Pile at Contact Surface...................................................5 54

Figure 2-28 - Buckling Near Contact Surface of Steel Splice Pile................................................. 54

Figure 2-29 - Shear Stress vs Deflection for FRP Splice......................................................... 57

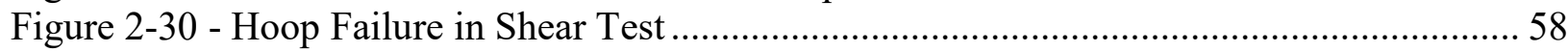

Figure 2-31 - FRP Splice Cracking Under Applied Load at Top ............................................... 58

Figure 2-32 - Bending Stress vs Deflection for FRP Splice ....................................................... 59

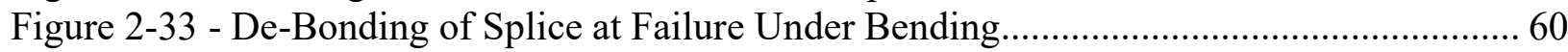

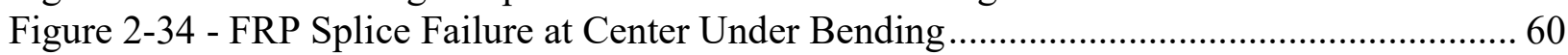

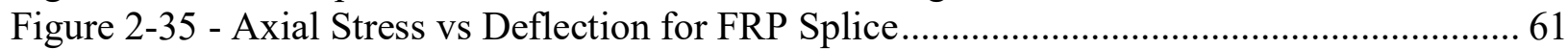

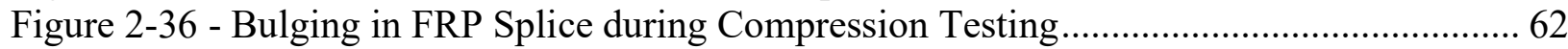

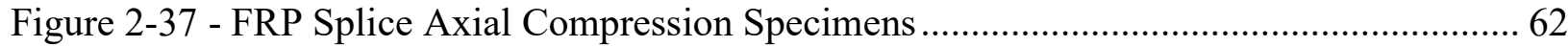

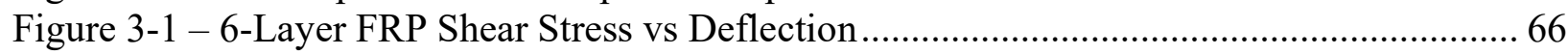

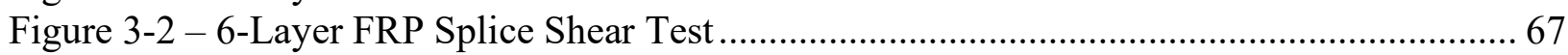

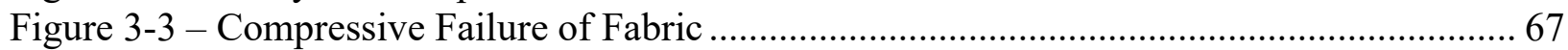

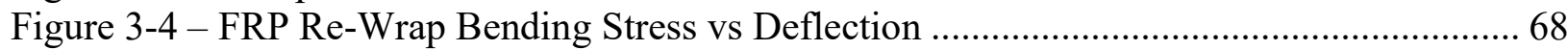

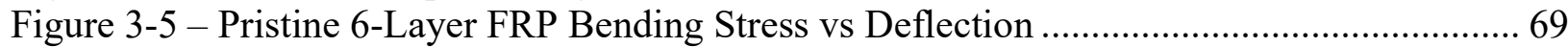

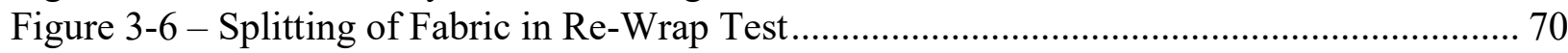

Figure 3-7 - Crumbling of FRP during 6-Layer Bending Test .................................................. 71

Figure 4-1 - Bending Stress vs Deflection Plot for Virgin Pile (No Splice)................................. 74

Figure 4-2 - Section Loss due to Rupture in Virgin Pile ............................................................ 74 


\section{LIST OF TABLES}

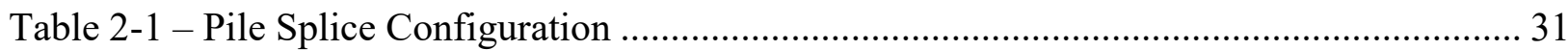

Table 2-2 - Maximum Shear Stress and Corresponding Deflection* ........................................ 41

Table 2-3 - Maximum Bending Stress and Corresponding Deflection* ....................................... 46

Table 2-4 - Maximum Axial Stress and Corresponding Deflection*............................................ 51

Table 2-5 - Average Maximum Stress and Deflection for Traditional Splice Methods ............... 55

Table 2-6 - FRP Splice Maximum Shear and Corresponding Deflection.....................................5 56

Table 2-7 - FRP Splice Maximum MOR and Corresponding Deflection...................................... 59

Table 2-8 - FRP Splice Maximum Axial Stress and Corresponding Deflection .............................. 61

Table 2-9 - Average Maximum Stress and Deflection for All Splice Methods................................ 63

Table 3-1 - New FRP Splice Maximum Shear Stress and Corresponding Deflection.................... 65

Table 3-2 - New FRP Splice Maximum MOR and Corresponding Deflection .............................6 68

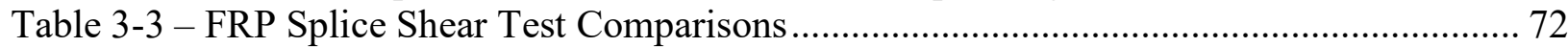

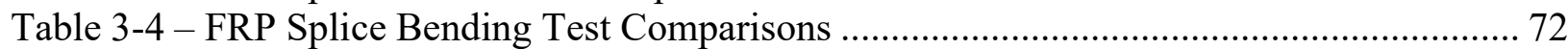

Table 4-1 - Virgin Pile Maximum Bending Stress and Corresponding Deflection...................... 73

Table 4-2 - Comparison of Bending Stress and Deflection between Virgin Pile and Spliced Piles

Table 5-1 - Shear Capacity Theoretical VS Experimental (3 Layers) ......................................... 77

Table 5-2 - Shear Capacity Theoretical VS Experimental (6 Layers) ........................................... 77

Table 5-3 - Bending Capacity Theoretical VS Experimental (3 Layers) ...................................... 79

Table 5-4 - Bending Capacity Theoretical VS Experimental (6 Layers)..................................... 80

Table 5-5 - Axial Capacity Theoretical VS Experimental (Compression Failure) ........................8 82

Table 5-6 - Axial Capacity Theoretical VS Experimental (Non-Compression Failure)............... 85

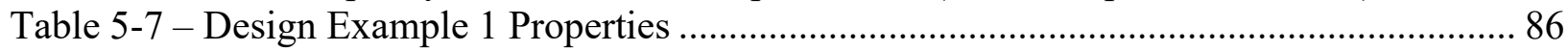

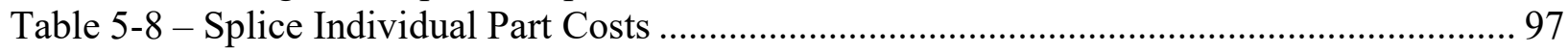

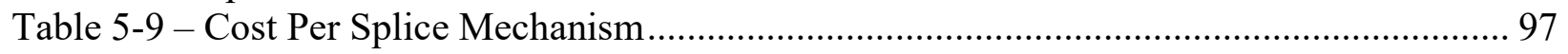




\section{INTRODUCTION}

Timber bridge piles often require repair due to decay of timber in areas of high moisture (areas where the pile is exposed to water). This repair can be carried out in several different ways. One method to rehabilitate timber piles is by using a splicing system. Splicing refers to the process of removing the deteriorated portion of a timber pile and replacing it with a new section of timber with similar size and material properties, this new timber section is secured to the existing pile using one of various splicing mechanisms. Several different splicing mechanisms are utilized in the field using conventional materials such as steel and wood; however, these mechanisms do not prevent future deterioration of piles. Fiber Reinforced Polymer wrapping can be utilized in splice repair of timber piles to provide a long-lasting solution to the problem of decay, while also providing adequate strength capacities to the pile system.

Through this report West Virginia University - Constructed Facilities Center (WVU-CFC) provides an analysis on various splicing methods used for timber pile repair. Three traditional (legacy) splicing mechanisms and a newly developed FRP wrap splice mechanism were constructed and tested under various loading conditions. The three traditional splicing mechanisms tested in this program were flat steel plate, C-Channel steel plate, and wooden plate. Each of the four splice designs were tested under shear, four-point bending, and axial compression loading conditions. Data from testing were analyzed to determine the strength capacities of each splice design and make comparisons of strength and stiffness between mechanisms. The FRP wrap splice

mechanism was further analyzed through theoretical analysis to develop strength capacity equations that can be adapted for design of FRP splice systems. 


\section{OBJECTIVES}

The objectives of this report are to determine the strength capacities of traditional (legacy) splicing methods and FRP wrap splicing and make comparisons between the two through laboratory testing and data analysis. This analysis can be used to determine if FRP wrap splicing provides an adequate replacement to traditional methods. Another objective is to determine if splicing a timber pile decreases the overall bending capacity of the system. Through

further evaluation of FRP wrap splicing, design equations can be developed to allow for field adaptation of this system. 


\section{SCOPE}

- Perform a literature review on the deterioration of timber piles

- Evaluate strength capacities of traditional (legacy) splicing and FRP splicing methods through laboratory testing under shear, bending, and axial loading

- Make strength comparisons between traditional and FRP wrap splicing

- Determine the decrease in bending capacity of timber piles caused by the addition of various splicing mechanisms

- Develop equations that can be utilized for design of FRP wrap splicing through

theoretical analysis 


\section{DESIGN METHODOLOGY}

Design methodologies for this report include the construction and testing of both the traditional (legacy) splice methods and the FRP wrap splice method. Legacy splice construction (Section 2.1) followed splice schematics provided by the Louisiana Department of Transportation and Development (LaDOTD), where three different splice mechanisms were recreated in the WVU-CFC laboratory: flat steel place, steel C-channel, and wooden plate. The construction of the FRP wrap splice (Section 2.2) followed the hand lay-up method utilizing a unidirectional Glass/Epoxy composite provided by Sika. Testing of specimens constructed in the lab consisted of three different loading scenarios: shear, four-point bending, and axial compression (Section 2.3). Each of these methodologies are discussed in further detail in CHAPTER 2 of this report. 


\section{CHAPTER 1 LITERATURE REVIEW}

A comprehensive literature review is performed to further evaluate degradation of timber column structures as well as various repair methods of deteriorated timber columns. The purpose of this literature is to gather information from literature and synthesize that info to get a better understanding on timber/pile column deterioration to arrive at a more practical solution. From the information gathered and the understanding gained, comparisons will be made to the findings from the research just concluded in 2021 on this topic here at West Virginia University.

\subsection{Timber Pile Degradation and Repair}

\subsubsection{Degradation of Timber}

According to Agricultural Handbook NO. 557, timber bridges are susceptible to decay caused by fungi [1]. This is due to a bridge's wet location of support structure, exposure to the elements (moisture, temperature variation, etc.), and design. Most bridges span a body of water with a pile structure that is exposed directly to the water. Many of the in-service timber bridges in the United States are old because timber was the primary material used in constructing bridges before the introduction of steel and concrete in the late $19^{\text {th }}$ century [2].

Decay in wooden structures that are in contact with water can be caused by living fungi that thrive in wet environments. Fungi can break down and utilize wood cells as food [1]. For the most part this fungus is invisible to the human eye, making it difficult to spot. However, signs of a fungal presence can be observed as softening of the wood, decrease in density, and discoloration can occur [3]. Fungi attacks wood in weak spots such as cracks and holes. The fungi can only survive under favorable conditions which consists of oxygen availability, temperature range, food 
supply, and availability of water [1]. Certain species of wood are more resistant to fungal attacks than others, due to their natural decay resistance. Water plays a major role in decay caused by fungi as it provides the type of environment for fungi to thrive. Wood is especially susceptible as its moisture content can change by absorbing or expelling water based on the environment it is exposed to. The constant wetting of wood causes it to lose its resistance to natural decay, making timber pile members in water especially susceptible to decay. As decay can be visually seen above the surface of the ground it also occurs underneath the surface of the soil. It is common for deterioration in timber members underneath a soil surface to be more severe than the deterioration of exposed timber above ground members [1]. This is due to the fact that there is more moisture exposure when in contact with the soil as compared to in the air. This is especially true in areas where the ground water table is not far beneath the surface of the soil. Pile portions exposed to the air have less wetting as compared to the consistent wetting through the ground water table of pile portions that are underground. This decay only goes slightly into the surface of the ground as the oxygen necessary for decay to occur decreases drastically with depth [4].

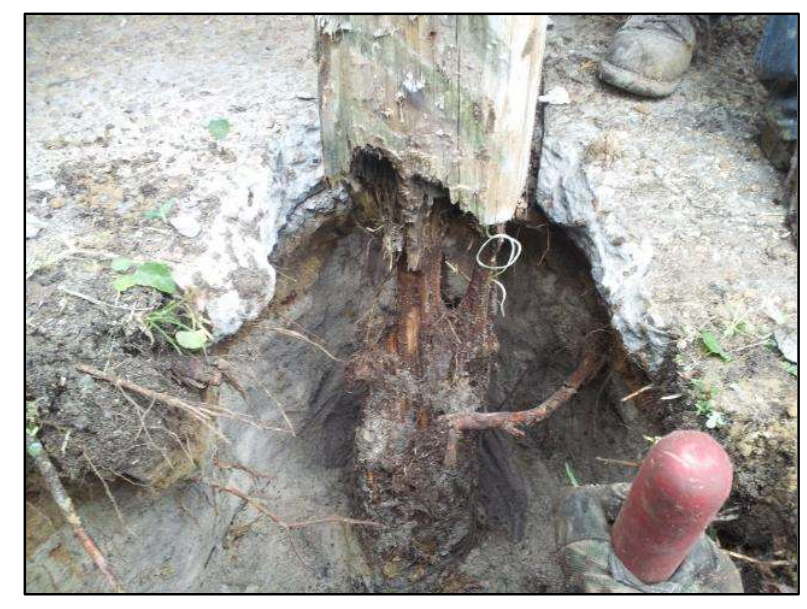

Figure 1-1 - Timber Pile Decay at Ground Surface [5]

Bacteria can have decaying effects on wood. Unlike fungal deterioration, bacterial deterioration can occur under a wide range of conditions based on the species [6]. It is known to 
thrive in conditions with low oxygen levels [6]. Slight decay to the wood cell structure by bacteria does not significantly affect the overall compressive strength of wood but significant decay can cause a major decrease in overall compressive strength [6]. At first the rate of timber pile decay due to bacteria is slow being about 0.04 inches per year [6]. However, after the bacterial infection has set in the rate of decay can increase to upwards of 0.1 inches per year [6]. At this rate major strength loss can occur much quicker than at initial bacterial decay introduction. Bacterial decay occurs along the whole length of the pile including areas above and below ground level. The rate of bacterial attack decreases beyond the interface of heartwood to sapwood in spruce and pine wood species. So it can be assumed that only the sapwood will deteriorate within the service life of piles made of these wood types (typical service life being 100 years or less) [7]. While bacterial decay can affect the compressive strength of timber piles it spreads slowly and will likely have little effect on overall compressive strength within the service life of piles. Bacterial infection can however be serious in situations where untreated wood is submerged for long periods of time [7].

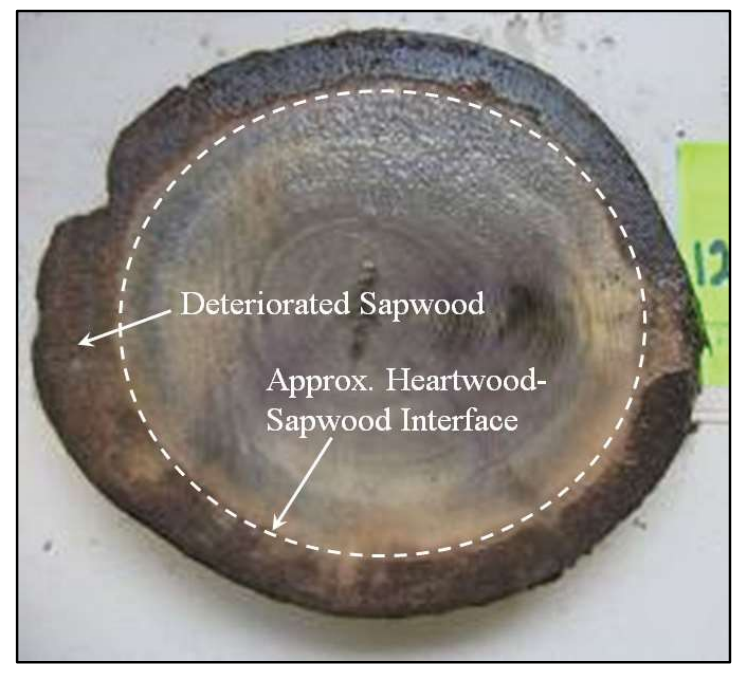

Figure 1-2 - Bacterial Decay of Timber Piles [6]

In locations where piles are in contact with ocean water deterioration can be caused by marine life. There are three main groups of marine borers or animals that bore into and eat wood; 
Limnora or "Gribbles", Shipworms, and Pholads [3]. These marine parasites leave timber piles in the shape of an hourglass (Figure 1-3). All three of these creatures are only found in ocean or brackish waters and pose no threat to wooden structures in contact with fresh water. Marine borers are responsible for over $\$ 250$ million in damage each year [7].

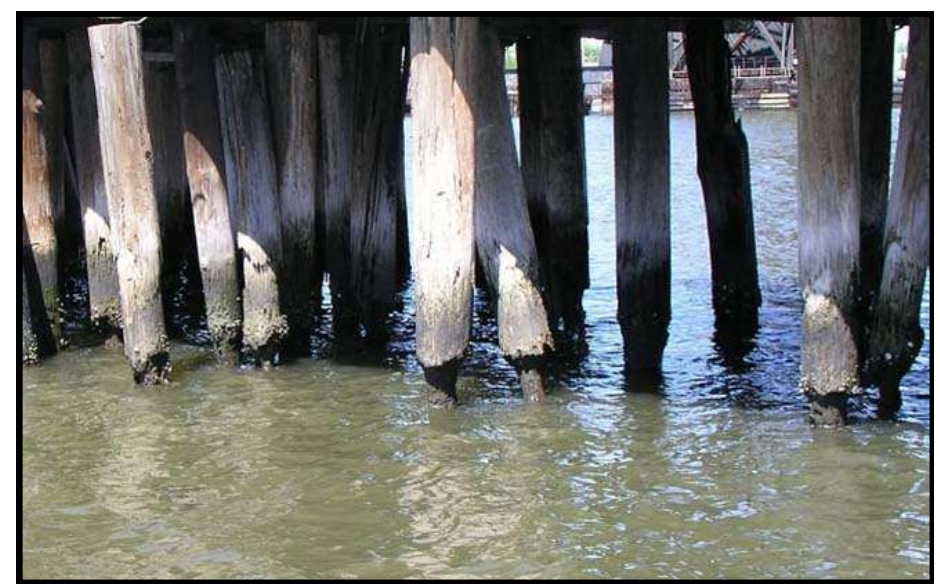

Figure 1-3 - Marine Timber Pile Decay [8]

Insects are also known for their ability to infect and feast on wood and in some cases wooden structures. There are many insects that can have effects on wood, however the most commonly known wood killing insects are termites as they use the wood itself as a food source. Three main species of wood attacking termites are found within the continental United States: subterranean, damp-wood, and dry-wood termites. Subterranean and damp-wood termites attack wood with high moisture content, whereas dry-wood termites are known to attack dry wood, hence the name [7].

Other insects can also contribute to deterioration of wooden structures. A few species of beetles are known to attack living wood and timber structures. While beetles do pose a threat they will not attack wood that is treated and most wood used in current construction practice is treated [7]. 


\subsubsection{Natural Decay Resistance}

Certain Species of wood have natural decay resistance under favorable decay conditions. It is variable by species but can play a factor in the service life of timber bridge structures [1]. Natural resistance from decay is based on properties of heartwood as sapwood has little to no decay resistance. The natural fungal decay resistance in heartwood can be categorized into four categories: highly resistant, resistant, moderately resistant, and nonresistant. Many timber bridges in the United States are constructed from either Douglas-fir or southern pine which are classified as moderately resistant [1]. While these species have at least some decay resistance, moderately resistant timbers do not provide sufficient resistance and often need to be treated with preservatives to increase resistance.

\subsubsection{Induced Decay Resistance with Preservatives}

Induced decay resistance refers to making a timber more resistant to decay by treating timber with preservatives before it is used in service. Preservatives can prolong the service life of timber piles [9]. A variety of different preservatives have been used to prevent decay with Creosote, which is the most commonly used preservative due to its history of success [1]. Other preservatives used to protect wood from environmental factors include: Pentachlorophenol, Copper Naphthenate, Chromated Copper Arsenate (CCA), Acid Coper Chromate (ACC), and Ammoniacal Copper Zinc Arsenate (ACZA) [9]. Creosote is most commonly used, however it has been banned for use in marine environments due to its negative environmental effects.

Inorganic salt based preservatives such as CCA and ACZA provide the disadvantage of lack of water repellency [1]. For this reason oil-based preservatives like Pentachlorophenol and Creosote are mainly used in bridge members that are in water contact. For larger timber piles it is usually impossible to obtain full depth penetration of preservatives. Full depth penetration is not 
necessary because even surface impregnation of preservative will create a toxic barrier preventing decay from attaching and spreading [1].

\subsubsection{Timber Pile Repair Methods}

The methods described in this section are determined to be commonly used by various state Departments of Transportations (DOT). The repair methods to be discussed include: posting/splicing, supplemental piles, concrete jacking, and Fiber Reinforced Polymer (FRP) shells and wraps.

The method of posting and splicing is often performed in situations where the pile needs to be accessed above ground, where accessibility to the pile is possible without difficulty. This method is used in situations where a pile undergoes significant section loss due to deterioration. The structure is supported with a strut and jack, the deteriorated pile portion is cut out and replaced with a section of similar diameter. Plate splicing consist of plates secured to sides of the pile using bolts to hold the separate pile sections together [10]. Figure 1-4 provides a schematic showing how this procedure is done. In this schematic the splicing methods used involve timber fishplates and concrete jacketing. When securing pile portions together a wide range of methods can be used including: concrete jacketing, draft supports, steel side supports, epoxy injection and FRP wraps [11]. In some situations deteriorated pile portions are removed and other materials are used for

posting. Figure 1-5 shows this procedure as completed using steel W sections [10]. Posted piles provide adequate replacement in terms of axial compressive strength but may compromise in flexure strength. 


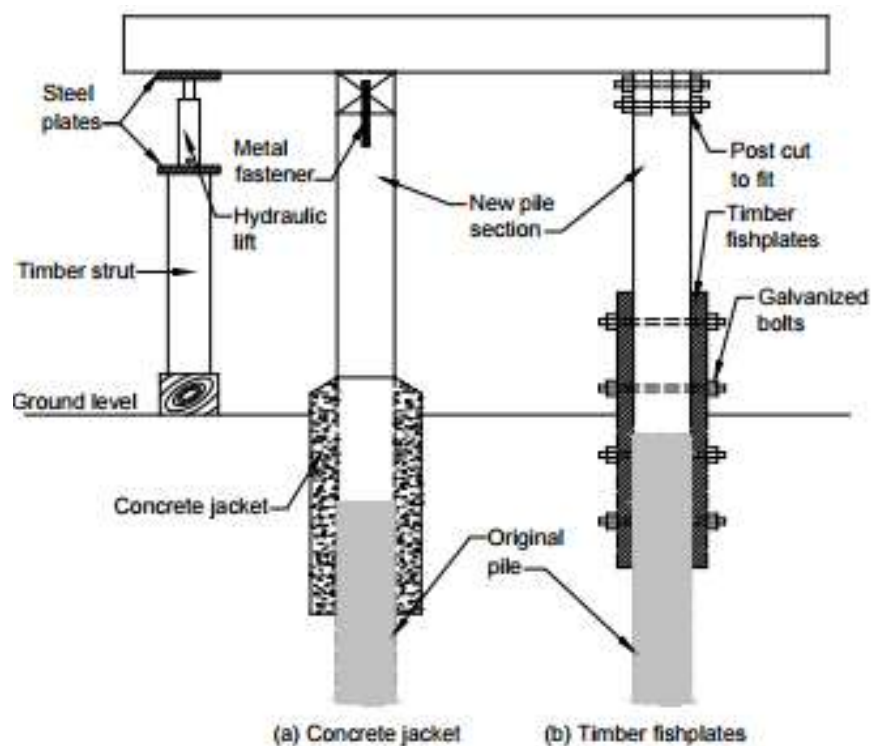

Figure 1-4 - Posting/Splicing Repair Schematic [10]

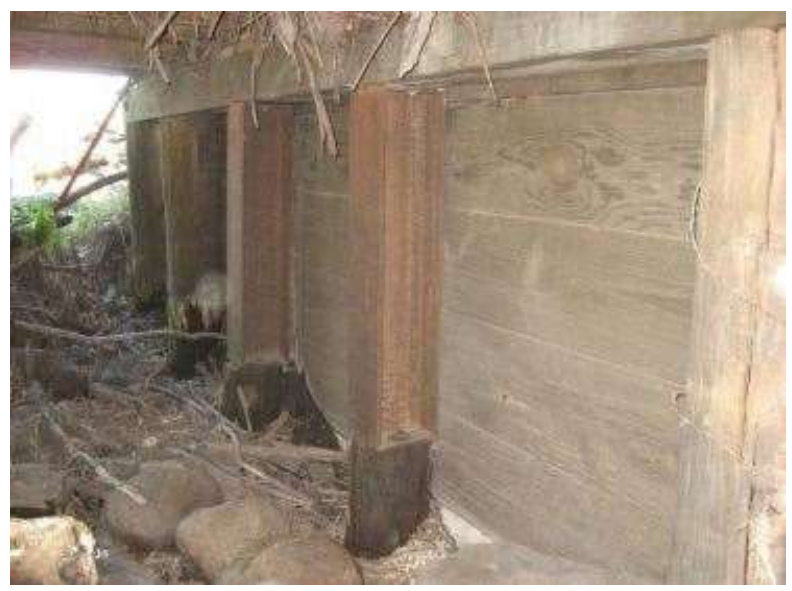

Figure 1-5 - Posting using Steel W-Section [10]

Supplemental piles are utilized for piles with severe deterioration resulting in large section loss. This method involves the addition of supplemental piles of either timber, steel, or concrete to supplement existing deteriorated timber piles. Depending on the material used for supplementation this process can provide pile strengths exceeding design strengths of existing members. Existing piles are supplemented by cutting the timber deck adjacent to existing damaged piles. A new pile is driven and cut to fit under the pile cap. The pile is pulled laterally into place (Figure 1-6) [12]. Shims are placed as needed between the pile and pile cap to ensure a good fit. 


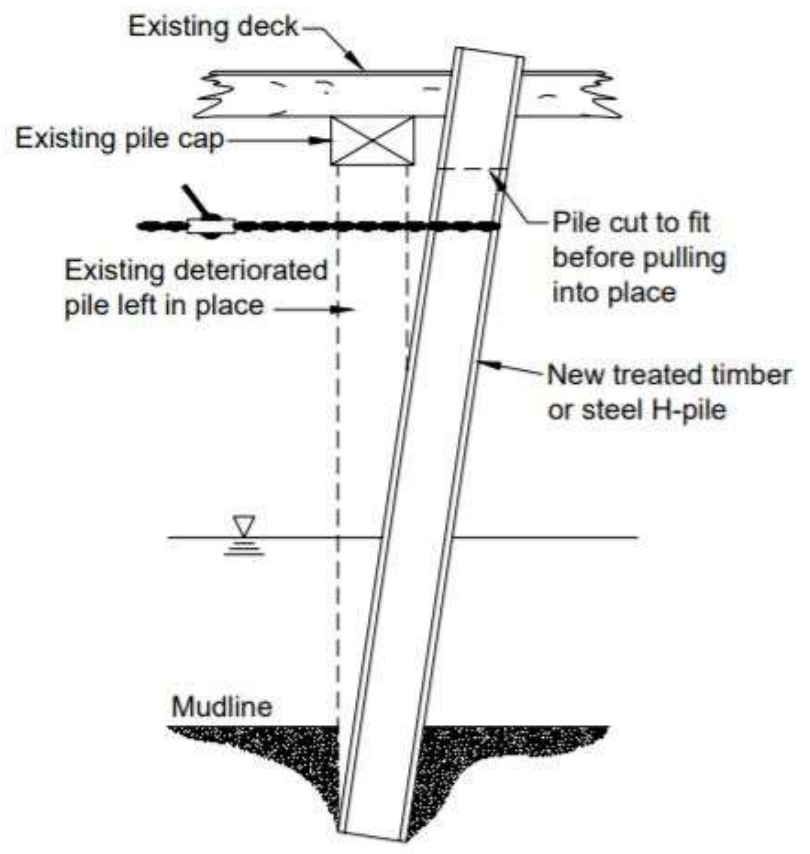

Figure 1-6 - Supplemental Pile Repair [12]

Concrete jacketing can be used to repair timber piles that have experienced $10-50 \%$ section loss due to deterioration [12]. This method can effectively be used to repair piles constructed of either timber or concrete. This effectively adds to the compressive strength of the deteriorated pile, exceeding its original design strength. The deteriorated portion of the pile is encased in concrete using either a fiberglass or steel jacket form. The surface of the pile is cleaned in the area where the jacket is to be installed. A reinforcing cage is secured around the pile using spacers to keep the reinforcement in place. A forming jacket is then placed around the pile and cage, being sealed at the bottom. Concrete is then pumped into the form through an opening at the top. The form must be sloped at the top to allow for runoff [13]. Two different types of forms can be used, flexible or split fiberboard. The only difference between how the two are installed is how they are secured to the pile. The flexible form is secured to the top and bottom of the damaged pile section and the split fiberboard form is secured with straps at a $1 \mathrm{ft}$. increment along the form (Figure 1-7) [12]. 


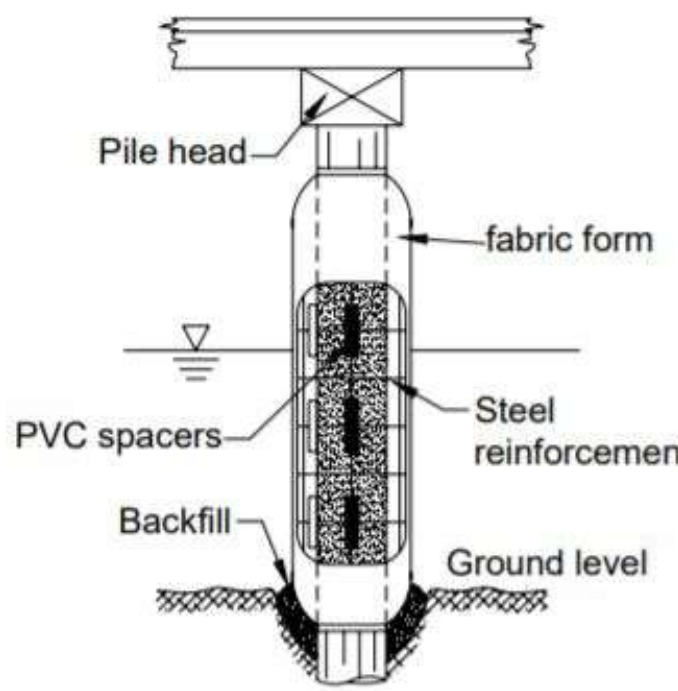

(a) Flexible form

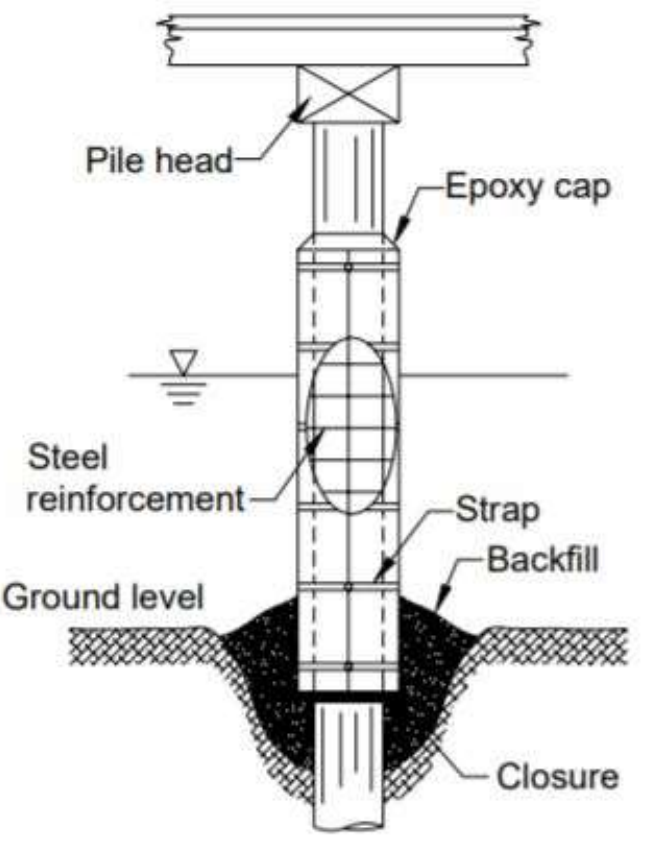

(b) Split fiberboard form

Figure 1-7 - Jacketing Flexible and Split Fiberboard Forms [12]

A form of FRP wrapping called Polyvinyl Chloride (PVC) Wrap is utilized to protect piles with minimal (10-15\%) section loss [14]. This method is used solely to prevent further damage due to deterioration; it does not increase the structural capacity of the existing pile. The PVC wrap provides a barrier preventing the exchange of water from outside of the wrap to the water inside the wrap surrounding the pile. This creates a toxic environment for wood damaging parasites, making survival impossible inside the barrier of the wrapping. This method effectively extends the life of timber piles by 35 years. This process is cheaper than concrete jacketing, in addition to this the PVC wrap also provides protection against abrasion [12].

The PVC wrap must extend at least $1 \mathrm{ft}$. above water level and extend to below ground level. The wrap is tightened using wood poles and is fastened using aluminum alloy bands around the top and bottom, with aluminum nails along vertical joints (Figure 1-8) [12]. 


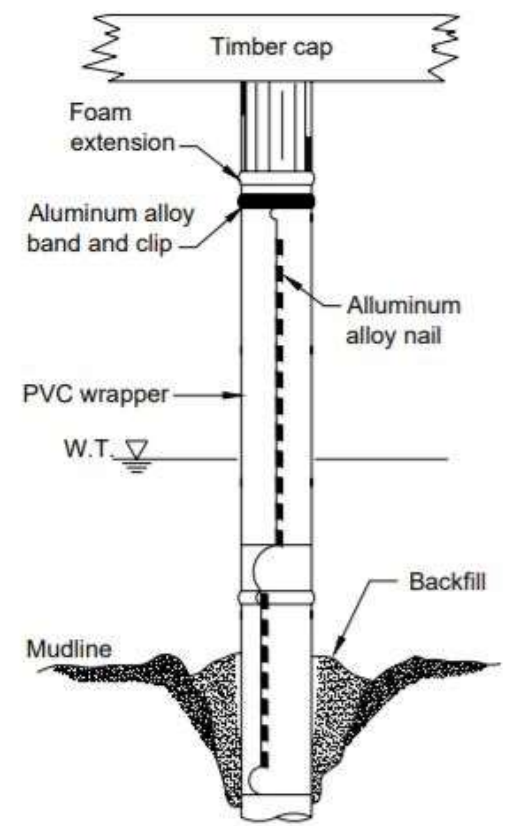

(a) Two-unit wrap

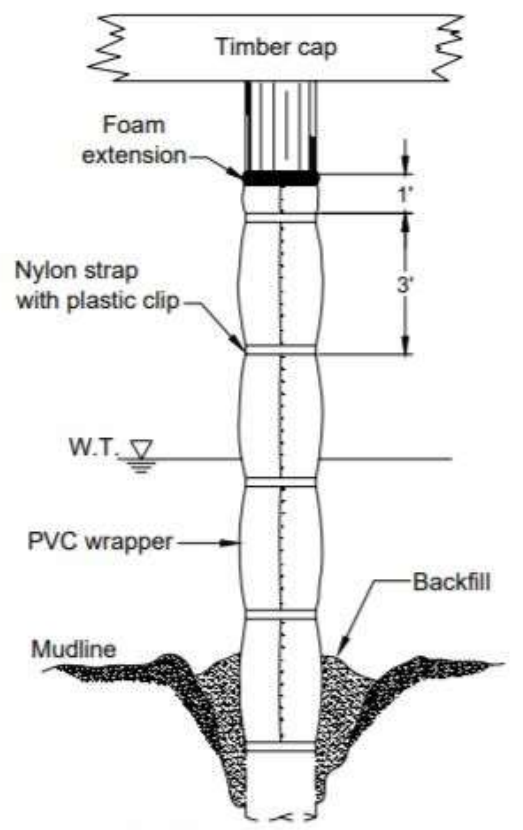

(b) Single-unit wrap

Figure 1-8 - Polyvinyl Chloride Wrapping [12]

FRP shells filled with grout are utilized in situations where preventing further deterioration and increasing the strength capacity of the pile are desired. For this method deterioration must not be severe to the point where replacement of the pile itself is required. This system provides shear transfer capability between the pile and the composite shell, strengthening the damaged portion. FRP shells act as a barrier between wood and parasites, protecting against further deterioration. The FRP shell has fiber orientation that allows for axial and hoop direction reinforcement, increasing the axial and shear capacities of the pile. The damaged portion of the pile is cleaned before being encased in a FRP shield and secured at the bottom of the shell mechanism, leaving an opening at the top. Epoxy/concrete grout is poured into the opening in the shell and left to cure [10]. Figure 1-9 provides a schematic of this repair mechanism. 


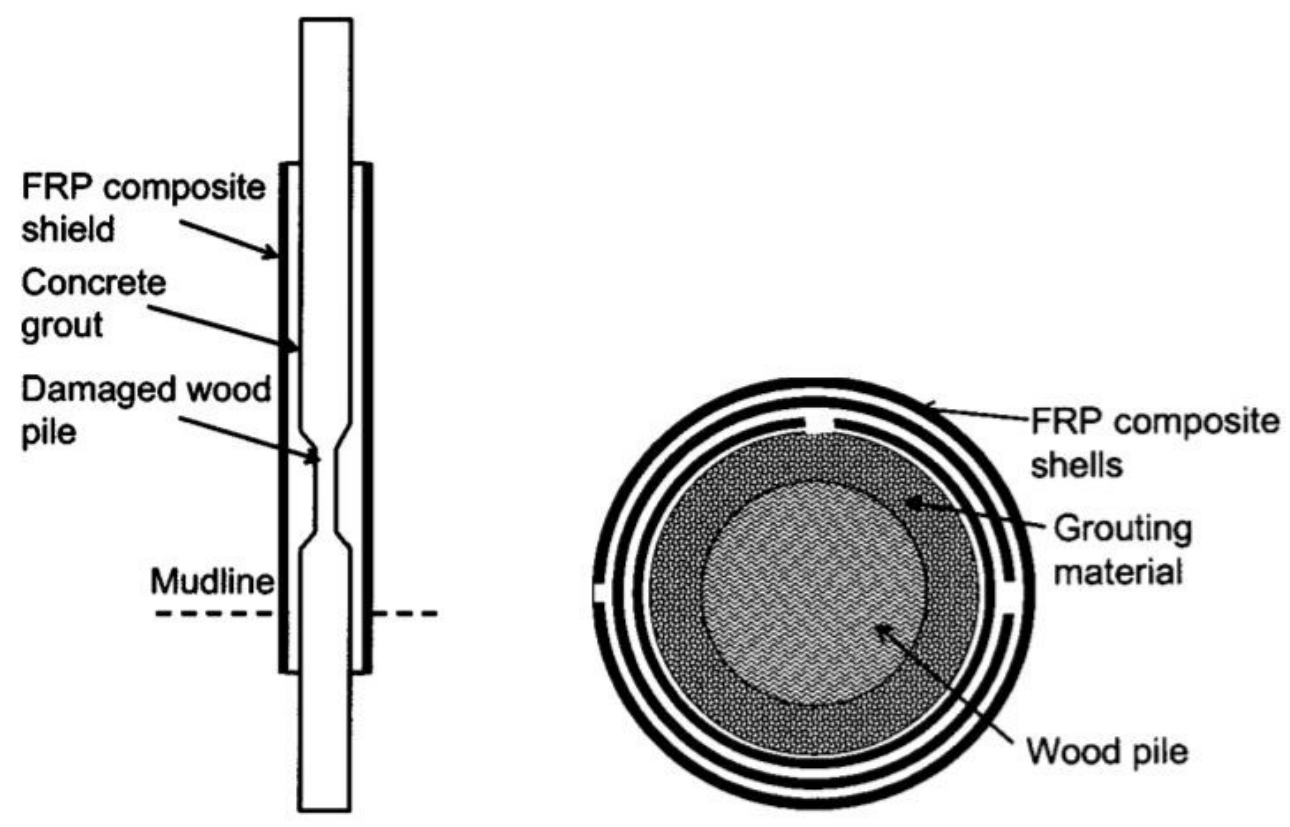

Figure 1-9 - FRP Shell with Grout Schematic [10]

\subsubsection{Recommendation}

The method of splicing to repair deteriorated timber piles can be improved with the use of FRP wrapping as a splicing mechanism. No literature was found on the strength capacity of spliced timber piles with current splice mechanisms. Strengths of existing splice mechanisms can be found through lab testing and compared to splicing with FRP wrap to establish which mechanisms are most durable and cost effective.

\subsection{Fiber Reinforced Polymer Design}

\subsubsection{FRP Systems}

Fiber Reinforced Polymer (FRP) systems consist of two main parts: fibers and resin. Fibers come in the form of a fabric that provides most of the strength to the system. The resin acts as a matrix that holds fibers together. FRP systems may also have additives and fillers to modify 
various properties of the final product. Primers may also be added to FRP wrapping systems to ensure a good bond between the fabric and the material being reinforced.

Many different fiber types are used in FRPs including carbon, glass, boron, aramid and natural fibers. The two most common fiber types used in the production of FRP systems are carbon and glass. Glass fibers are the most used of all fiber types. It is widely used because of low relative cost, high tensile strength, high chemical resistance, and desirable insulating properties [15]. Carbon fiber is utilized for high strength applications, such as spacecraft and airplanes. It provides many advantages including high tensile strength and modulus to weight ratio, low coefficient of linear thermal expansion, high fatigue strength, and high thermal conductivity [15].

The resin or matrix of a composite consists of a polymer that can be classified as either thermoplastic or thermoset. For the purpose of this literature review the focus will be on thermosets as they are most used for structural applications. Some types of thermoset resins include epoxy, vinyl ester, phenolic, and polyester. Epoxies are often used in high performance composites to achieve superior mechanical properties and create corrosion resistance [16]. Vinyl Ester is a derivative of epoxy resin that provides corrosion resistance and high fracture toughness [16]. Phenolic resins are commonly used in applications involving wood as they provide fire resistance and produce low toxicity in smoke from fires [16]. Polyester resins provide lower strength and modulus than epoxy but provide a variety of desirable properties making the final product as hard or brittle as desired [16].

\subsubsection{FRP Manufacturing}

Many different manufacturing techniques exist for the production of composite materials including automated and manual processes. Automated methods are not commonly used for FRP wraps. For FRP wraps, prefabricated fiber fabrics and resin mixtures are utilized for ease of field 
installation. Hand lay-up is the most commonly used technique for the manufacturing of FRP wraps. For this method fibers in a form of chopped or continuous fabric are impregnated with resin using rollers and brushed (Figure 1-10) [16] . Several layers of fabric are laid in the desired fiber orientation are stacked on top of one another, with each layer being coated with resin [16]. For field application of FRP wraps, forms are not always necessary. There are multiple steps to this process that vary based on application. Some common steps followed are mold preparation, gel coating, and hand lay-up and finishing. This process is simple but slow, it involves several laborintensive steps. Proper ventilation and PPE must be utilized to protect laborers from fumes and toxins that result from this process [16].

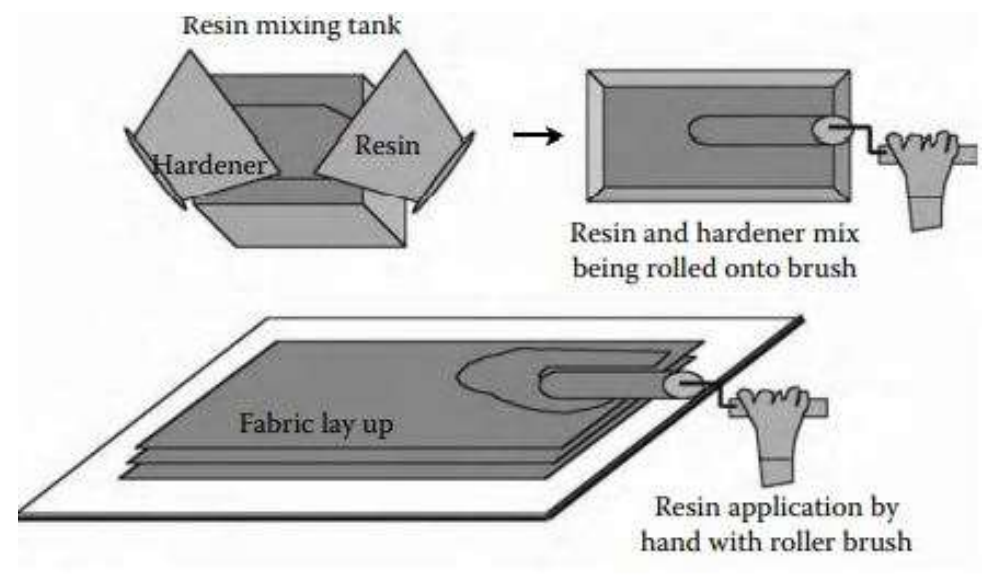

Figure 1-10 - Hand Lay-Up Process [16]

\subsection{Applications of FRP Wrap}

Over time structures deteriorate and lose strength capacity. Replacement of structural members is expensive and time consuming. FRP wraps can be utilized to strengthen and repair existing structural members, saving both time and money. Columns and beams can also be 
designed utilizing FRP wraps as a form of reinforcement, replacing the need for additional rebar in concrete members.

\subsubsection{FRP Concrete Systems}

FRP wraps are used as a method of retrofit and strengthening of concrete structures. FRP wrap systems can be used to increase bending and shear strength in concrete members and are also used for concrete column confinement and ductility improvement. Figure 1-11 provides an image of FRP wrapping used for strengthening and confinement of a concrete column. This column confinement makes concrete columns more resistant to buckling related failures, effectively increasing axial capacity. FRP wraps are also used for tensile reinforcement of concrete beams and slabs, effectively improving their flexural strength [17]. Wrap systems can also be utilized to limit cracking in members where design or service loads need to be increased [16]. Glass Fiber Reinforced Polymer (GFRP) and Carbon Fiber Reinforced Polymer (CFRP) wraps are the most commonly utilized wrap systems for reinforcing existing concrete structural members.

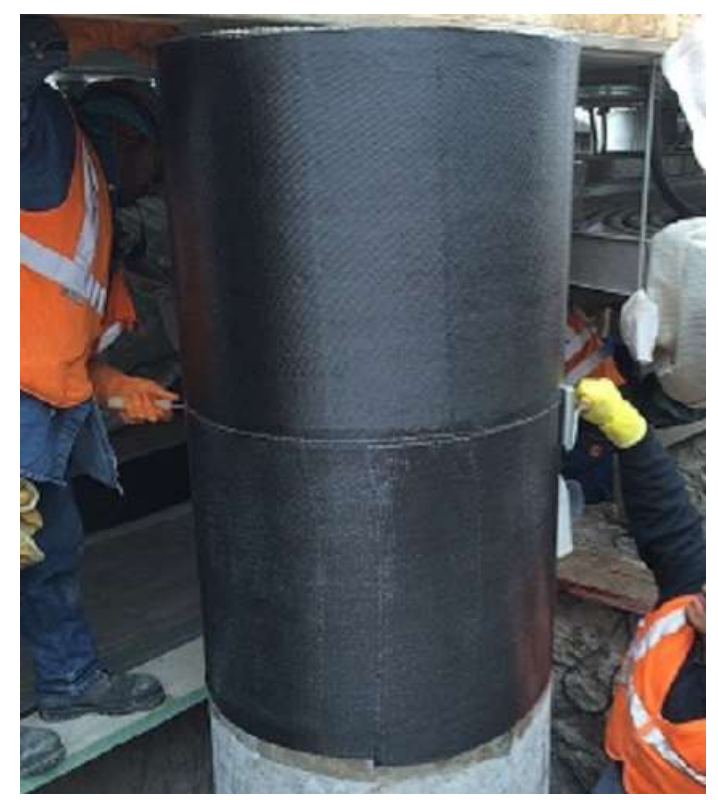

Figure 1-11 - FRP Wrap for Strengthening of Concrete Column [18] 
A study on FRP retrofit in reinforced concrete columns was performed by Ilki et al. at Istanbul Technical University, where axial compression testing was performed on 68 reinforced concrete column specimens of circular, square and rectangular cross sections [19]. Specimens were prepared using different variations of CFRP wrapping, with variation being in number of fabric layers and fiber orientation. Test results showed that confining concrete columns with CFRP did increase the axial capacity of columns, this strength increases with an increased number of ply layers. Failure occurred suddenly in the mode of fracture of CFRP sheets. This failure occurred at midheight of specimens, in rectangular and square shaped columns failure occurred at corners where stress concentrations were greater [19]. For FRP confinement systems for concrete columns it is crucial to have adequate reinforcement in the hoop direction to account for the week tensile stress capacity of concrete, which concentrates around the circumference of concrete columns. Uniformity of hoop direction fibers is also necessary to avoid creating weak spots of stress concentration in the FRP confinement system. Overall, this research proves that FRP wraps increase the axial capacity of concrete columns.

A study by Baggio et al. from the University of Waterloo provides an analysis of reinforced concrete beams with various FRP systems. This study focused on using different variations and types of FRP wrap as shear reinforcement for reinforced concrete beams. Nine shear deficient reinforced concrete beams were constructed; using one beam as a control and eight other beams with CFRP, GFRP and fiber reinforced cementitious matrix (FRCM) sheets [20]. Four of these eight composite reinforced beams contained FRP anchors to further increase shear capacity of beam specimens. Wrap configuration consisted of multiple, full depth or partial depth, U-shapped wrap sections along the length of the beam, resembling a similar orientation to stirrups used for shear reinforcement in concrete beams (Figure 1-12) [20]. Of the nine specimens tested, each 
yielded similar results regarding flexural stiffness values. Specimens containing a form of FRP reinforcement showed an increase in shear capacity from the control specimen. CFRP specimens showed the largest increase in shear capacity, $75 \%$ increase in one case. Specimens with FRP anchors increased ultimate stress experienced and changed the failure mode from brittle shear failure to flexural mode of failure [20]. U-shaped FRP sheets increase the shear capacity of reinforced concrete beams and can be adapted for shear reinforcement in timber sections.

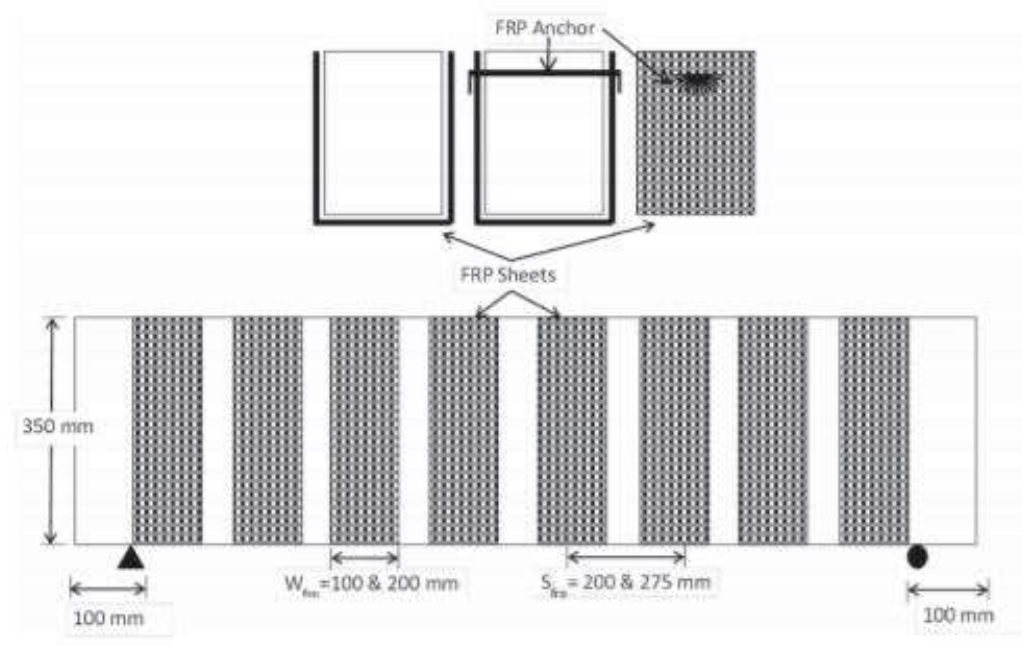

Figure 1-12 - Full Depth FRP U-Shaped Shear Reinforcement [20]

\subsubsection{FRP Timber Systems}

Timber is a widely used construction material in buildings as it provides a good ratio between mechanical characteristics and self-weight. Composite materials can be utilized to maintain and strengthen timber members. In timber beams bending capacity is controlled by the tensile stress exerted on the bottom side of beams. U-shaped FRP reinforcement is optimized to increase the tensile capacity of the beam system [21]. Column confinement using FRP wrapping is used to increase stiffness and axial strength capacity in timber columns, in a similar manner to that of concrete column confinement. 
For the confinement of timber columns a large variety of fabric orientations can be utilized to increase stiffness and axial capacity of the system. A study performed by Land et al. discusses how different wrap orientations influence the performance of timber columns under axial loading. For testing, CFRP wrap was utilized in six timber column specimens with different wrapping orientations including toroidal, single helix, double helix, cross helix, and all helix (Figure 1-13) [22]. Between helix and toroidal fabric orientations, toroidal tested the strongest in axial carrying capacity. The lateral strain of FRP sheets is lower than that of wood, which indicates that FRP sheets can restrict the lateral strain in wood effectively. The ultimate carrying capacity and stiffness of timber columns can be greatly improved with confinement using FRP wraps.

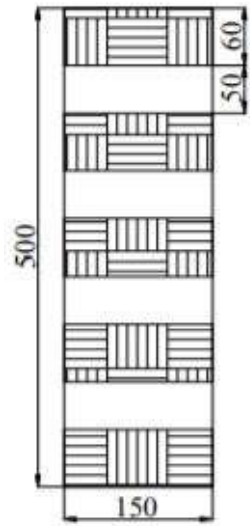

(a) toroidal

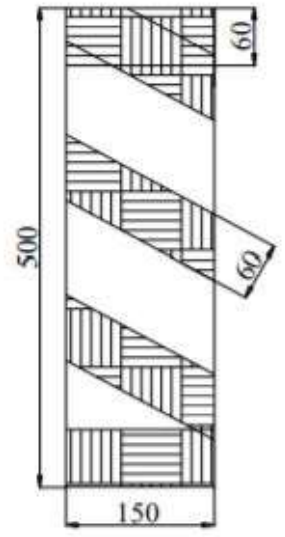

(b) single helix

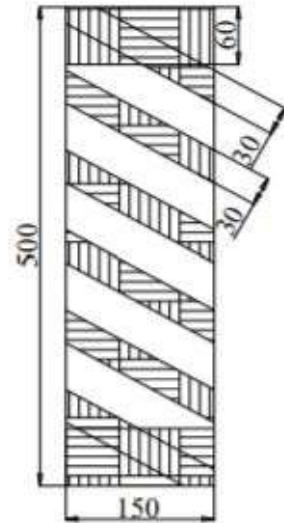

(c) double helix

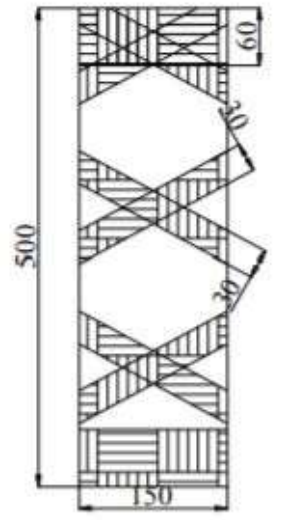

(d) cross helix

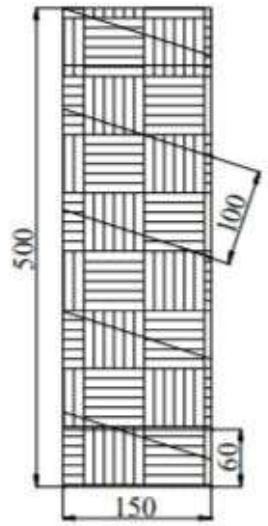

(e) helix all

Figure 1-13 - Timber Column Confinement Types [22]

A study performed by Garcia et al. at the Polytechnic University of Madrid provides an analysis on timber beams with U-shaped FRP reinforcement. Tests were performed on wooden pine beams using carbon and basalt fiber composites with unidirectional and bidirectional fiber orientation. From testing it was concluded that FRP U-shaped wrapping increased beam stiffness and structural capacity [21]. Unidirectional basalt FRPs performed better than unidirectional carbon FRPs. Bidirectional fiber orientations performed better than unidirectional fibers in stiffness and stress capacity. The addition of multiple layers of bidirectional fabric did not greatly 
increase load from using a single layer of bidirectional fabric. With these FRP systems tensile failure occurred due to fracture of wooden fibers, not fibers in the composite reinforcement material. Figure 1-14 provides data from testing at the Polytechnic University of Madrid, highlighting experimental data of each of the composite systems used and percentage of load increase brought on by these systems [21]. Variations of basalt FRPs are denoted as FB, variations of Carbon FRPs are denoted as FC. In each of the composite-beam systems tested it is apparent that FRP U-shaped reinforcement increases the overall bending strength capacity of the beam system.

\begin{tabular}{|c|c|c|c|c|}
\hline Reinforcement type & $F_{\exp }(\mathrm{kN})$ & $\Delta F^{\mathrm{a}}(\%)$ & $F_{\text {th }}(\mathrm{kN})$ & $F_{\text {exp }} / F_{\text {th }}$ \\
\hline SR & 47.01 & - & - & - \\
\hline FB 280 & 58.55 & 24,55 & 49.68 & 1.18 \\
\hline FB 600 & 54.04 & 14,95 & 49.85 & 1.08 \\
\hline FC 300 & 48.64 & 3,47 & 50.50 & 0.96 \\
\hline FC $160 \# 1$ & 66.35 & 41,14 & 49.68 & 1.34 \\
\hline FC $160 \# 2$ & 67.45 & 43,48 & 49.84 & 1.35 \\
\hline FC 210\#1 & 51.73 & 10,04 & 49.77 & 1.04 \\
\hline FC 210\#2 & 47.54 & 1,13 & 50.10 & 0.95 \\
\hline
\end{tabular}

\section{Figure 1-14 - Strength of Timber Beams with U-Shaped FRP [21]}

WVU-CFC performed laboratory testing on Glass Fiber Reinforced Polymer (GFRP) wrapping on timber railroad bridge beams in 2007. This research consisted of repairing four 50+ year old, creosote treated, timber bridge beams that have been deemed deficient and removed from bridge structures. Each of these four specimens were first tested to failure and then repaired using U-shaped GFRP wraps (Figure 1-15), two under four-point bending loading and two under fourpoint bending loading with orientation to induce shear failure. All the repaired specimen tests yielded lower load capacity results than the control specimens. This was expected as the beams underwent significant damage as they were taken to ultimate failure before repair. The bending 
specimens had a recovery strength of $55 \%-60 \%$ of the control bending strength and showed a significant improvement in ductility [23]. One of the shear specimens showed an increase in shear modulus after the specimen was repaired using GFRP wrap. Overall, specimens performed well after being repaired with GFRP wraps. Repairing members in the field in this manner can provide an alternative to bridge replacement [23].

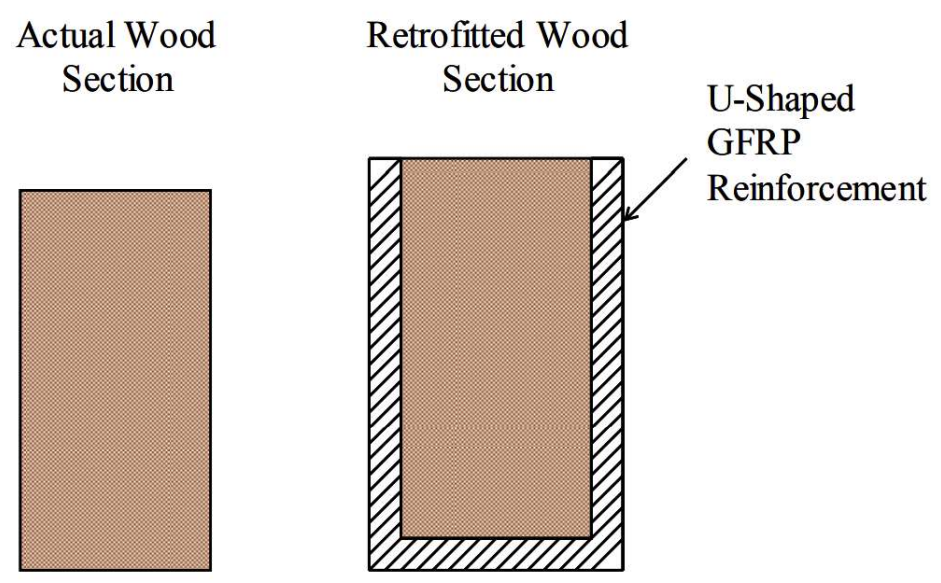

Figure 1-15 - U-Shaped GFRP Wrap Reinforcement [23]

\subsubsection{Conclusions from FRP Wrap Applications}

Fiber Reinforced Polymer wrap systems are utilized to strengthen and repair existing concrete and timber structural members. FRP wrapping provides a great method of retrofit as it is easily adaptable to different design scenarios. Different wrap geometry can be used and adapted to shear, bending and axial loading conditions. Strength in axial compression in this system can be optimized and used for a FRP wrap splice design. 


\subsection{Field Implementation}

\subsubsection{Field Installation}

Field installation procedures were gained through literature from WVU-CFC in the rehabilitation of timber bridge structures using FRP wrapping. Timber bridges structures were repaired in 2004 [24], 2007 [23], and 2011 [25] by WVU-CFC. Images provided come from within the WVU-CFC database. Repair of decayed timber pile portions was performed not as a splice but as a filler/FRP system. For this literature review steps involving filler materials will not be mentioned because they are not necessary for FRP wrap as a splice mechanism. Instances where procedures vary are noted in the steps below. The steps to field installation involve site preparation, removal of decay, sanding of pile, priming pile, application of FRP wrap, and pressure application. 1. Site Preparation

When necessary, water must be redirected to ensure a dry work area, this was done by WVU-CFC using a coffer dam [23]. Tarps can be placed above the work area to prevent moisture from interfering with the cure process. Soil and debris must be removed for pile sections at or above ground level to ensure proper load transfer of the system.

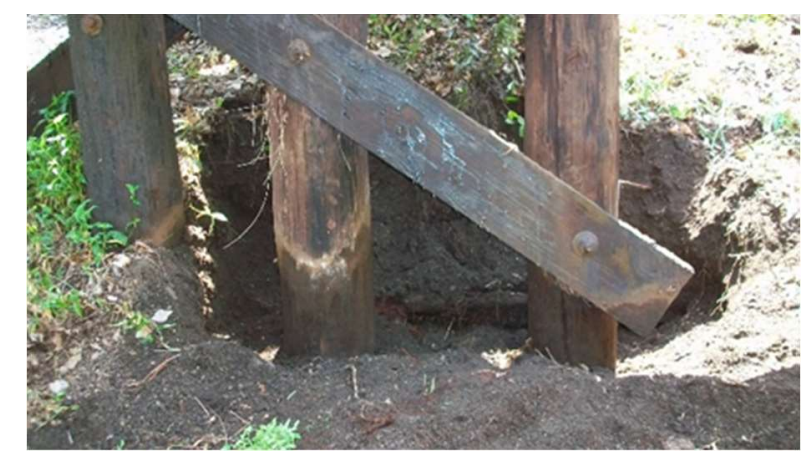

Figure 1-16 - Pile Excavation and Removal of Debris

2. Removal of Decay 
From WVU-CFC literature the decayed portion of the pile was removed by removing the outer decayed layer, leaving behind a smaller diameter clean portion. To perform a splice the entire deteriorated pile portion must be removed and replaced with a new timber section of similar diameter. These sections can be temporarily held in place using nails to prevent movement of pile sections during application of wrap and curing of the FRP material.

3. Sanding of Pile

The new and existing pile sections are sanded using a hand sander to open up the pores of the wood for good adhesion and to provide an even bond surface. Sanding also helps to minimize the amount of chipped or loose wood that could weaken bond strength.

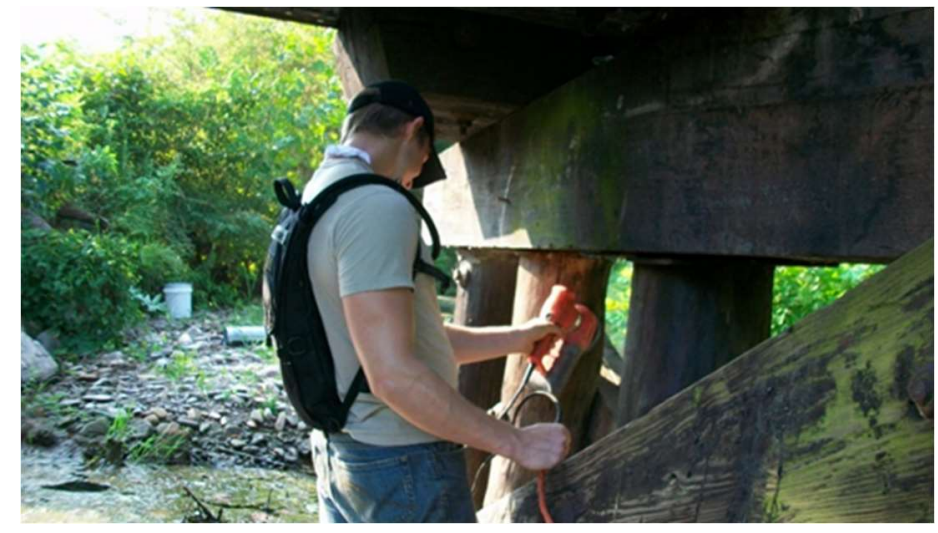

Figure 1-17 - Sanding of Pile in Field

4. Priming Pile

Piles should be primed immediately after sanding. WVU-CFC used a phenolic based adhesive as a primer. Primer should be cured as per manufacturer's recommendation.

\section{Application of Wrap}

Fabric sheets are precut to desired length depending on the amount of ply layers needed. WVU-CFC soaked and pulled the wrap using the hand wringer method. The hand lay-up method can also be used for the soaking of fabric wrap. The wrap was initially stapled to the pile to hold 
it in place, allowing for the wrap to be pulled tight to minimize voids as it is applied. Staples can be used more as the fabric is wrapped around the pile to prevent movement or sliding of the wrap.

6. Pressure Application

After the wrap was applied the pile is wiped by hand, pressing hard on the fabric to eliminate wrinkles and push out voids. WVU-CFC has also used rubber bands and clamping to ensure pressure application as the resin cures (Figure 1-18). Shrink wrap may also be used to ensure applied pressure during the curing process.

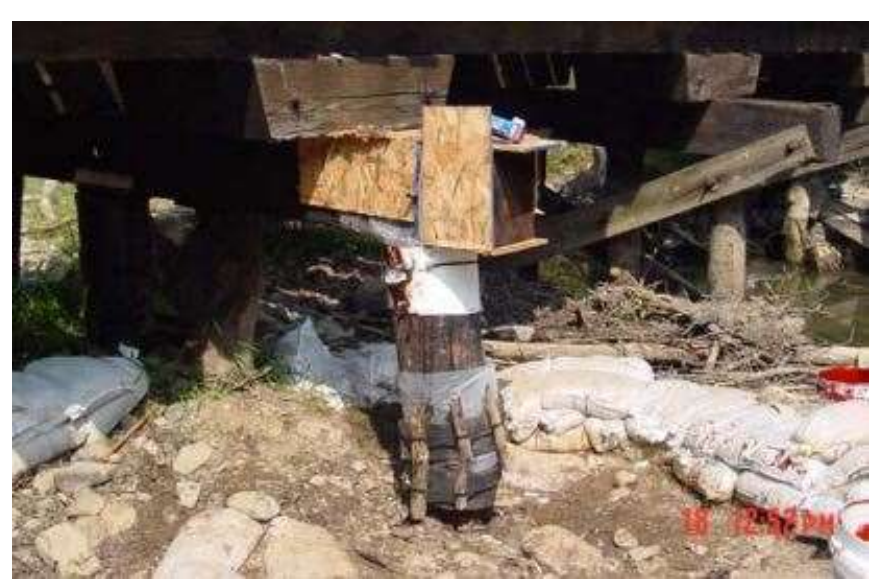

Figure 1-18 - Rubber Banding of Pile

\subsubsection{Quality Control}

Sample specimens can be made according to ASTM D7565 to ensure that the FRP composite matches the material properties required [26]. These specimens are constructed in the field using the same material and method as the wrap used for rehabilitation, but should be constructed on a material that will not bond to the FRP. These specimens can be taken to the lab and tested to verify material properties as per ASTM D3039 [27].

After the FRP has been installed and cured, it is necessary to conduct testing on the bond strength and integrity. In the past WVU-CFC has used digital tap hammers (DTH), infrared thermography (IRT), pull-off testing, and visual inspection [28]. These testing methods help to 
determine the reliability of FRP/timber bonds after installation. Both IRT and DTH are nondestructive methods while pull-off testing causes localized damage to the FRP that is repaired by patching. Visual inspection is subjective, the wrap is inspected in search of visual signs of damage such as peeling and detachment. A hammer or stiff object can be used to tap the FRP, listening for hollow sounding areas that signify a de-bond between the FRP and timber.

Infrared thermography can be used to determine areas of de-bond in FRP that is externally bonded to structural members, that may be caused by deterioration over time. The surface of FRP is heated by an external source and the IRT system is positioned to record temperate response on the FRP's surface [29]. The surface is heated to penetrate into the wood, too much heat can cause damage to the resin so it must be monitored. The IRT system creates thermal images where voids and subsurface flaws can be identified as areas where heat concentrates (Figure 1-19) [29].
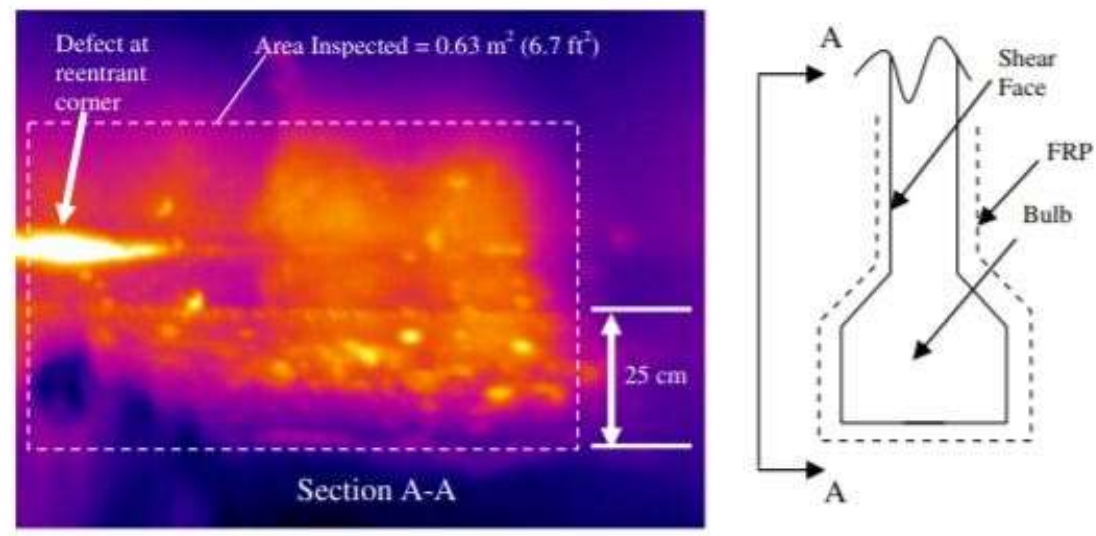

Figure 1-19 - Infrared Thermography of Concrete AASHTOH Girder Wrapped with FRP [29]

A digital tap hammer can be used as a non-invasive method of determining areas of debond in the FRP wrap (Figure 1-20). The hammer has an accelerometer built into the tip that translates a force-time pulse into a voltage pulse. Lower numbers indicate a stiffer surface where higher numbers indicate voids or de-bond. The DTH is a localized measurement, making it time 
consuming to test large areas. However, this method is effective in finding flaws in FRP wraps bonded to concrete and timber members [30].

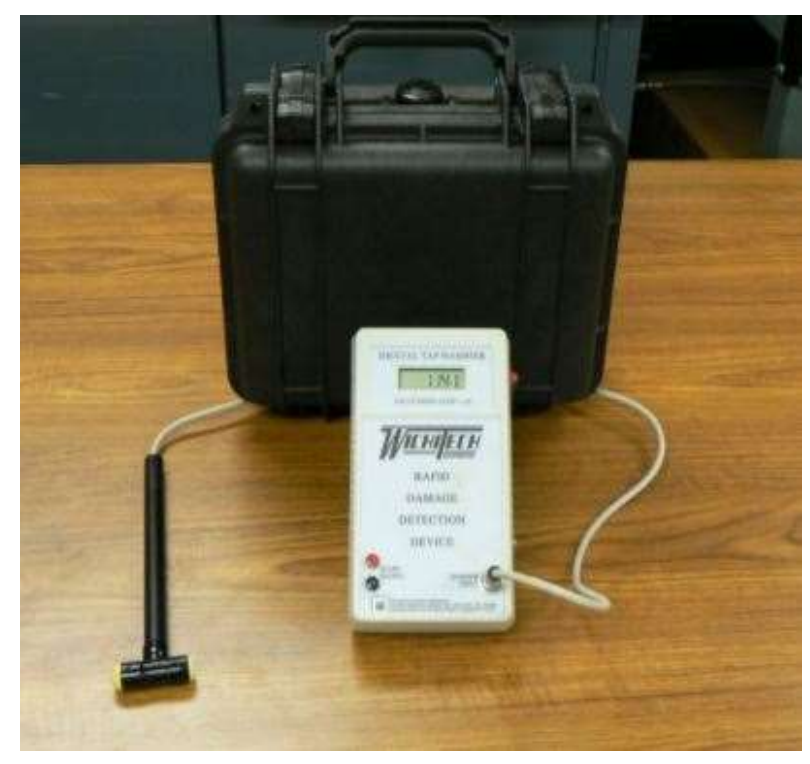

Figure 1-20 - Digital Tap Hammer

As mentioned before pull-off testing is another method to determine the strength of FRP bonds however it is invasive. Specimens can be taken and tested in the lab with accordance to ASTM D7565 [26].

\subsection{Conclusions from Literature Review}

Minimal literature exists on the study of splicing mechanisms for timber piles. The strength capacities of these existing splicing mechanisms must be evaluated to determine if a FRP wrap splice is an adequate replacement. FRP wrap is a versatile material that can be used in many different applications to improve the strength and durability of existing or repaired structures.

The following recommendations for FRP wrap splice design based on information gained through this literature review are listed below: 
Repair Mechanism: Traditional splicing methods can be recreated and tested in the WVU-CFC lab based on schematics provided by the Louisiana Department of Transportation (LaDOTD). Splicing of timber piles with FRP wrap is also to be tested, the hand layup method is recommended for wrap application due to its low cost, rapid repair time, and ease of repair.

FRP Fabric: E-Glass fabric is recommended due to its low cost, high strength, and good durability. Unidirectional or 0/90 bidirectional fabric is recommended for wrapping, unidirectional fabric is sufficient for a splice scenario.

Resin: Epoxy resin is recommended as it provides high mechanical strength properties and creates corrosion resistance.

Number of Wraps: The amount of FRP wraps required for strengthening of timber members is not well defined. Three layers of unidirectional glass/epoxy composite will be utilized with the dominant fiber direction aligned with the lateral direction of the pile to optimize axial strength capacity. Due to the ease of construction of FRP wrapped specimens additional layers can be added to increase strength capacity if needed. 


\section{CHAPTER 2 SPLICE DESIGN AND ANALYSIS}

\subsection{Timber Pile Splice Repair}

Splice repair was conducted by cutting out the damaged timber pile portion and replacing it with a new pile section of the same diameter as the original pile. The newly inserted pile section was secured to the preexisting pile using three different traditional splicing methods: flat steel plate splicing, C-channel steel plate splicing, and wooden plate splicing. The effectiveness of splicing methods was evaluated by measuring the shear, bending, and axial strengths. In addition, splicing of the new pile section and the old (undamaged) pile section was done by wrapping with glass FRP fabrics overlapping the new and old (undamaged) pile sections. The following sections expand upon the outcomes of timber pile repair using the above splicing methods and through the strength analyses.

\subsubsection{Assembly of Timber Piles}

A total of 36, 12-inch diameter, creosote-treated, southern pine piles were tested under axial, shear, and bending forces with four splice configurations. The test specimen configurations for each loading connection are detailed in Table 2-1 below. Virgin piles were cut to desired lengths of $5 \mathrm{ft}$., $8 \mathrm{ft}$., or $16 \mathrm{ft}$. and were cut further at midspan for splicing, with specifications (directions and drawings) provided by LTRC. Timber pile diameter varied approximately \pm 1 inch in some cases. Therefore, the exact diameter of each pile was recorded for stress computation and reported herein. 
Table 2-1 - Pile Splice Configuration

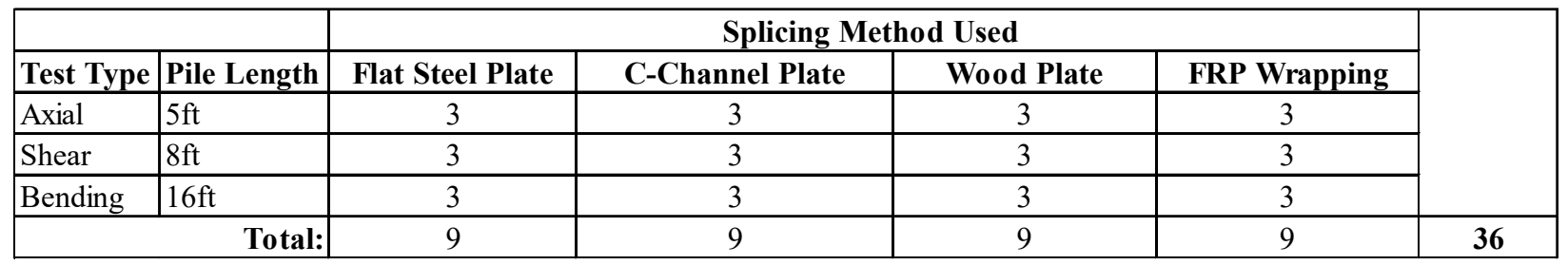

The cut pile pieces were joined together with steel plates as shown in the schematic diagram of Figure 2-1. The steel plate and C-channel splicing methods used 18 -inch-long bolts of $3 / 4$ inch diameter (Grade B61). The wooden plate method used 24-inch-long bolts of $3 / 4$ inch diameter (Grade B61) to accommodate approximately 3-inch-thick timber splices. All joints were spliced with 54-inch-long plates that were 5.5-inch and 6-inch in width for timber and steel plate splices, respectively. However, the $\mathrm{C}$-channel splicing mechanism also included an 8-inch-wide steel channel. Steel plate schematics are provided in Figure 2-2. An image of an assembled pile prepared for shear testing, using the steel plate splicing method is provided in Figure 2-3.
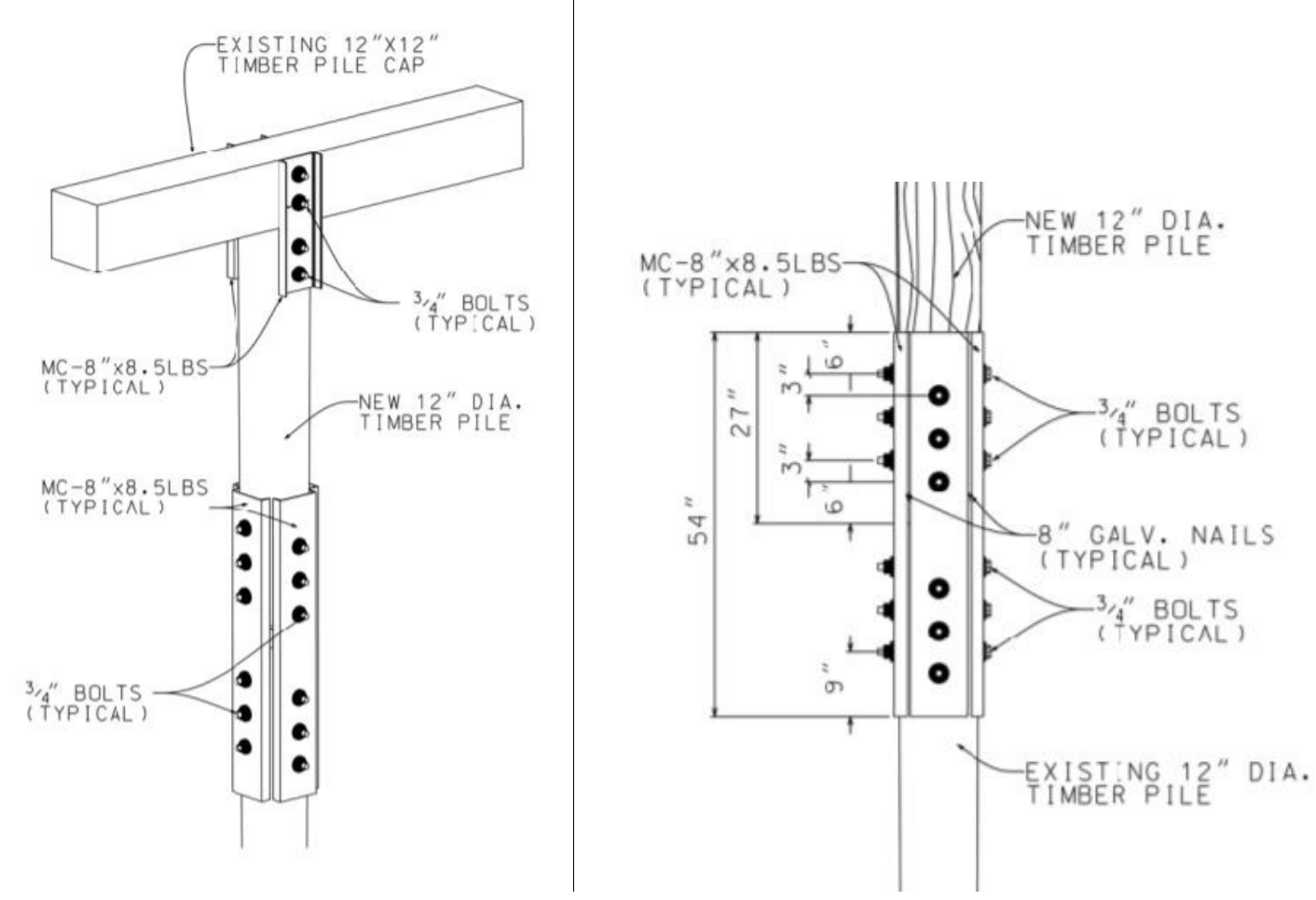

Figure 2-1 - C-Channel Splice Detail 


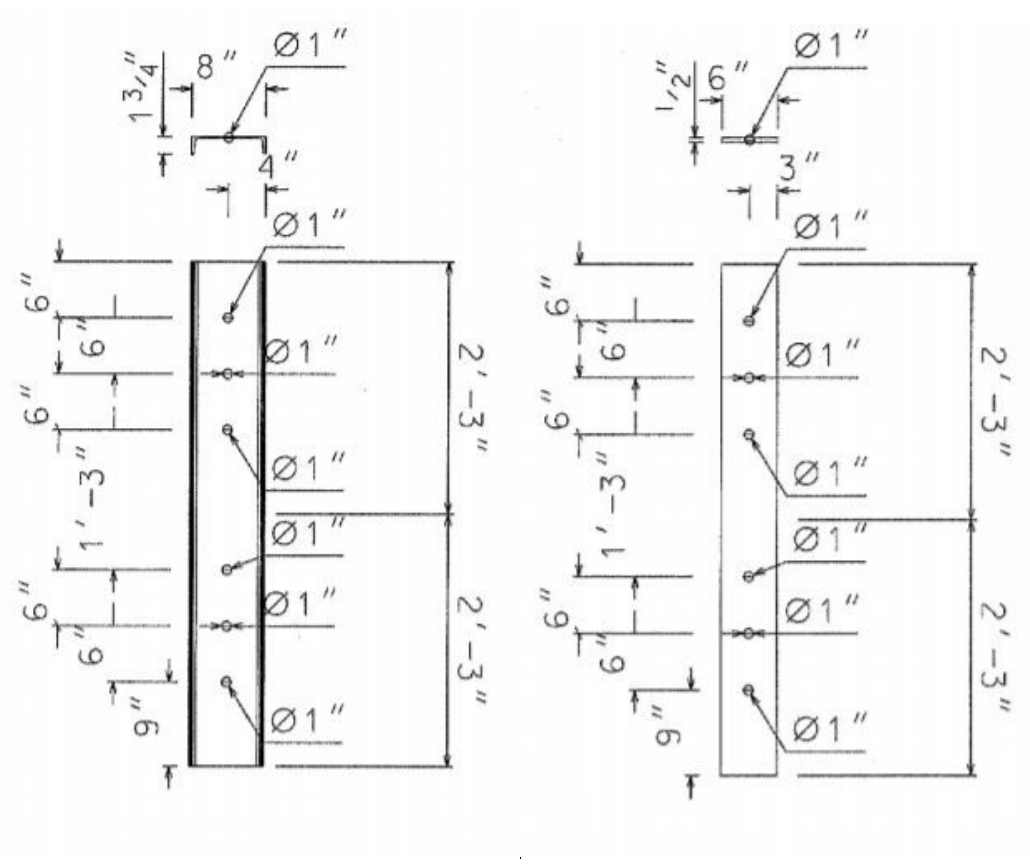

Figure 2-2 - C-Channel and Flat Steel Plate Detail

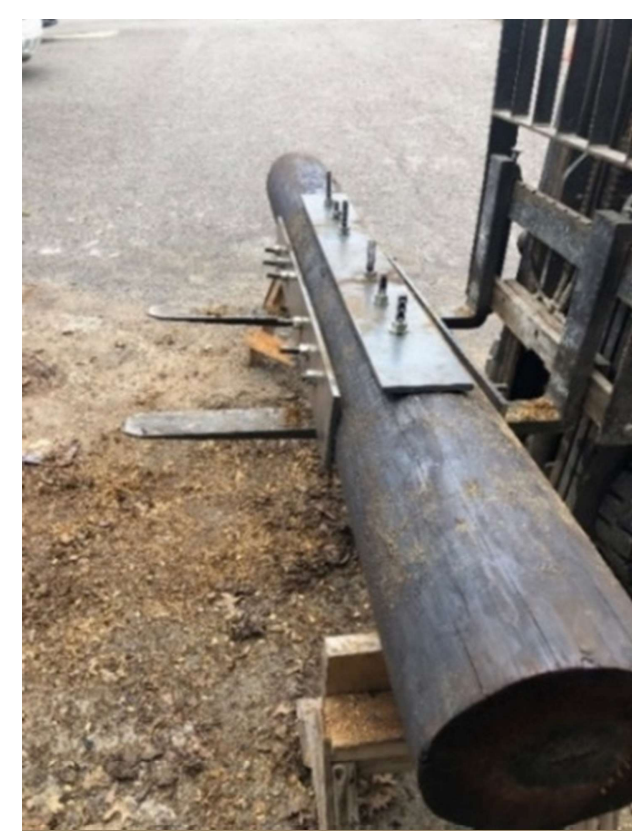

Figure 2-3 - Steel Splice Specimen Constructed in WVU-CFC Lab 


\subsection{Timber Pile Repair Using Fiber Reinforced Polymers}

Timber piles may be repaired in several ways, but a potentially more efficient method to obtain comparable strength to the legacy splicing systems is to use composite materials. A Fiber Reinforced Polymer (FRP) composite was used to rejoin a pile cut into two parts. It was hypothesized that once the FRP was bonded to the pile, the wrap would act similar to the steel and wooden plates used to splice the samples and provide a confinement stress. FRP splicing method was tested for shear, bending and axial compressive strengths compared to other splice methods. These concepts were evaluated for the influence of FRP wraps for timber piles.

Fiber reinforced polymers consist of fibers and resin as shown in Figure 2-4. For civil structures, a variety of commercially available fiber and resin systems are used. The Sika system used in Phase 1 research of this project was used again herein, i.e., Sika Hex 100G, a unidirectional glass fabric, and Sikadur Hex 300, a two-part epoxy resin. Together it created a glass-epoxy composite that connects wooden pieces. Unidirectional refers to the orientation of fibers primarily within the matrix, in a single direction. Sika Hex 100G fabric has a density of $0.092 \mathrm{lb}$./in .

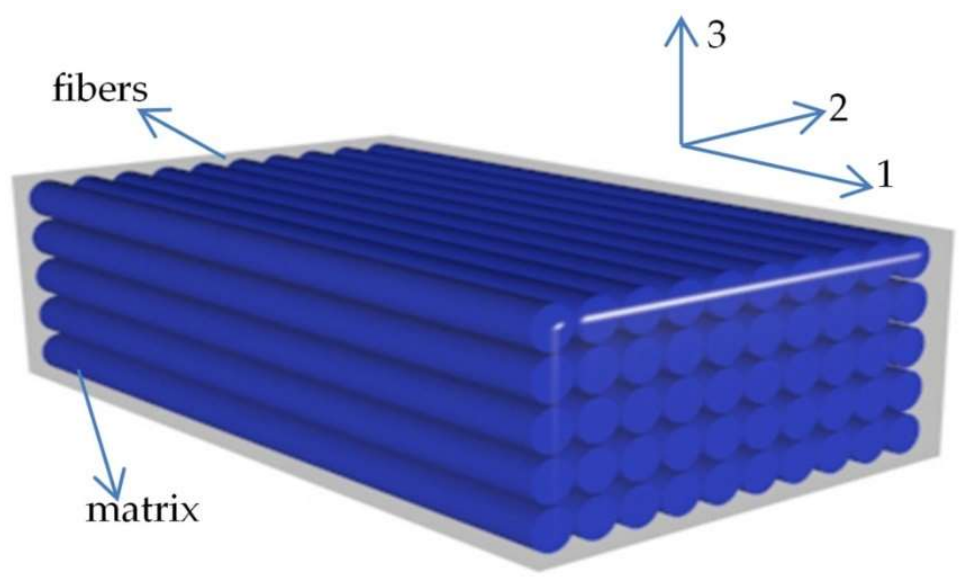

Figure 2-4 - Unidirectional FRP Composite Orientation [31] 


\subsubsection{Assembly of Fiber Reinforced Polymer Splicing}

Piles were cut to the desired length for each test, i.e., $16 \mathrm{ft}$. for bending, $8 \mathrm{ft}$. for shear, and $5 \mathrm{ft}$. for axial testing. The piles were cut in half before splicing with FRP wraps. Only three piles of each length were needed for this portion of testing to keep consistent with testing performed on piles with traditional splicing methods. The sections of each pile were nailed together to prevent pile separation or movement during wrapping. Sheets of fabric are cut to $4 \mathrm{ft}$. in length, creating a rectangular sheet of fiber with dimensions $48 \times 51$ inches. 51 inches is the width of the glass fabric roll supplied by Sika. The resin was prepared by mixing part A with part B as per the manufacturer's instructions. The contents were mixed using a mixer drill bit for five minutes. After thorough mixing of the resin, it was used to prime the pile and saturate the glass fabric sheets. Each pile tested was wrapped with three layers around the circumference. The pile was primed by thoroughly brushing the primer (resin) onto the surface of the pile and subsequently prepared by rolling resin onto both sides of the fabric, ensuring that the entire sheet was fully saturated. After the pile was primed, the fabrics were then applied (wrapped around) to the pile. The fabrics were stapled at the ends and pressed. While the fabric was wrapped around the pile, the resin saturated fabric was wiped and pressed by hand to remove voids and ensure a tight, void free wrap. After both sheets were applied to the pile, it was set aside to cure for at least three days before testing. An image of a finished FRP splice is provided below in Figure 2-5. 


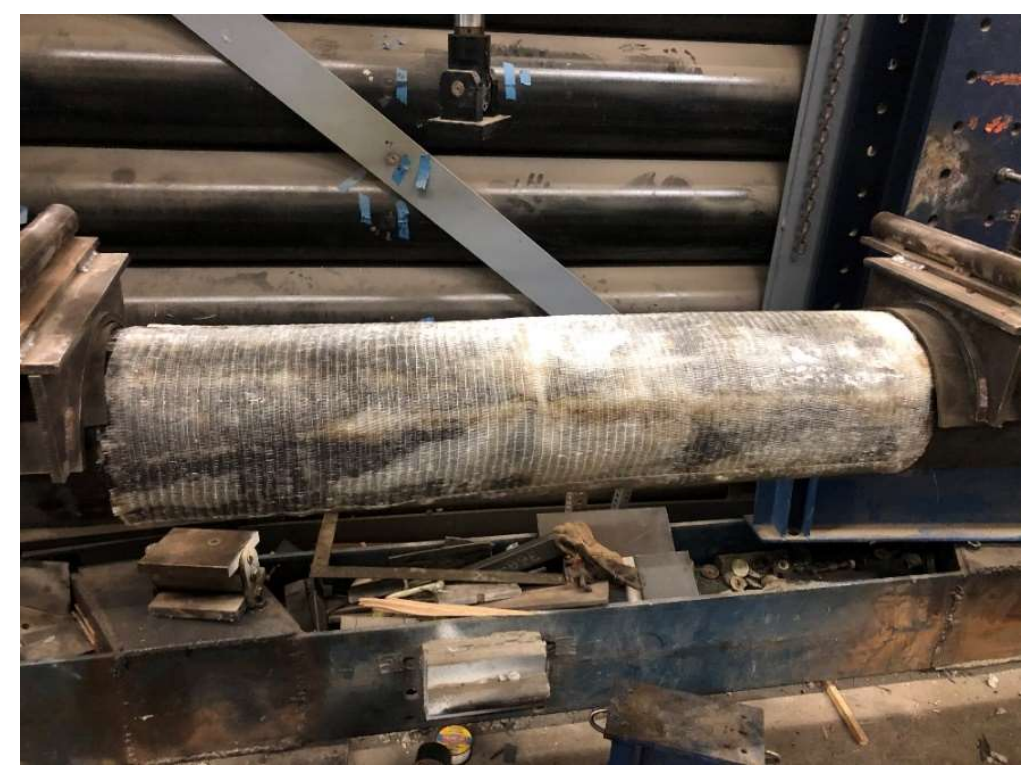

Figure 2-5 - Finished Pile with Glass Fiber Reinforced Polymer Splice

\subsection{Testing Methods and Setup}

\subsubsection{Test Methodology}

In order to compare FRP to the traditional splicing methods, certain tests were conducted; this section provides details on the test procedures for shear, bending, and axial loading. All tests were conducted in compliance with ASTM D198-15 [32] for static tests of lumber components.

\subsubsection{Shear Test Setup}

The shear test was prepared by placing two concrete supports with clear span of $4 \mathrm{ft} ., 8$ inches apart. To induce a shear mode of failure, 1/d ratio ranging between 4 and 10 must be achieved. However, $1 / \mathrm{d}<6$ is recommended as per ASTM D198-15. The test span (4 ft., 8 inches) for shear test provides a $1 / \mathrm{d}$ of 4.67 .

An $8 \mathrm{ft}$. long pile was placed on steel saddles following splicing at the center of the span of the refurbished pile (Figure 2-6). A concentrated load was applied using a hydraulic actuator. 
The load was transferred from the actuator to a load cell that was placed on top of a spacer on the pile specimen. The load cell records the amount of force applied to the pile from the actuator. A linear variable differential transformer (LVDT) was placed at the center span to measure deflection. A shear test setup with wood plate splicing, connecting two timber pile pieces is shown in Figure 2-7.

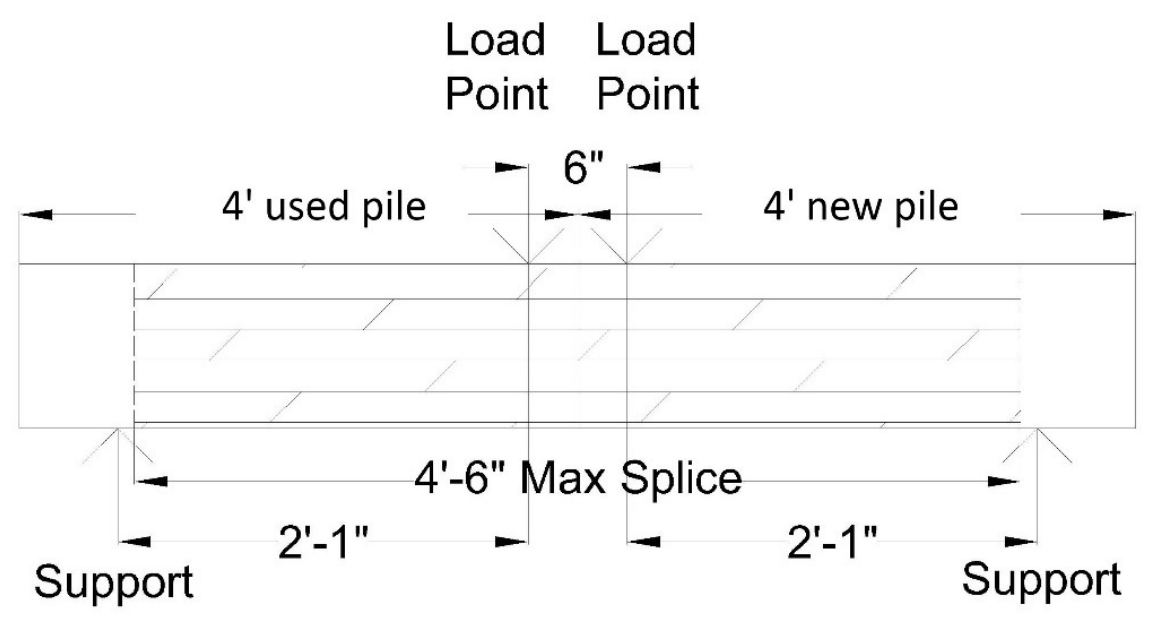

Figure 2-6 - Shear Test Schematic 


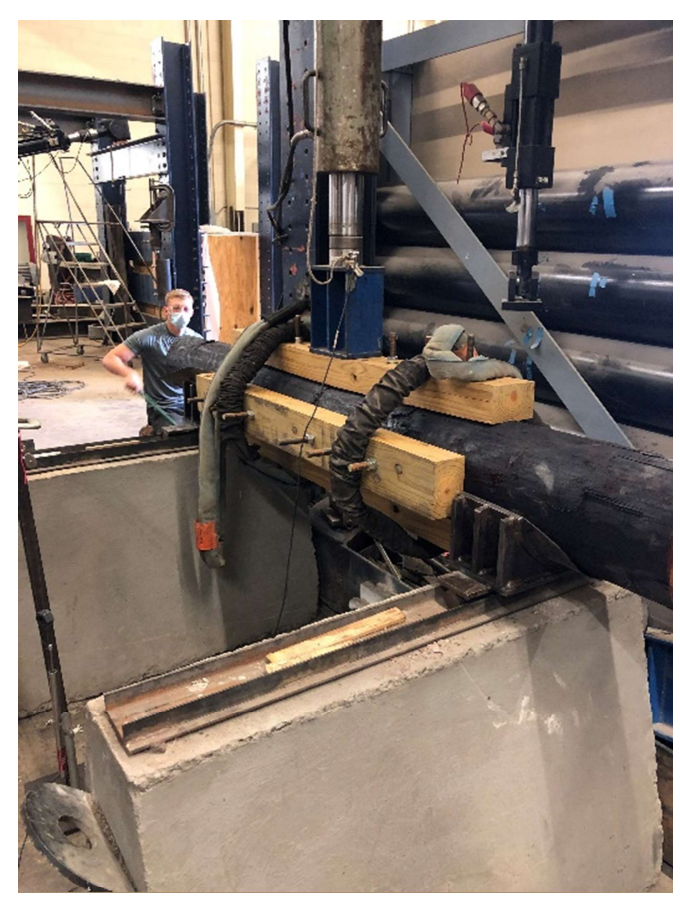

Figure 2-7 - Shear Test Setup with Wooden Splice

\subsubsection{Bending Test Setup}

To obtain bending mode of failure the $1 / \mathrm{d}$ ratio was taken as 15 . Therefore, the test specimen was spanned at $15 \mathrm{ft}$. (clear span) between support saddles. Other instrumentation remained the same as in the shear test setup. With the pile in position, an I-beam shown in Figure 2-9 was placed on top to distribute the loading and create a test setup that generates a 4-point bending test. This Ibeam distributed the actuator induced load at two points (middle third section) on the pile. The Ibeam weight was accounted for in the stress-deflection computations. A string pot was used to measure the downward deflection induced by the vertical load application. The string pot was placed directly underneath the center of the splice and was attached to the bottom of the pile using fishing line. All sensors were initialized (zeroed) before the I-beam was placed on the specimen. Figure 2-8 provides a schematic of the test setup under four-point bending loading as per ASTM 
D198. Figure 2-9 gives additional details of the bending test setup with a C-channel spliced member.

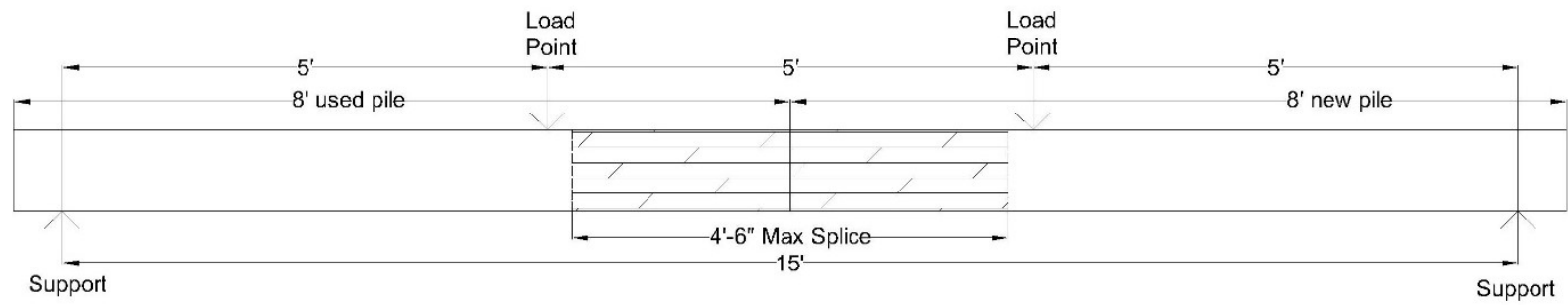

Figure 2-8 - Flexural Test Schematic

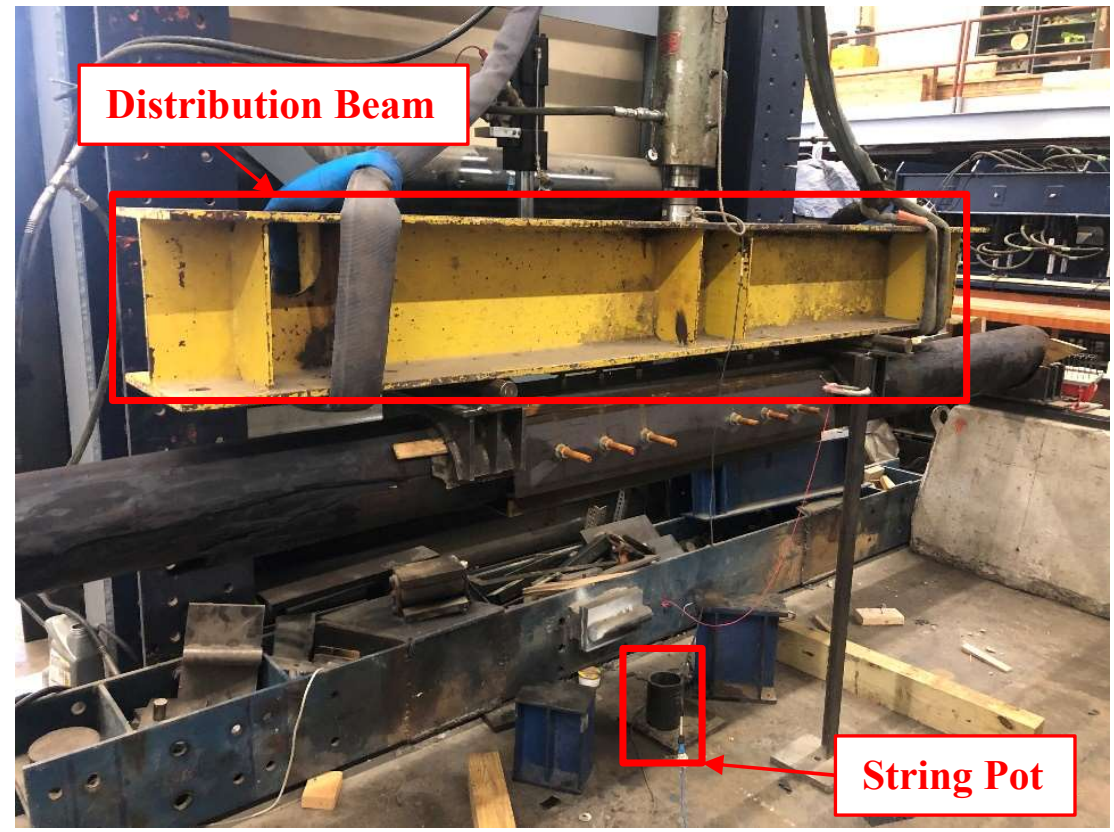

Figure 2-9 - Flexure Test Setup with C-Channel Splice

\subsubsection{Axial Test Setup}

The axial compression test was performed by placing the $5 \mathrm{ft}$. long pile sections in a compression test frame, which had a load capacity of 750 kips. Hydraulic jack was used to apply load to a $16 \times 16$ inch steel plate, which in turn exerted axial force on to the pile cross section. A LVDT was used to measure longitudinal displacement under compression. Figure 2-10 is a 
schematic of the axial compression test. Figure 2-11 provides an image of axial testing performed with C-channel splicing.

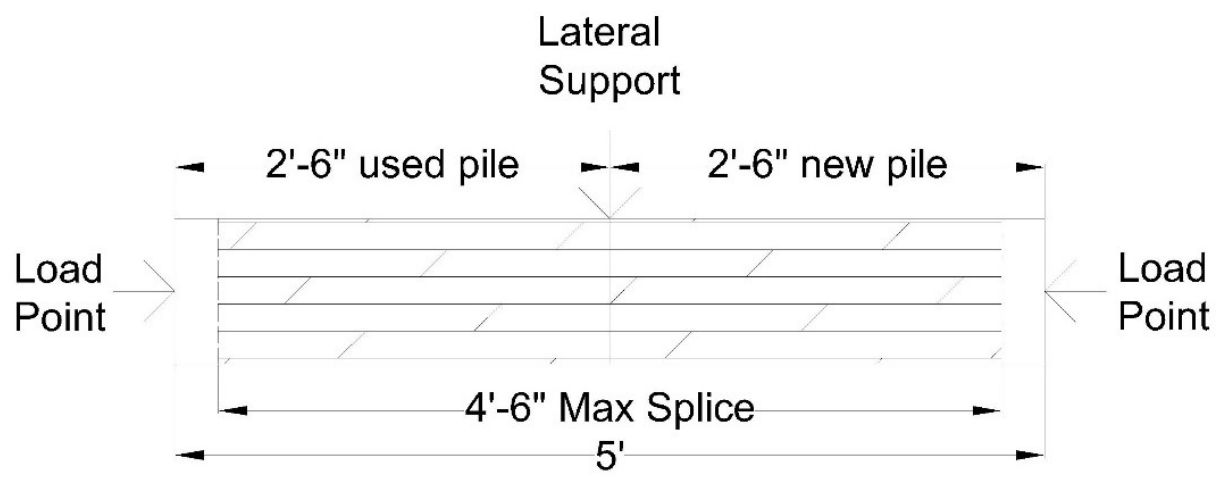

Figure 2-10 - Axial Compression Test Schematic

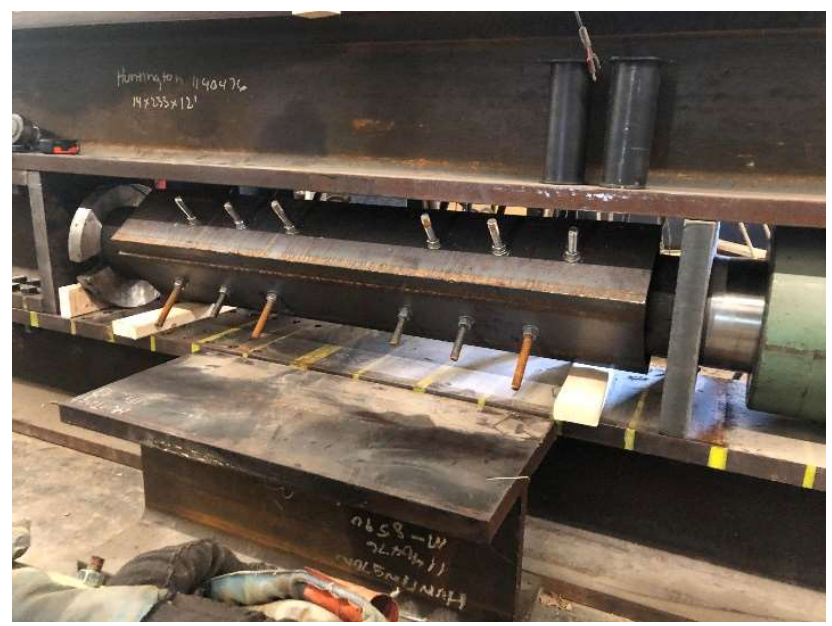

Figure 2-11 - Axial Test Setup with C-Channel Splice

\subsection{Test Results and Data Analysis for Traditional Splicing}

This section provides data gathered through testing of timber piles after splice repair under shear, bending, and axial loading. The experimental data was evaluated and discussed herein, highlighting responses of timber piles with traditional splicing. 


\subsubsection{Data Analysis under Shear Testing}

Data were analyzed for maximum shear stress and deflection after plotting shear stress versus deflection diagrams. Maximum shear stress of each test specimen, induced at depth $\mathrm{d} / 2$, is determined using Equations (1) and (2).

$$
\begin{gathered}
A=\frac{\pi d^{2}}{4} \\
\tau=\frac{4 F}{3 A}
\end{gathered}
$$

$\mathrm{d}$ - Diameter of the pile cross section

A - Area of the pile cross section

$\tau-$ Shear Stress

F - Force applied to the pile

For simplicity, shear stress was computed using the cross-sectional area of each timber pile, neglecting the shear resistance offered by the splicing mechanism and the stress concentration induced by the holes drilled for splicing. A shear stress-displacement plot was made for each specimen, shown in Figure 2-12, Figure 2-13, and Figure 2-14.

Shear tests were performed on three, 8-ft. long piles of each of the three repair methods, resulting in a total of nine tests (Table 2-1). Table 2-2 shows the maximum shear stress and the corresponding deflection for each of the nine test specimens, including their averages. 
Table 2-2 - Maximum Shear Stress and Corresponding Deflection*

\begin{tabular}{|l|c|c|c|c|}
\hline \multicolumn{5}{|c|}{ Flat Steel Plate Splicing } \\
\hline Test & $\mathbf{1}$ & $\mathbf{2}$ & $\mathbf{3}$ & AVG \\
\hline Maximum Shear Stress (psi) & 614 & 701 & 452 & 589 \\
\hline Deflection at Maximum Stress (in) & 2.4 & 3.1 & 2.5 & 2.7 \\
\hline \multicolumn{5}{|c|}{ Steel C-Channel Splicing } \\
\hline Test & $\mathbf{1}$ & $\mathbf{2}$ & $\mathbf{3}$ & AVG \\
\hline Maximum Shear Stress (psi) & 715 & 761 & 873 & 783 \\
\hline Deflection at Maximum Stress (in) & 2.3 & 2.3 & 2.0 & 2.2 \\
\hline \multicolumn{5}{|c|}{ Wooden Plate Splicing } \\
\hline Test & $\mathbf{1}$ & $\mathbf{2}$ & $\mathbf{3}$ & AVG \\
\hline Maximum Shear Stress (psi) & 484 & 528 & 610 & 541 \\
\hline Deflection at Maximum Stress (in) & 1.7 & 2.1 & 1.5 & 1.8 \\
\hline
\end{tabular}

*Note: Deflections shown here were recorded at the point of maximum shear stress.

Shear stress versus transverse deflection for timber piles spliced with flat steel plates is shown in Figure 2-12. The test data revealed a 40\% variation in shear stress (500 psi vs 700 psi) which was attributed to the quality of pile specimens. Pre-existing flaws such as cracks and other natural variations of timber may have contributed to the shear stress (magnitude) variation. The random cracking was observed visually and can be attributed to internal flaws in large size timbers. It was observed that the first test exceeded the deflection measurement limit of the LVDT; hence unable to record ultimate deflection, perhaps due to improper zeroing technique.

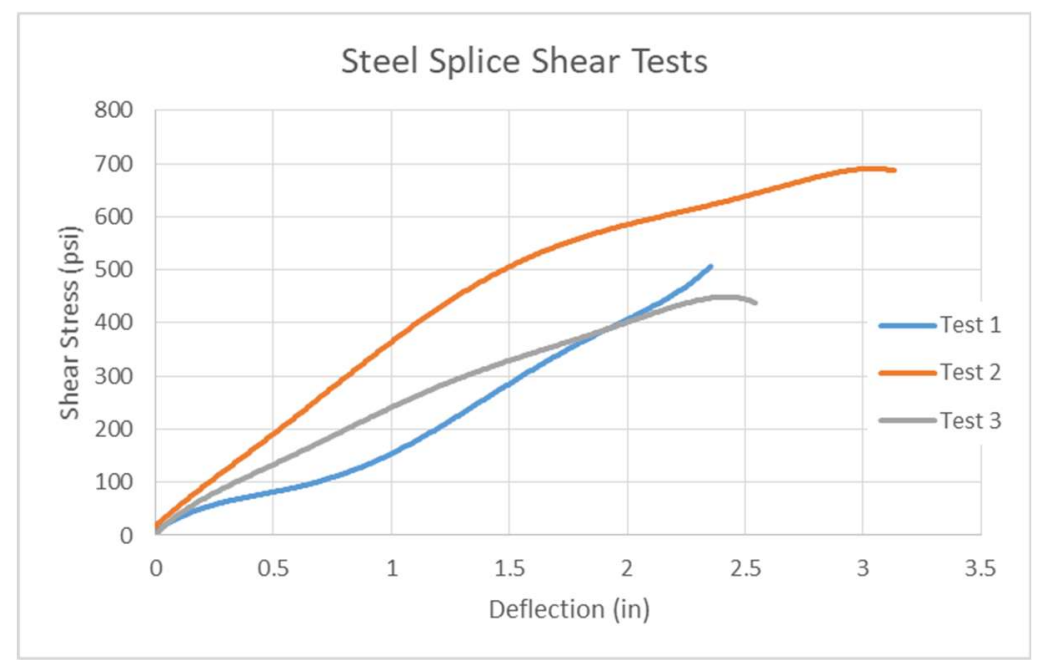

Figure 2-12 - Shear Stress vs Deflection for Steel Plate Splice 
A graphical representation of shear stress versus deflection relationship for timber piles spliced with steel C-channel splicing is provided in Figure 2-13. The test data revealed that the shear failure mode is nearly identical in all piles. It is also noted that the C-channel method of splicing is stronger than the steel plate splicing method. This is to be expected as the C-channel method provides higher shear resistance than the steel plate splice. Similar to the shear deflection response using steel plate, deflection peaked above the constraints of the test device (LVDT) for test one of this method. The initial slope change in Tests 1 and 2 may be attributed to the initial internal adjustment of the test specimen and the test frame at the early stages of loading. The Cchannel splicing dug into the wooden pile upon initial loading. These changes in slope may also be a result of yielding of steel at the load location, which is observed in multiple specimens of this repair type.

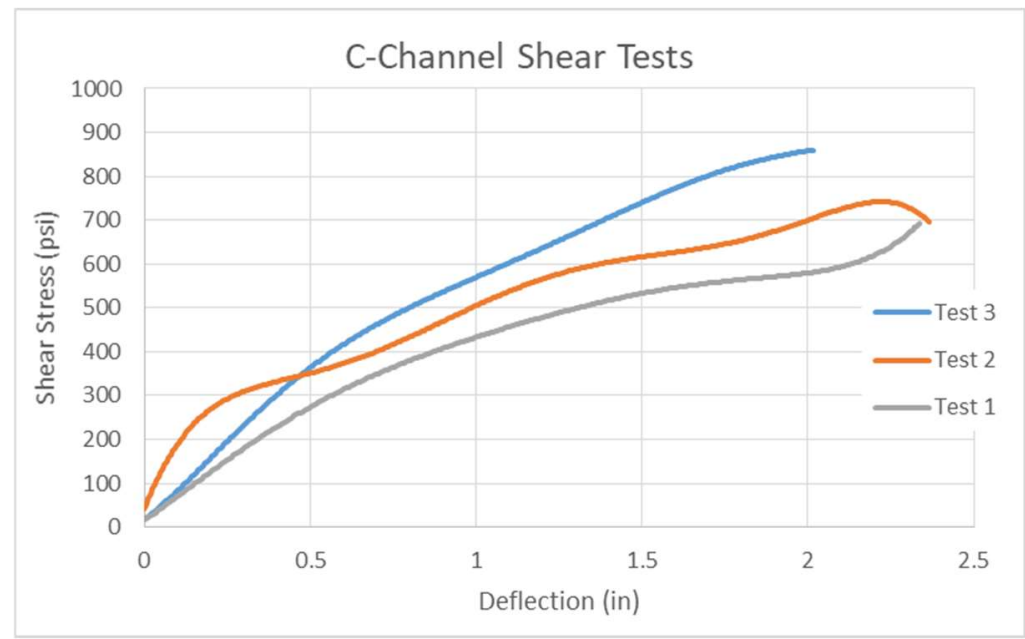

Figure 2-13 - Shear Stress vs Deflection for C-Channel Splice

Figure 2-14 provides the shear stress versus deflection plots for tested specimens with the wooden plate splicing. The applied load induced an indentation in the splicing at the point of contact. The wooden plate splice, however, does not have the same yielding effect as the other two splicing methods. This method of splicing with wood was slightly weaker than the other two in terms of shear stress at failure. 


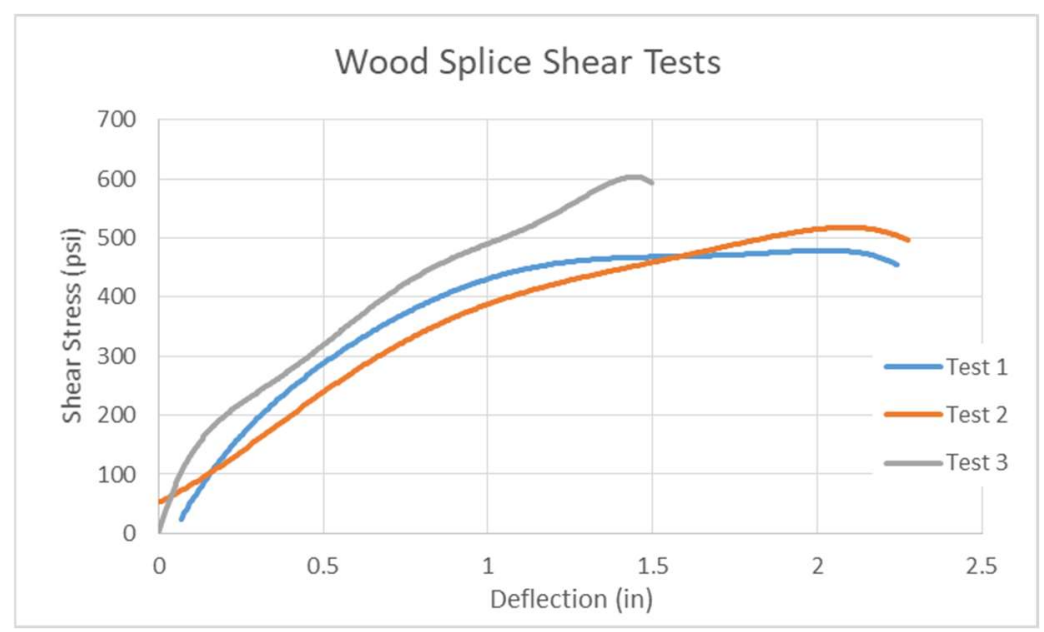

Figure 2-14 - Shear Stress vs Deflection for Wood Splice

\subsubsection{Shear Analysis - Summary and Failure Modes}

In terms of shear strength of the piles based on the three methods of splicing, the C-channel method was the strongest and the wood plate method was the weakest, with a $30 \%$ variation. This observation was based on the maximum shear stress resisted by each of the splicing mechanisms. The C-channel splice method provides a higher shear stress resistance than the other 2 methods due to its large material volume and shape compared to the lesser volume of the flat steel plate splice. Its connection to the pile through its channel shape provides additional shear resistance to the specimen. Data from Test 2 (Table 2-2) revealed that the wooden plate method provided the least deflection at failure in comparison with the other two methods, indicative of higher shear stiffness over the other two methods. Under loading, the wooden splice plates interacted more in unison with the timber pile than the steel plates or C-channel splicing devices. Better response of wood splicing was largely attributed to the similarity in modulus of the splicing mechanism and the timber pile. In the steel and C-channel splicing steel yielded prior to ultimate shear failure of the splicing system, allowing the piles to continue to deflect. 
While this test data was helpful in terms of understanding the strengths of different splicing methods, it was important to keep multiple variables in mind, including clear identification of peak experimental values of failure loads. Visual signs of failure are observed before a pile reached its ultimate strength. Multiple signs of visual failure were observed during testing. For the steel plate and C-channel splicing methods, it was observed that the steel plate at the surface yielded significantly. The plates on the side of the pile would not yield but it was observed that the bolts would bend and yield inside the timber pile. When a specimen could not carry any more load while deflection was increasing under load application, failure of a specimen was established. These two forms of visual failure can be seen in Figure 2-15 and Figure 2-16. In the case of the wood splicing method, indentation from the applied load as well as cracking on the top and bottom plates were observed. This failure mode can be seen in Figure 2-17.

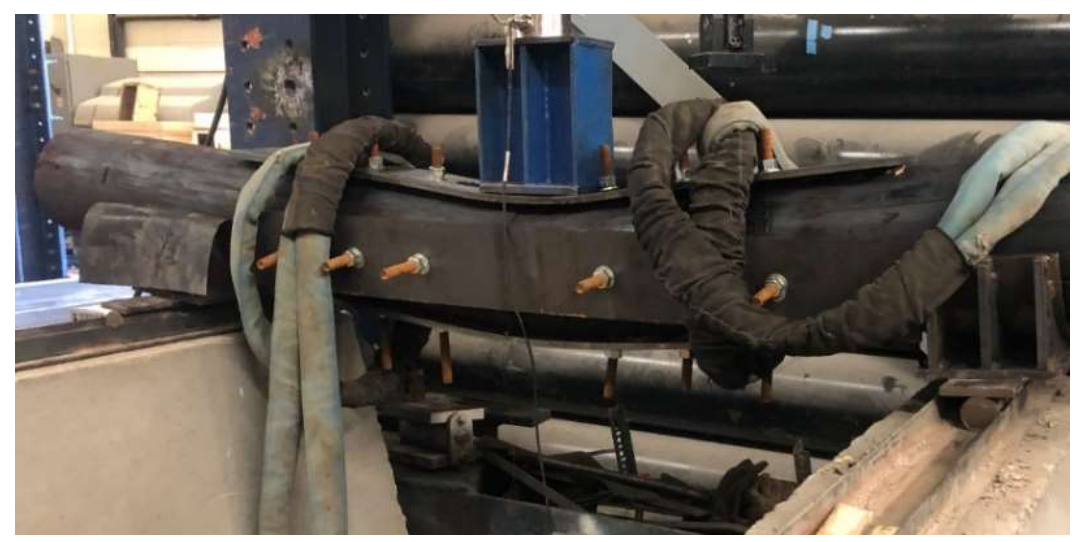

Figure 2-15 - Yielding of Top and Bottom Plates in Steel Splicing 


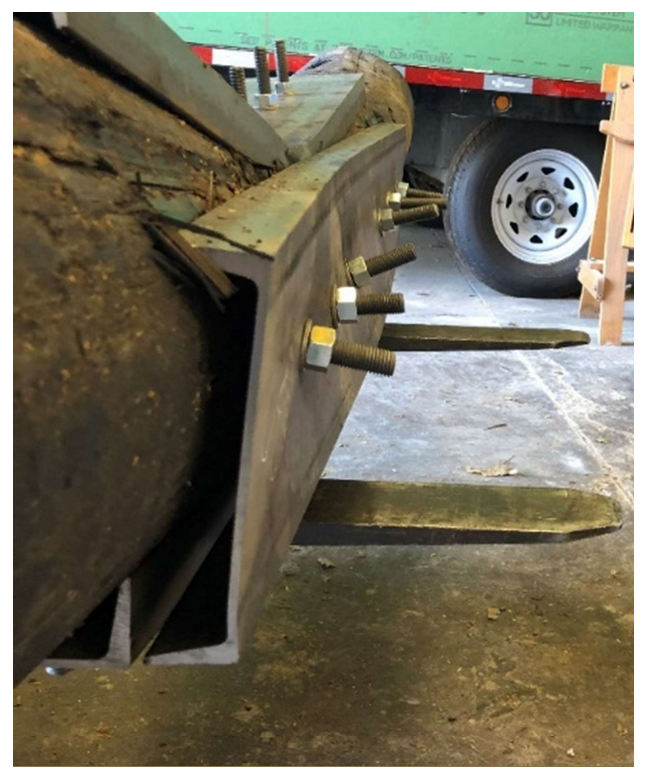

Figure 2-16 - Yielding of Bolts in C-Channel Splicing

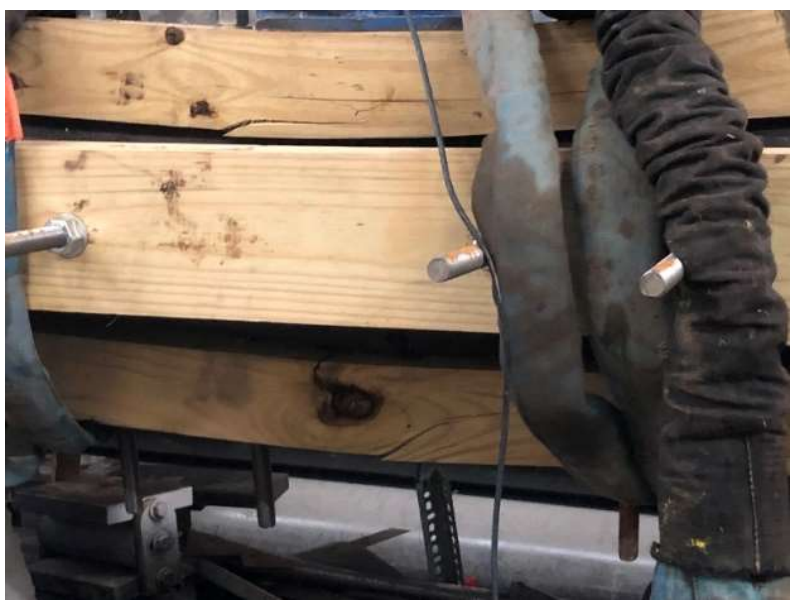

Figure 2-17 - Cracking of Top and Bottom Plates in Wood Splicing

\subsubsection{Data Analysis under Bending Testing}

The pile test data under bending were analyzed to establish maximum bending stress and deflection after plotting bending stress versus deflection curves. Cross sectional diameter was measured and recorded. Modulus of rupture was determined using Equation (3). Once the maximum bending stress values were obtained for each load point, bending stress versus deflection plots were made. 


$$
M O R=\frac{2 P a}{\pi r^{3}}
$$

MOR - Modulus of Rupture

P - Total applied load

a - Distance between the support and nearest point load

$\mathrm{r}-$ Radius of cross section

The bending tests were performed on three $16 \mathrm{ft}$. long piles using each of the three repair methods, giving a total of nine tests (Table 2-1). Table 2-3 shows the maximum bending stress (MOR) and the corresponding deflection for each of the nine tests, including their averages.

Table 2-3 - Maximum Bending Stress and Corresponding Deflection*

\begin{tabular}{|c|c|c|c|c|}
\hline \multicolumn{5}{|c|}{ Flat Steel Plate Splicing } \\
\hline Test & 1 & 2 & 3 & AVG \\
\hline Maximum Modulus of Rupture (psi) & 6674 & 3647 & 3417 & 3532 \\
\hline Deflection at Maximum Stress (in) & $3.6^{*}$ & 9.5 & 10.6 & 10.1 \\
\hline \multicolumn{5}{|c|}{\begin{tabular}{|c|} 
Steel C-Channel Splicing \\
\end{tabular}} \\
\hline Test & 1 & 2 & AVG & \\
\hline Maximum Modulus of Rupture (psi) & 2826 & 4731 & 3778 & \\
\hline Deflection at Maximum Stress (in) & 10.2 & 9.0 & 9.6 & \\
\hline \multicolumn{5}{|c|}{ Wooden Plate Splicing } \\
\hline Test & 1 & 2 & 3 & AVG \\
\hline Maximum Modulus of Rupture (psi) & 4609 & 4860 & 2415 & 3962 \\
\hline Deflection at Maximum Stress (in) & 6.3 & 7.6 & 5.4 & 6.5 \\
\hline
\end{tabular}

*Note: Deflections shown here were recorded at maximum bending stress. Deflection for Test 1 was recorded using LVDT and deflection was maxed at 3.6 inches; hence does NOT represent the actual deflection at maximum stress.

Figure 2-18 shows the graphical relationship of bending stress versus deflection. Deflection was measured using an LVDT instead of a string pot in test 1 of the bending tests with steel plate splicing mechanism, which has exceeded maximum deflection measurement capacity of the LVDT. Hence data could not be included in Figure 2-18. Test 1 for the fllat steel plate splicing showed stress values much larger than the other two tests and for this reason was marked as an anomaly and not included in the average stress calculation for the flat steel plate specimens. The 
maximum deflections recorded in this test are highlighted in Table 2-3. This being the first specimen to be tested in bending, adjustments in testing procedure were made for the remaining tests, i.e., using the string-pot to measure deflections.

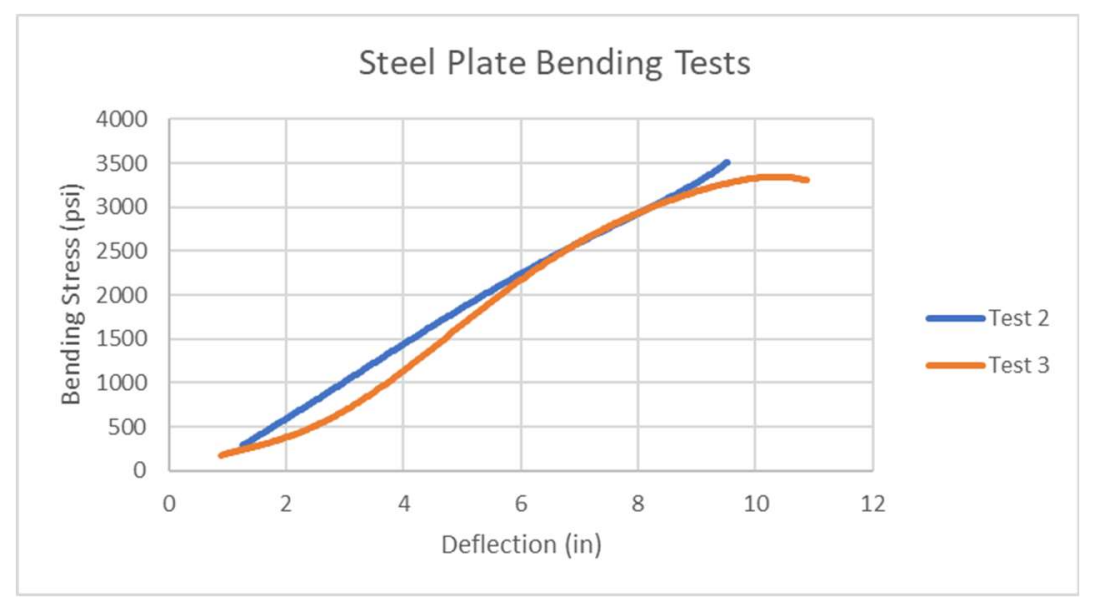

Figure 2-18 - Bending Stress vs Deflection for Steel Splice

For the timber piles spliced with the C-channel three specimens were tested. The data for the third test specimen was not retrieved and was not included in Table 2-3 and Figure 2-19. Figure 2-19 provides the bending stress versus deflection relationship for timber piles with C-channel splicing. The data from the two tests have a large deviation in bending stress to failure. This was attributed to the strength of the timber pile itself. The failure behavior of the test specimens was similar, to the flat plate splicing mechanism but not identical. Both specimens deflected greatly before reaching maximum load, as $\mathrm{C}$-channel splicing yields greatly under bending. 


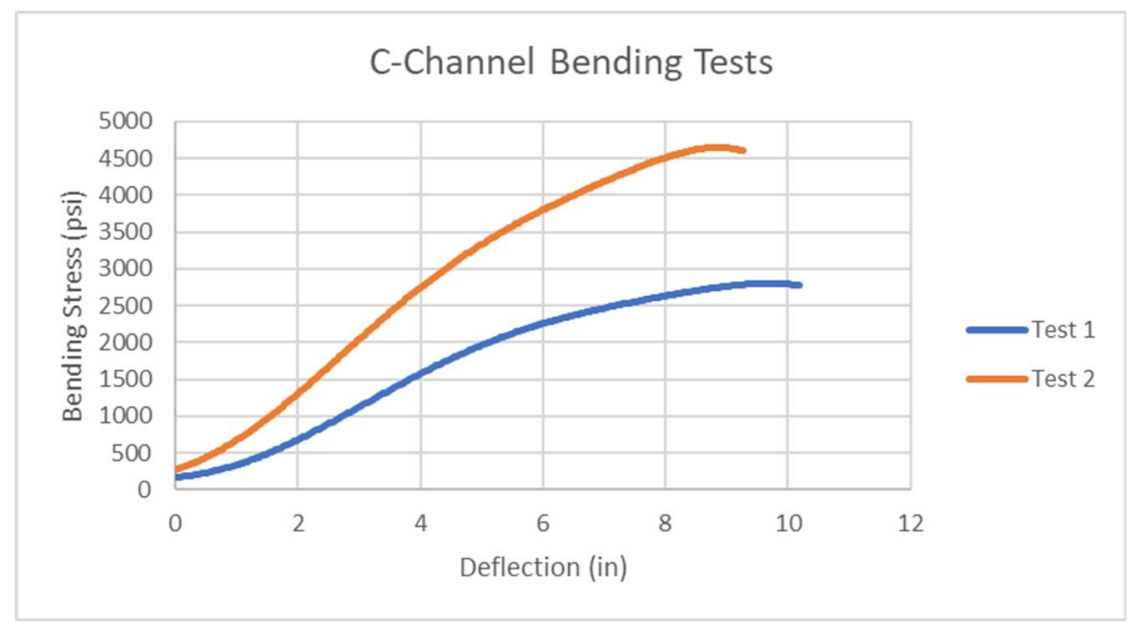

Figure 2-19 - Bending Stress vs Deflection for C-Channel Splice

Figure 2-20 provides the graphical relationship of the bending stress versus deflection of specimens of wood splicing. Deflection is relatively low at failure. Also, there is no drastic change in slope leading up to failure in the stress versus deflection curve. This signifies that the splicing system causes the pile to split rather than yielding of splice, as in the other methods. Any change in slope leading to rupture signifies splitting or excess movement within the splicing mechanism itself.

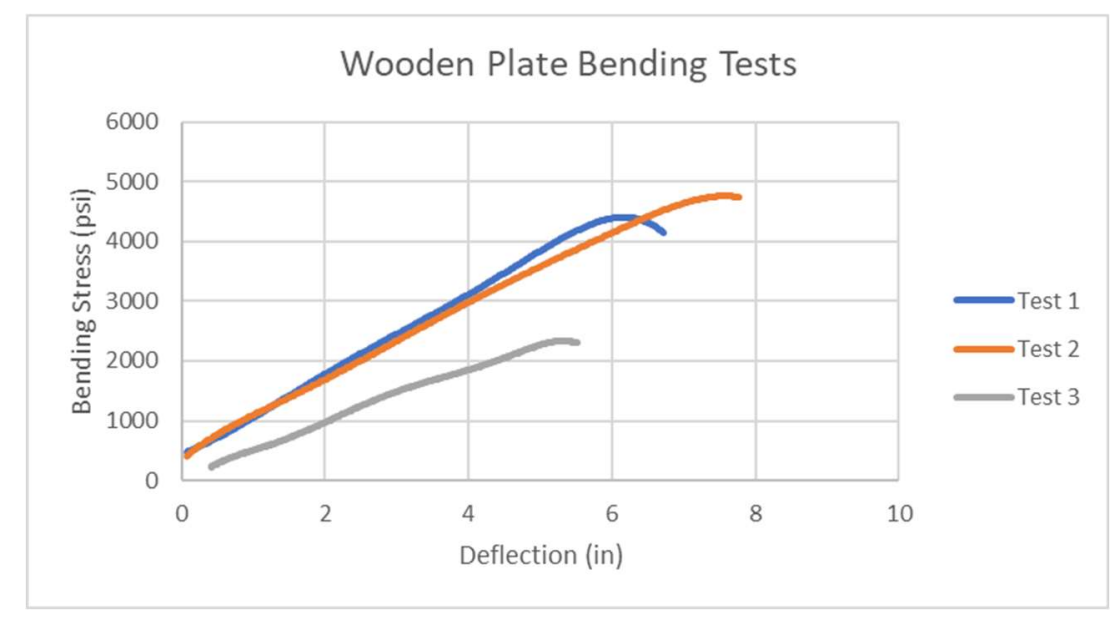

Figure 2-20 - Bending Stress vs Deflection for Wood Splicing 


\subsubsection{Bending Analysis - Summary and Failure Modes}

The three different splicing methods exhibited similar strength to failure and large deformation to failure. The steel flat plate and C-channel methods exhibited higher deflection to failure compared to the wood plate splicing method. The disparity in results is attributed to the maximum load resistance of steel splice mechanisms which exceeded that of wood. The wooden plate method exhibited higher flexural rigidity than the steel splicing methods, due to higher bending rigidity of wood splice. Unlike the gradual yielding exhibited by steel splicing methods, the wooden plates exhibited splitting or cracking. The bending deformation pattern with increasing applied load is similar to the ones observed during shear testing.

The steel plate and C-channel splicing bowed a significant amount before yielding of the top and bottom plates. An image of the steel plate splice yielding is provided in Figure 2-21. When using the steel plate splicing method, a pile cracked along its entire span during one of the tests. This signifies that the pile was split by the localized force exerted by bolts (stress concentration) onto the timber pile at small locations. An image of this failure is shown in Figure 2-22. As identified in Figure 2-23, failure in the wooden plate splicing method left cracks along both the top and bottom plates, similar to those in shear testing cases.

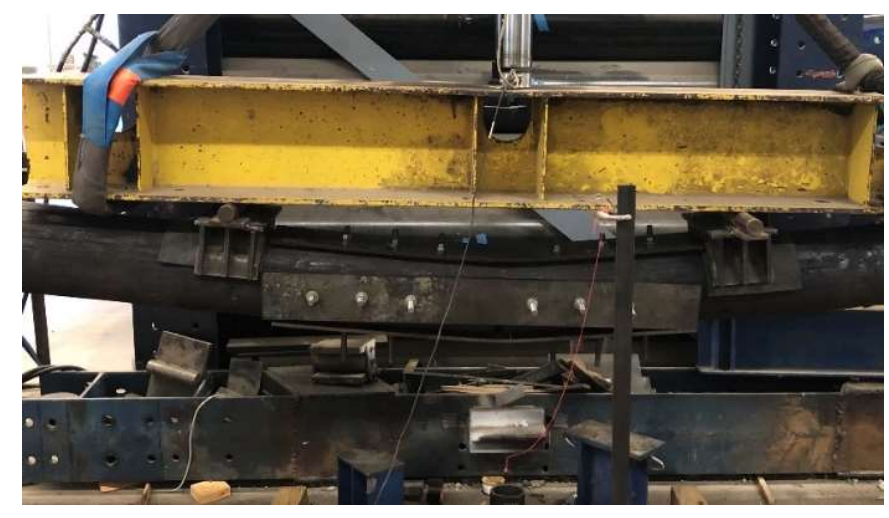

Figure 2-21 - Steel Splice Yielding During Bending Test 


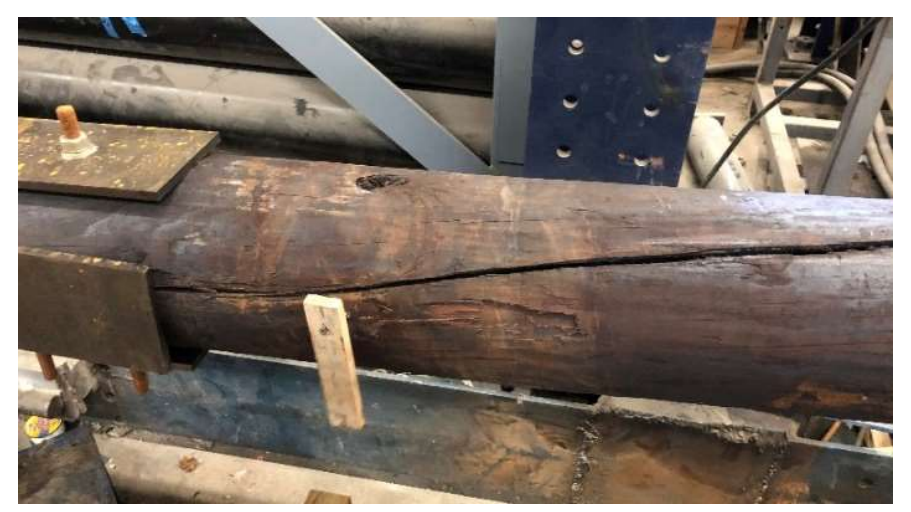

Figure 2-22 - Steel Splice Cracked Pile

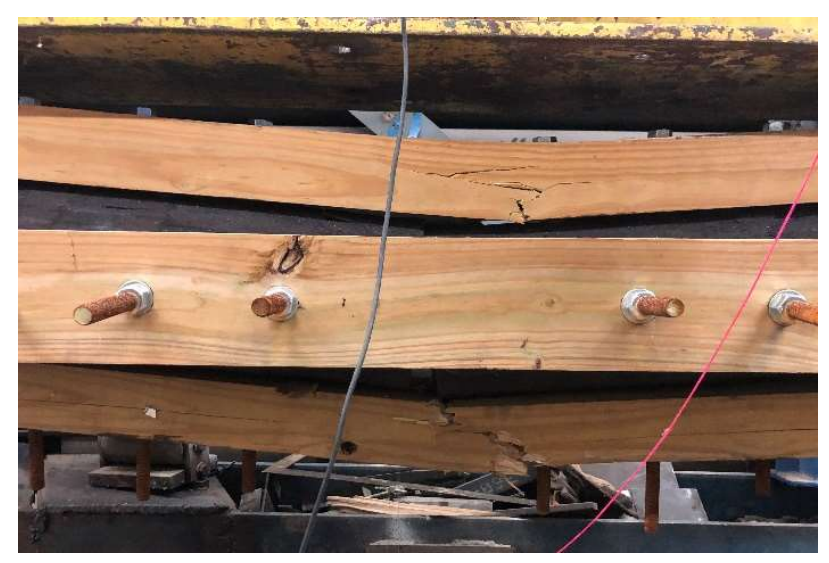

Figure 2-23 - Wood Splicing Crack during Bending Test

\subsubsection{Data Analysis under Axial Testing}

The test data developed under axial compression was analyzed to establish the maximum normal stress to failure and the corresponding deflection. Axial stress versus deflection plots were analyzed, hereunder. The cross-sectional area of each pile was considered using Equation (1). Equation (4) was then used to determine the normal stress at each data point.

$$
\sigma=\frac{F}{A}
$$

$\sigma-$ Axial Stress

F - Applied Load

A - Area of cross section 
Axial stress in a pile is very important as it is the controlling force that carries the load from the superstructure to the foundation. The axial tests were performed on three $5 \mathrm{ft}$. long piles of each of the three repair methods, giving a total of nine tests. Table 2-4 shows the maximum axial stress and the corresponding deflection for each of the nine tests, including their averages. Splice contribution to axial stress was not included for simplicity in calculations.

Table 2-4 - Maximum Axial Stress and Corresponding Deflection*

\begin{tabular}{|l|c|c|c|c|}
\hline \multicolumn{5}{|c|}{ Flat Steel Plate Splicing } \\
\hline Test & $\mathbf{1}$ & $\mathbf{2}$ & $\mathbf{3}$ & AVG \\
\hline Maximum Axial Stress (psi) & 1038 & 856 & 831 & 909 \\
\hline Deflection at Maximum Stress (in) & 0.4 & 0.7 & 0.5 & 0.5 \\
\hline \multicolumn{6}{|c|}{ Steel C-Channel Splicing } \\
\hline Test & $\mathbf{1}$ & $\mathbf{2}$ & $\mathbf{3}$ & AVG \\
\hline Maximum Axial Stress (psi) & 2214 & 1423 & 1412 & 1683 \\
\hline Deflection at Maximum Stress (in) & 0.5 & 0.6 & 0.6 & 0.6 \\
\hline \multicolumn{7}{|c|}{ Wooden } & Plate Splicing & \\
\hline Test & $\mathbf{1}$ & $\mathbf{2}$ & $\mathbf{3}$ & AVG \\
\hline Maximum Axial Stress (psi) & 1492 & 1494 & 1709 & 1565 \\
\hline Deflection at Maximum Stress (in) & 0.6 & 1.1 & 0.3 & 0.6 \\
\hline
\end{tabular}

*Note: Deflections shown here were recorded at the point of maximum axial stress.

Figure 2-24 shows the axial stress versus deflection relationship for specimens with flat steel plate splicing. Piles did not have perfectly flush cuts at the ends where they were in contact with the steel plates at each end of the pile. Hence, there was an initial loading period of each test when the pile settles into the stiff steel plates that are exerting axial stress at the ends of the pile cross section. Due to this initial settling period, actual axial deflection was skewed by a small amount and was evident in Figure 2-24, where the slope of the normal stress vs deflection curve was not linear. 


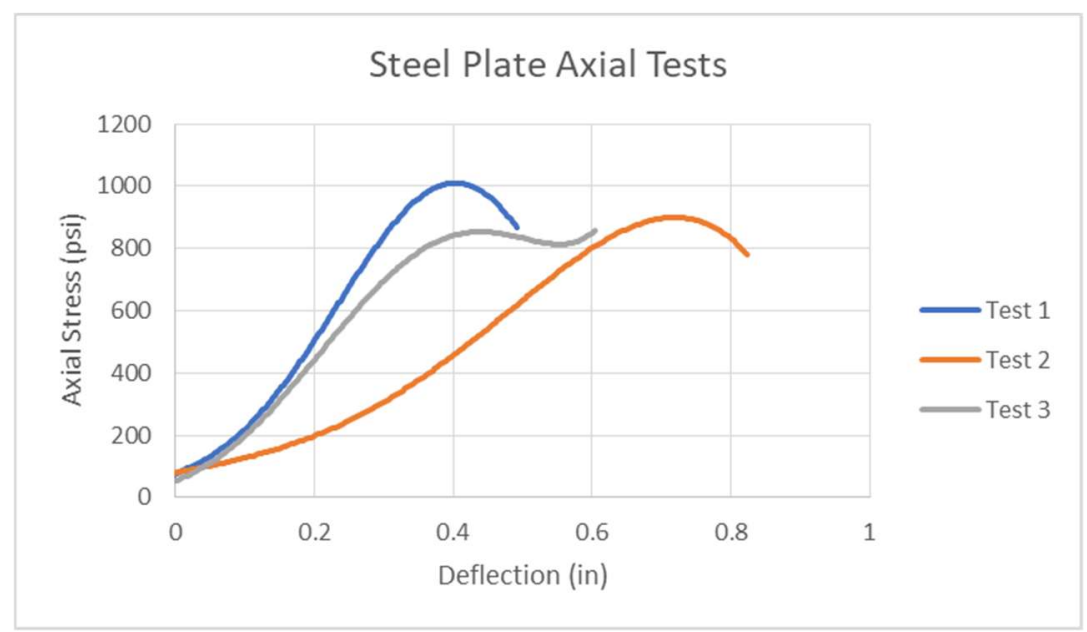

Figure 2-24 - Axial Stress vs Deflection for Flat Steel Plate Splice

Figure 2-25 provides the axial stress versus deflection relationship for piles spliced with the steel C-channel splice. From Table 2-4 it is apparent that the C-channel splice was stronger than that of the flat steel plate splice method in resisting axial compressive loading which incidentally induces a small amount of bending due to eccentricity of applied loads. This variation was attributed to secure connections that the $\mathrm{C}$-channel provides to the pile through its cross sectional shape and area.

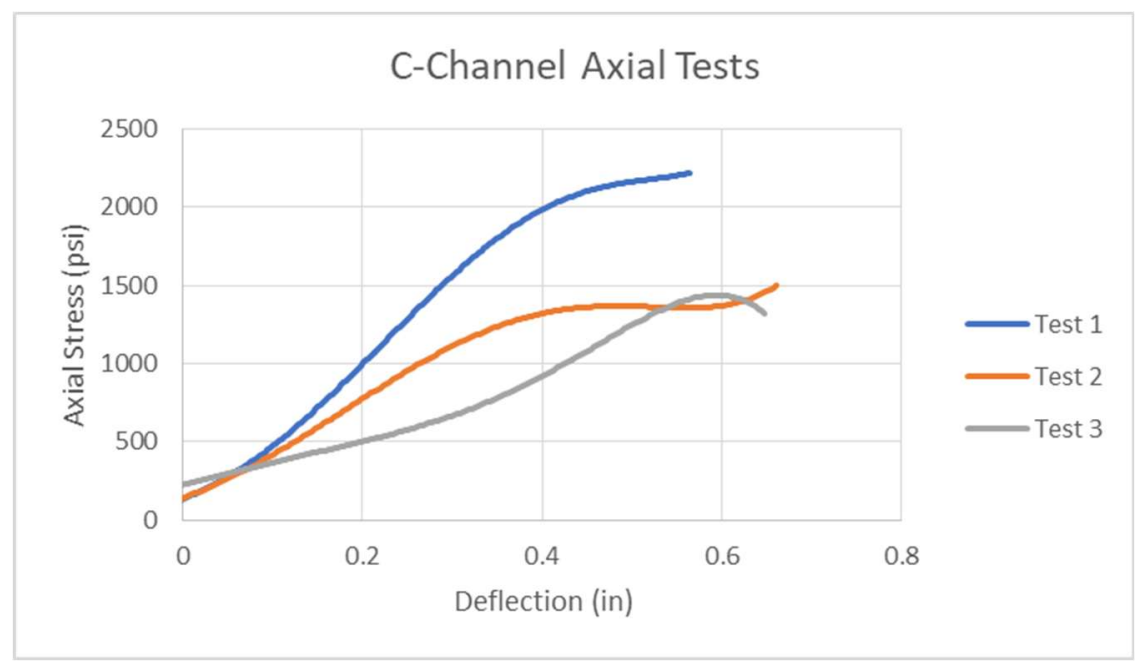

Figure 2-25 - Axial Stress vs Deflection for C-Channel Splice

Figure 2-26 provides the axial stress versus deflection relationship for piles spliced with wood plate splicing. As seen in the axial stress versus deflection plot, test two provided a large 
amount of deformation due to axial loading. This was attributed to possible "looseness" of the splicing mechanism with the pile, along with the gap separating the cut portions of the pile at the cut location. Each pile splice varies in this aspect and can be attributed to the pile assembly method. Results from the wood plate splice are comparable to those of the C-channel splice in terms of axial stress to failure.

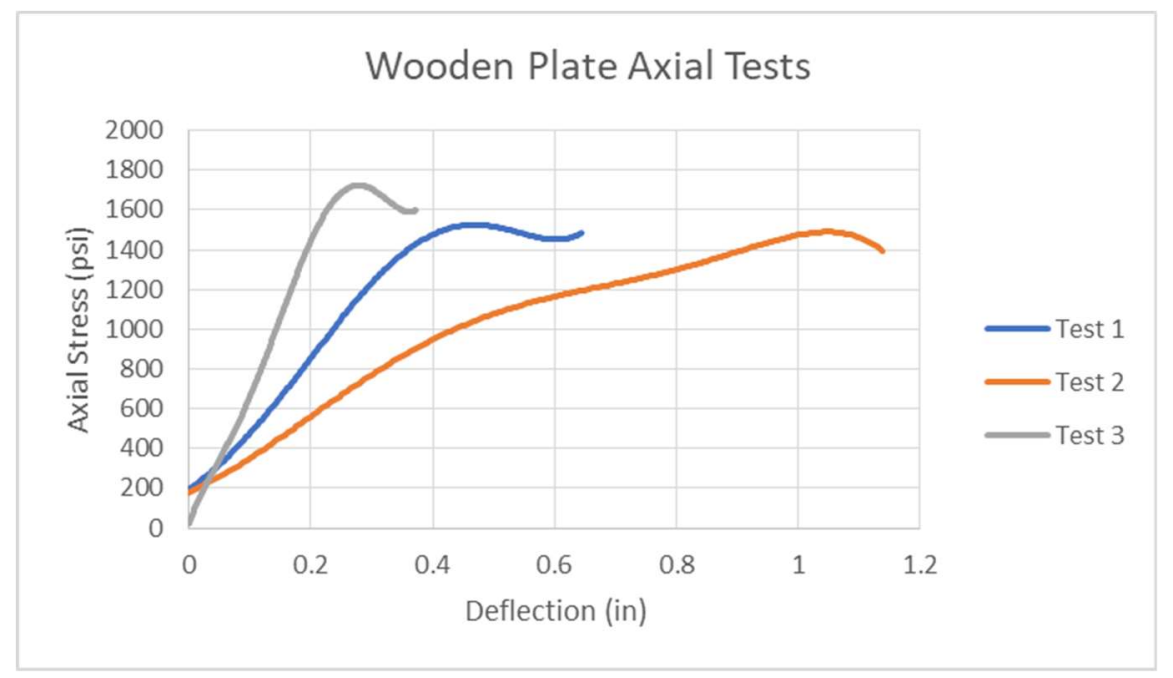

Figure 2-26 - Axial Stress vs Deflection for Wood Splice

\subsubsection{Axial Analysis - Summary and Failure Modes}

It was apparent that the steel plate splicing method was the weakest to transfer axial forces because of the steel plates inability to resist bending stressed as compared to the other splice mechanisms. The $\mathrm{C}$-channel method was the strongest, with similar failure strength as the wooden plate method. All methods provide similar deformation due to axial loading which induces small magnitude of bending. Results from all three splice methods revealed similar deformation values.

A common visual failure observed in majority of the tests was the cracking of the pile cross section at both ends where the pile was in contact with the steel plates. This is indicative of Poisson's effect, in which failure occurs at higher axial loads due to the weak tensile resistance of wood along the cross section of the pile. A photograph of this failure mode is shown in Figure 
2-27. Another observed failure was localized buckling along the pile near the contact surfaces. A photograph of this failure mode is shown in Figure 2-28.

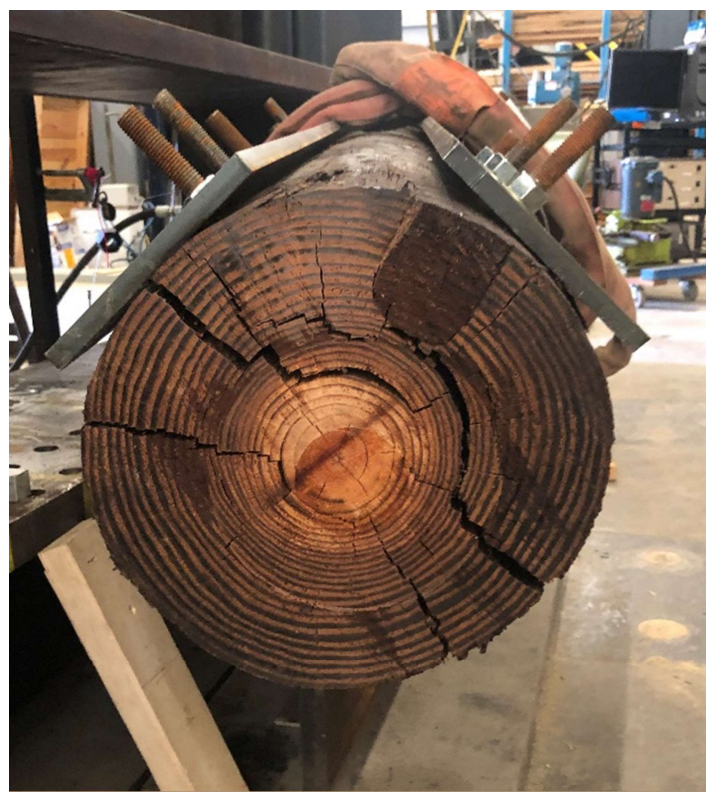

Figure 2-27 - Cracking of Steel Splice Pile at Contact Surface

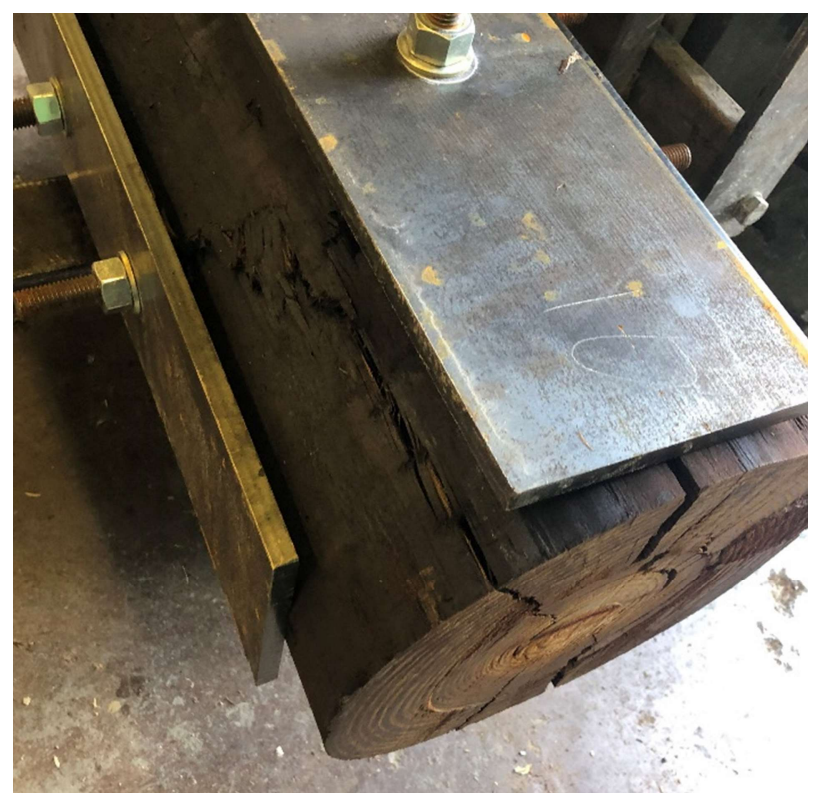

Figure 2-28 - Buckling Near Contact Surface of Steel Splice Pile 


\subsubsection{Summary of Traditional Splicing Methods}

The C-channel splicing method provides the maximum strength to failure. The high strength capacity was attributed to the C-channel's ability to resist bending stress induced by uneven end cuts. Also, this method provides maximum axial resistance as well as shear resistance, which are attributed to the additional resistance offered by the C-channel in terms of geometry and splice material volume as compared to the flat steel plate and wooden plate methods. Deflections of test specimens obtained from the steel C-channel splice method were higher than the deflections from the wooden plate splice method under shear and bending conditions. Wooden plate spliced specimens provide adequate strength values under axial and bending conditions but lack in shear resistance. Additionally, the wooden plate splicing method was that the material exhibits stronger axial and bending stiffness, providing less deflection under loading. The higher stiffness from wood splicing led to cracking in timber and does not yield as much as steel channel under loading. Flat steel plate spliced specimens provide low axial loading resistance compared to the other two methods. Axial load resistance was the controlling factor for piles supporting superstructures. Therefore, the flat steel plate splicing method was the least viable option of the three in terms of strength. Table 2-5 gives the average stress at failure and corresponding deflection for each of the testing and splicing methods.

Table 2-5 - Average Maximum Stress and Deflection for Traditional Splice Methods

\begin{tabular}{|l|c|c|c|}
\hline Method of Splicing & Steel Plate & C-Channel & Wooden Plate \\
\hline Shear Stress (psi) & 589 & 783 & 541 \\
\hline Deflection in Shear (in) & 2.7 & 2.2 & 1.8 \\
\hline Modulus of Rupture (psi) & 3532 & 3778 & 3962 \\
\hline Deflection in Bending (in) & 10.1 & 9.6 & 6.5 \\
\hline Axial Stress (psi) & 909 & 1683 & 1565 \\
\hline Deflection in Axial (in) & 0.5 & 0.6 & 0.6 \\
\hline
\end{tabular}




\subsection{Test Results and Data Analysis for FRP Splicing}

\subsubsection{Data Analysis of FRP Splicing under Shear Testing}

Shear testing was conducted to determine the maximum shear stress and the corresponding deflection for each of the three FRP specimens tested herein. Table 2-6 shows the maximum shear stress and the corresponding deflection for each of the three FRP spliced specimens. It also shows that the average maximum shear stress and average deflection at failure for FRP splicing. Splice contribution to shear stress was not included for simplicity in calculations. Figure 2-29 provides a graphical representation of the shear stress versus deflection.

Table 2-6, reveals that low deflection values at maximum stress are apparent with this splicing method, compared to the other splicing methods. FRP wrap completely confines pile specimens, covering the entire circumference of the spliced area. It also bonds to the timber creating a full shear transfer without slip between the splice mechanism and the pile. Because of these two reasons deflections are much smaller than in traditional methods. As shown in Table 2-6, the maximum shear stress that the FRP spliced piles can withstand is comparable in magnitude to that of the steel plate splicing method.

Table 2-6 - FRP Splice Maximum Shear and Corresponding Deflection

\begin{tabular}{|l|c|c|c|c|}
\hline Test & $\mathbf{1}$ & $\mathbf{2}$ & $\mathbf{3}$ & AVG \\
\hline Maximum Shear Stress (psi) & 657 & 643 & 539 & 613 \\
\hline Deflection at Maximum Stress (in) & 0.9 & 0.9 & 0.9 & 0.9 \\
\hline
\end{tabular}




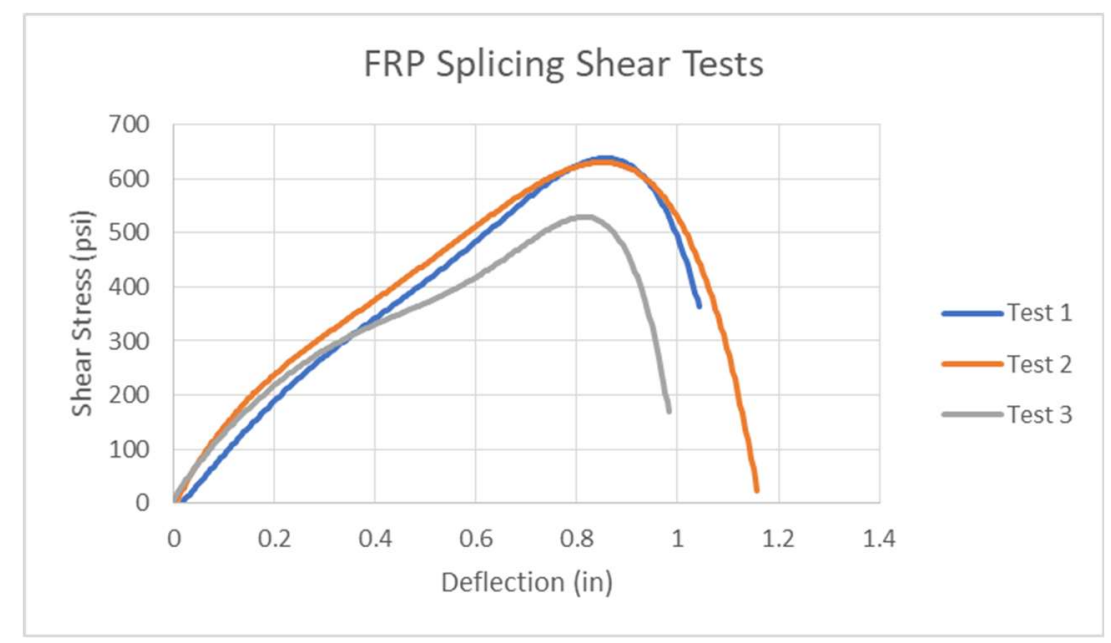

Figure 2-29 - Shear Stress vs Deflection with FRP Splice

\subsubsection{Discussion of Failure Modes in Shear for FRP Splicing}

FRP splicing ruptures longitudinally near the neutral axis of the pile with the FRP wrap splitting between fibers running longitudinally along the pile are noted from the center of the tested specimens because of maximum shear stress induced under bending at the mid-depth of the test specimens. Furthermore, the failure mode revealed that the failure occurred in the hoop direction of fibers. This was to be expected as there are very few fibers resisting forces in the hoop direction. Upon initial loading of each pile, it was observed that there was cracking at the contact surface of the applied load. This implied local buckling occurred from the compressive force induced under applied load. During testing and during load retrieval, buckling related cracking was observed in the center of the splice on the top of the specimen (Figure 2-31). 


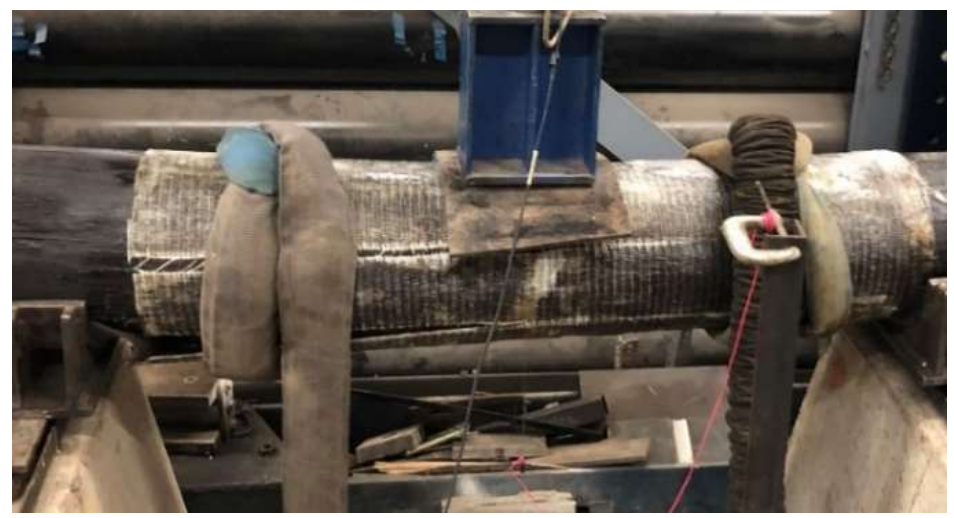

Figure 2-30 - Hoop Failure in Shear Test

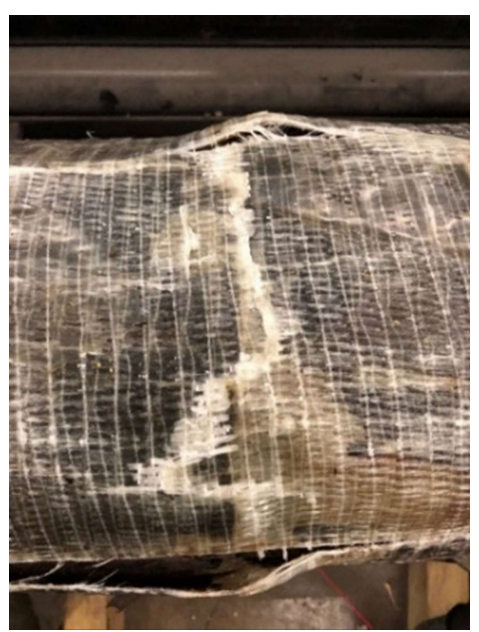

Figure 2-31 - FRP Splice Cracking Under Applied Load at Top

\subsubsection{Data Analysis of FRP Splicing under Bending Testing}

The bending test data was analyzed in terms of maximum bending stress versus the corresponding deflection (Table 2-7). Also provided were the average maximum bending stress and average deflection at failure for the thin FRP splicing. Figure 2-32 provides the bending stress versus deflection plot for piles spliced with FRP wraps. The test data revealed that FRP spliced test specimen provides lower deflection values as well as lower maximum stress values than the traditional methods of splicing. This indicates that not enough reinforcement was provided through the FRP wrap for adequate resistance to bending stress. The "dips" in Tests 2 and 3 in the bending 
stress versus deflection plot (Figure 2-32) are an indication of local buckling occurring under low bending induced stresses, which is discussed further in the following paragraph.

Table 2-7 - FRP Splice Maximum MOR and Corresponding Deflection

\begin{tabular}{|l|c|c|c|c|}
\hline Test & $\mathbf{1}$ & $\mathbf{2}$ & $\mathbf{3}$ & AVG \\
\hline Maximum Modulus of Rupture (psi) & 2032 & 2402 & 2129 & 2188 \\
\hline Deflection at Maximum Stress (in) & 2.3 & 3.5 & 5.1 & 3.6 \\
\hline
\end{tabular}

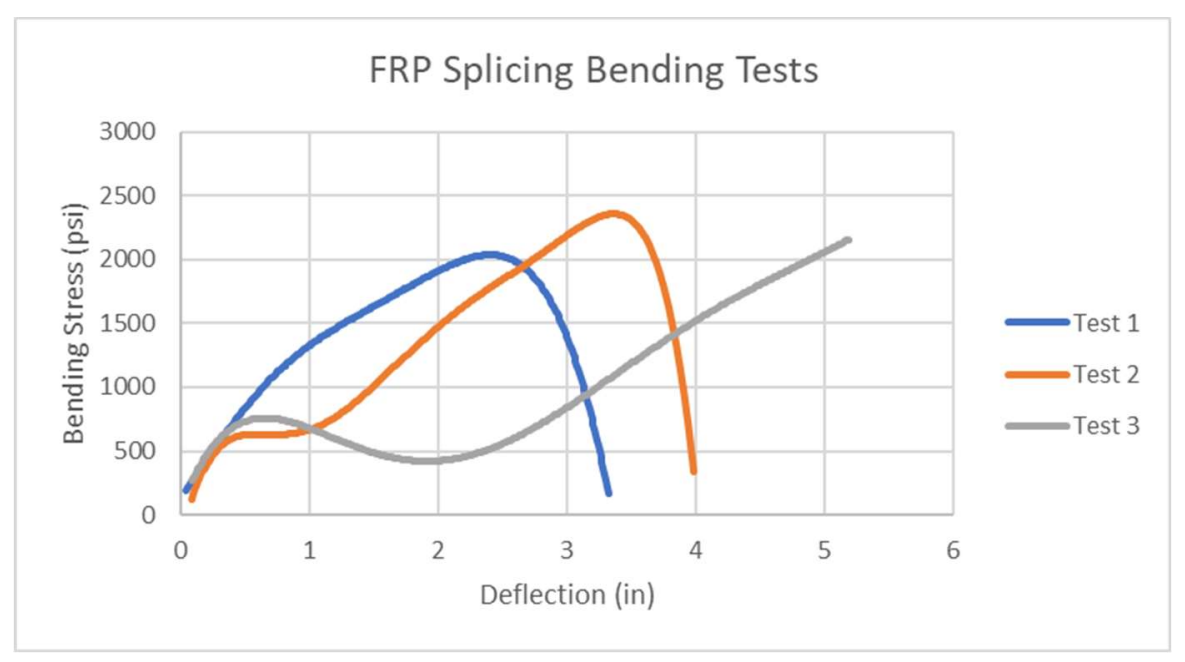

Figure 2-32 - Bending Stress vs Deflection with FRP Splice

\subsubsection{Discussion of Failure Modes in Bending for FRP Splicing}

Lack of adequate quantity of fibers in the hoop direction caused the FRP to "unzip" along its length with increasing deformation. This deficiency could be remedied easily by adding a layer of fibers in the hoop direction on top of the longitudinal glass fabric layers. As in shear testing, ultimate failure happened rapidly and occurred between fibers in the longitudinal direction indicating failure in hoop fibers. Under bending, large portions of FRP fabric de-bonded from the pile (Figure 2-33). In one of the specimens, a different form of failure was observed, as shown in Figure 2-34. The splice failed at the center, splitting in the longitudinal direction of fibers. During testing, it was also noted that two of the specimens (Tests number 2 and 3), cracked at the center 
of the splice under compression. This could be due to the fact that between the two halves of the pile there is a small gap, initiating local buckling from high stress concentration on the compression surface at the center of the splice.

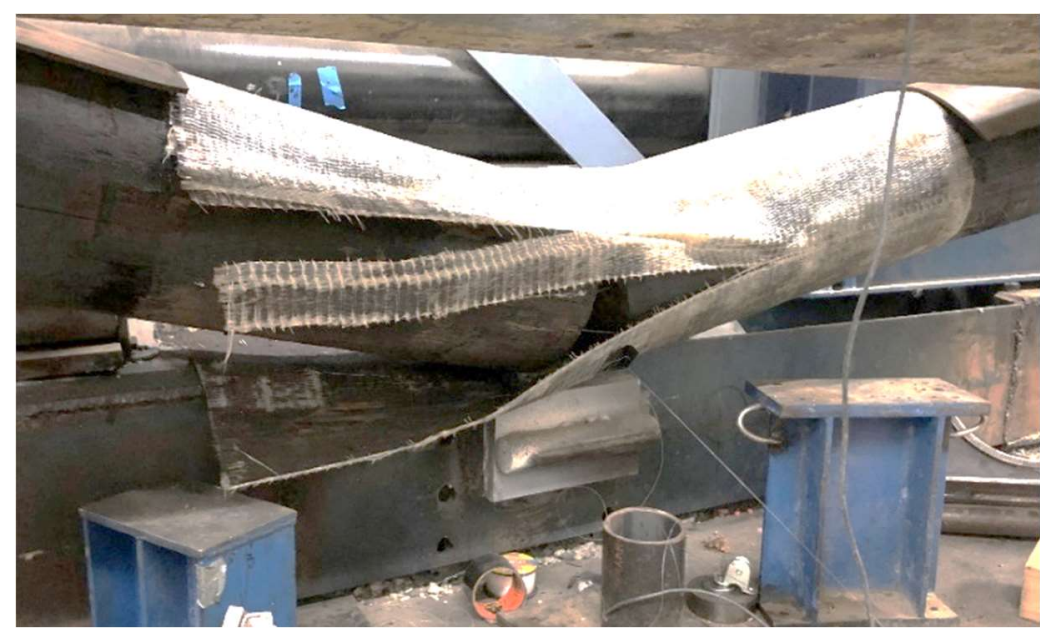

Figure 2-33 - De-Bonding of Splice at Failure Under Bending

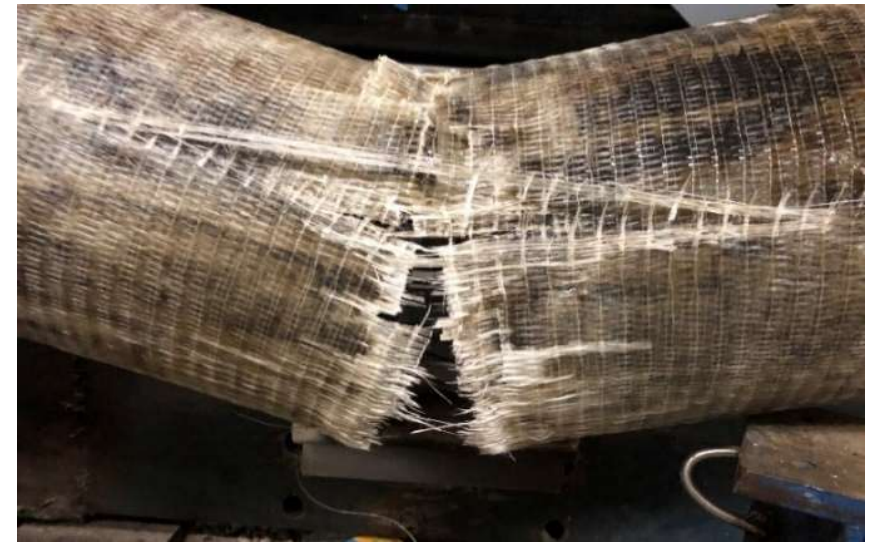

Figure 2-34 - FRP Splice Failure at Center Under Bending

\subsubsection{Data Analysis of FRP Splicing under Axial Testing}

The purpose of the axial test was to determine the maximum normal stress and its corresponding deflection for each of the three FRP specimens tested herein. Table 2-8 shows the maximum axial stress versus deflection for each of the three FRP spliced specimens tested herein. It also shows the average maximum axial stress and average axial deflection at failure for the FRP 
splicing. Figure 2-35 provides the normal stress versus deflection relationship for piles spliced using FRP wrap. There is some variance in the data obtained from these three tests. However, taking the averages into account, FRP splicing provides a significant amount of strength in axial compression, higher than the conventional splicing methods. The FRP splicing was the strongest out of all the methods splicing employed in this study. The strongest of the traditional methods is the C-channel splice which failed slightly under 1700 psi. The FRP splicing resulted in axial compression failure at around $1750 \mathrm{psi}$.

Table 2-8 - FRP Splice Maximum Axial Stress and Corresponding Deflection

\begin{tabular}{|l|c|c|c|c|}
\hline Test & $\mathbf{1}$ & $\mathbf{2}$ & $\mathbf{3}$ & AVG \\
\hline Maximum Axial Stress (psi) & 1339 & 1776 & 2143 & 1753 \\
\hline Deflection at Maximum Stress (in) & 0.5 & 0.6 & 0.7 & 0.6 \\
\hline
\end{tabular}

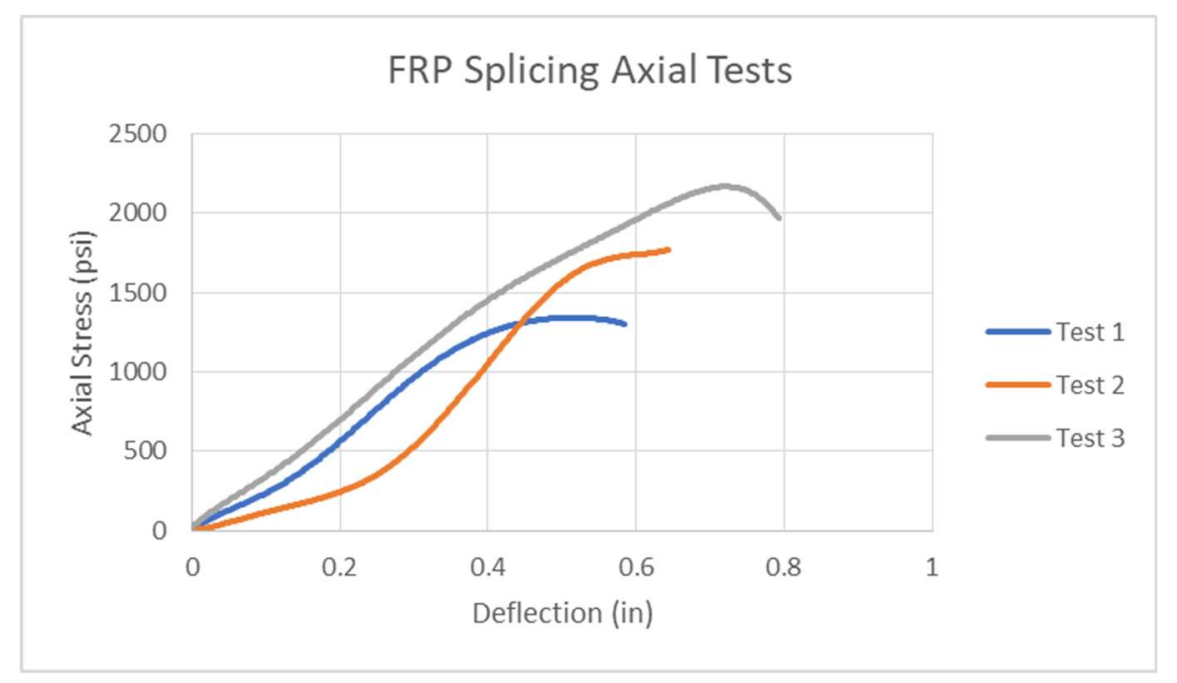

Figure 2-35 - Axial Stress vs Deflection for FRP Splice

\subsubsection{Discussion of Failure Modes in Axial for FRP Splicing}

Due to the gap between the two halves of the pile specimen, bulging of fiber in the FRP wrap at the center is noticed. This occurred in each of the three specimens tested. Adding a layer of high strength caulking in the gap between pile halves can help prevent bulging. In this test, bulging fibers were split in the hoop direction but remained intact in the longitudinal direction 
along the pile (Figure 2-36). This bulging indicates that buckling followed by de-bond of the FRP wrap occurred at the center of the splice. Using FRP reinforcement under axial loading can provide a confinement strength to the pile system, in this case since a unidirectional composite was utilized this added confinement stress is negligible and has little effect on overall strength of the system. As opposed to traditional methods, buckling effects were not observed at the ends of these tested piles. Bolts were not used in this method, i.e., no internal forces were acting on the pile causing it to crack, and no high stress concentration was induced from bolting at the connector locations as in legacy connections. Each of the piles failed similarly, as shown in (Figure 2-37).

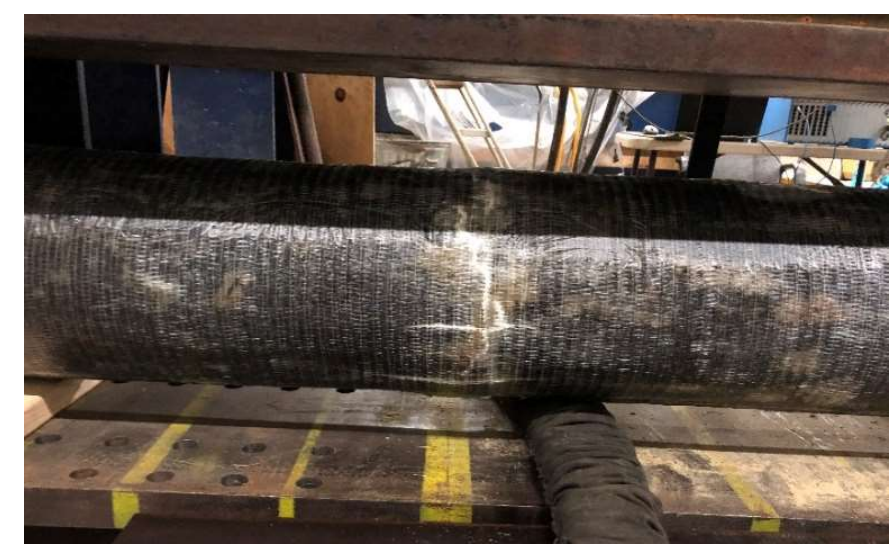

Figure 2-36 - Bulging in FRP Splice during Compression Testing

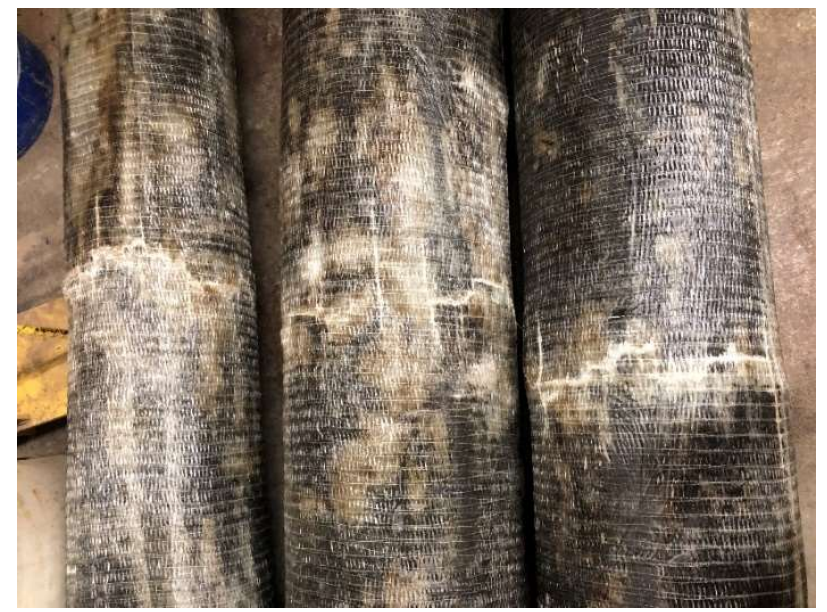

Figure 2-37 - FRP Splice Axial Compression Specimens 


\subsubsection{Summary of FRP Splicing Method Results}

Splicing of timber piles with FRP wraps provides structural performance comparable to legacy splicing methods. The shear stresses to failure of FRP reinforced piles were comparable to that of traditional methods of splicing. Bending stresses, however, were not as high as anticipated, which could be improved easily by adding extra layers of fabric in the hoop direction of fibers. Placing more sheets with fiber orientation perpendicular to the existing wrap will greatly increase the amount of stress to failure in the hoop direction. The bending stress was not very critical for piles since $90 \%$ of the load tends to be axial load. This method was very effective to resist axial compressive stress. The absence of bolts in this splicing method prevented internal cracking due to reduced stress concentration. While using two wraps of FRP was effective, adding an extra layer of glass fabric along the hoop direction, would decrease the amount of bulging (local debonding of wrap) in the center of the splice. In terms of deflection, FRP splicing performed well, and made the pile stiff. Table 2-9 incorporates the results of the FRP wrap repair method and other splicing methods.

Table 2-9 - Average Maximum Stress and Deflection for All Splice Methods

\begin{tabular}{|l|c|c|c|c|}
\hline Method of Splicing & Steel Plate & C-Channel & Wooden Plate & FRP Wrap \\
\hline Shear Stress (psi) & 589 & 783 & 541 & 613 \\
\hline Deflection in Shear (in) & 2.7 & 2.2 & 1.8 & 0.9 \\
\hline Modulus of Rupture (psi) & 3532 & 3778 & 3962 & 2188 \\
\hline Deflection in Bending (in) & 10.1 & 9.6 & 6.5 & 3.6 \\
\hline Axial Stress (psi) & 909 & 1683 & 1565 & 1753 \\
\hline Deflection in Axial (in) & 0.5 & 0.6 & 0.6 & 0.6 \\
\hline
\end{tabular}




\section{CHAPTER 3 IMPROVEMENT OF FRP SPLICE}

\subsection{Improved Design}

Timber piles wrapped with three lateral unidirectional layers of wrap performed well compared to the three traditional splicing mechanisms under axial compressive loading. However, shear and bending capacities of FRP wrap splicing were lower than those of traditional splicing methods. Piles spliced with the FRP wrap that were tested under shear and four-point bending loading failed because of weakness (inadequate number of fibers) in the hoop direction. To account for this failure mode, a modified design was developed, i.e., a six-layer, bidirectional FRP wrap design. This six-layer design was aimed at reinforcing the hoop direction to prevent unzipping mode of failure. Three additional layers of FRP wrap were added to the original splice design. The same unidirectional Sika fabric was used (dry density of $0.092 \mathrm{lb} / \mathrm{in}^{3}$ ) with six total layers, with fiber orientation of three layers each in the hoop and longitudinal directions of the pile $\left[0_{3} / 90_{3}\right]$. For clarity the (0) direction runs along the pile length and the (90) direction refers to the "hoop" or circumference of the pile.

\subsection{Testing Methods}

Shear and bending tests were performed in the same manner as initial shear and bending testing (Sections 2.3.2 and 2.3.3). For additional data evaluation based on extra wraps three specimens were tested. One with the six-layer splice design under shear dominant loading, the other two under bending dominant loading. The shear specimen and one of the bending specimens were repaired entirely using virgin FRP wrap. A pile with the three-layer unidirectional fabric design that was taken to failure under four-point bending loading was repaired using three 
additional virgin layers of fabric, with the strength dominant fiber direction aligned with the hoop direction of the pile. This repaired specimen was tested again under four-point bending load condition. An additional pile was spliced with virgin FRP wrap using the six-layer bidirectional splice design and tested under four-point bending loading condition.

\subsection{Shear Analysis for Improved FRP Wrap}

The maximum shear stress and its corresponding deflection from the six-layer shear test specimen is provided in Table 3-1. The shear stress versus deflection plot for this test is shown in Figure 3-1. This splice performed well compared to the three traditional splicing methods and the three-layer FRP splice, having shear stress to failure of 987 psi. Deflection recorded at maximum stress is higher for this specimen than deflections recorded during the testing of the original threelayer design specimens whose dominant fiber orientation was in the longitudinal direction (Table 2-6). Figure 3-1 indicates that initial failure occurred before the ultimate stress was reached. This can be seen from Figure 3-1 as the stress-deflection curve levels off after about 1 inch of deflection. It could be that failure occurred and the mechanism was able to continue to resist load for a short period of time.

Table 3-1 - New FRP Splice Maximum Shear Stress and Corresponding Deflection

\begin{tabular}{|l|c|c|}
\hline Test & 6-Layer & 3-Layer AVG \\
\hline Maximum Shear Stress (psi) & 987 & 613 \\
\hline Deflection at Maximum Stress (in) & 2.0 & 0.9 \\
\hline
\end{tabular}




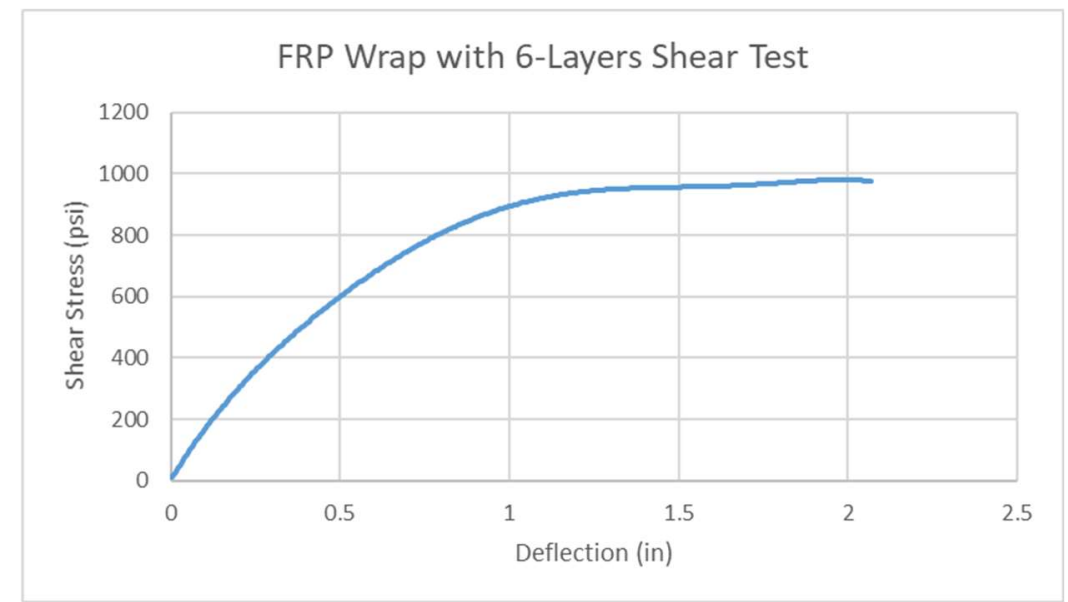

Figure 3-1 - 6-Layer FRP Shear Stress vs Deflection

\subsubsection{Summary and Failure Modes of Six-Layer FRP Wrap Under Shear}

Higher deflection recorded in this test is attributed to additional movement after initial failure occurred. In Figure 3-1 the slope levels were not matching after about 0.8 in. of deflection where the stress versus deflection plot was getting to be nonlinear. Deflection at failure of this sixlayer FRP rehab specimen compared well with the three-layer FRP splice specimens, i.e., difference on deflections is less than $10 \%$. Failure mode was ductile as it failed in a more conventional manner than the three-layer FRP splice mechanism. In the six-layer FRP wrap test specimen, failure occurred at the top in lateral compression at the center of the splice (Figure 3-3), unlike the unzipping in the original three-layer design. This failure is expected as the compressive strength of Sika Glass/Epoxy composite is slightly lower than its tensile strength. No unzipping of fabric occurred indicating hoop direction reinforcement was sufficient to provide adequate confinement strength. 


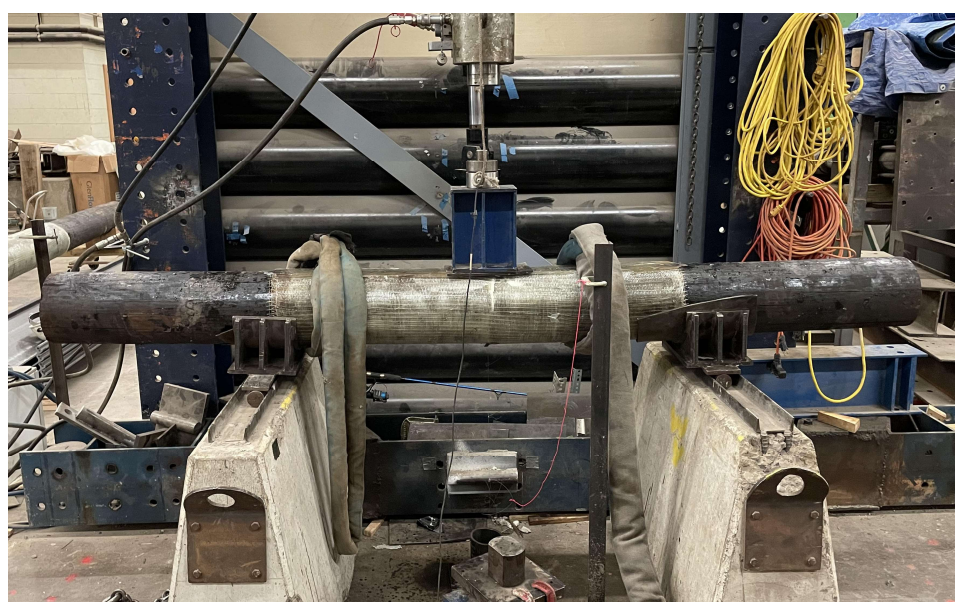

Figure 3-2 - 6-Layer FRP Splice Shear Test

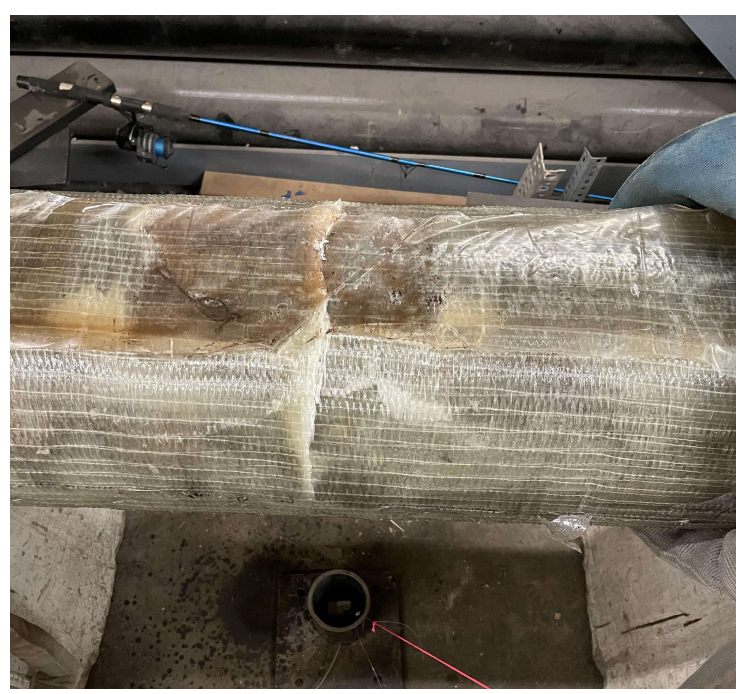

Figure 3-3 - Compressive Failure of Fabric

\subsection{Bending Analysis for Improved FRP Wrap}

Bending testing was performed in the same manner as discussed in Section 2.3.3 with failure modes and calculations are consistent with those of Section 2.4.2.

Data was analyzed for maximum bending stress and its corresponding deflection for both the aforementioned bending tests (Table 3-2). The re-wrap specimen recorded a lower maximum bending stress and higher deflection at failure than the six-layer splice specimen. The maximum bending stress recorded in the re-wrap test is similar to the maximum bending stress recorded from 
the test data of the original three-layer FRP wrap spliced specimens. The deflection recorded at maximum bending stress for the re-wrap test is higher than the deflection recorded in the original three-layer splice design testing. The six-layer pristine specimen showed an increase in bending stress to failure with lower deflection than deflections obtained from the original splice design testing (Table 2-7), indicating higher stiffness of the six-layer wrapped beam.

Table 3-2 - New FRP Splice Maximum MOR and Corresponding Deflection

\begin{tabular}{|l|c|c|c|}
\hline Test & Re-Wrap & 6-Layer & 3-Layer Avg \\
\hline Maximum Modulus of Rupture (psi) & 2321 & 2974 & 2188 \\
\hline Deflection at Maximum Stress (in) & 5.0 & 2.7 & 3.6 \\
\hline
\end{tabular}

A bending stress versus deflection plot for the repaired or re-wrapped test specimen is provided in Figure 3-4. The slope of the curve is lower than that of other FRP spliced specimens due to inadequate bending transfer across the joint. Large deflections from this test are attributed to already failed original splice. With the three bottom layers having already failed there is significant de-bond between the splice mechanism and the pile, resulting in larger deflection. The bending strength capacity of this system comes totally from the three additional layers added to the splice.

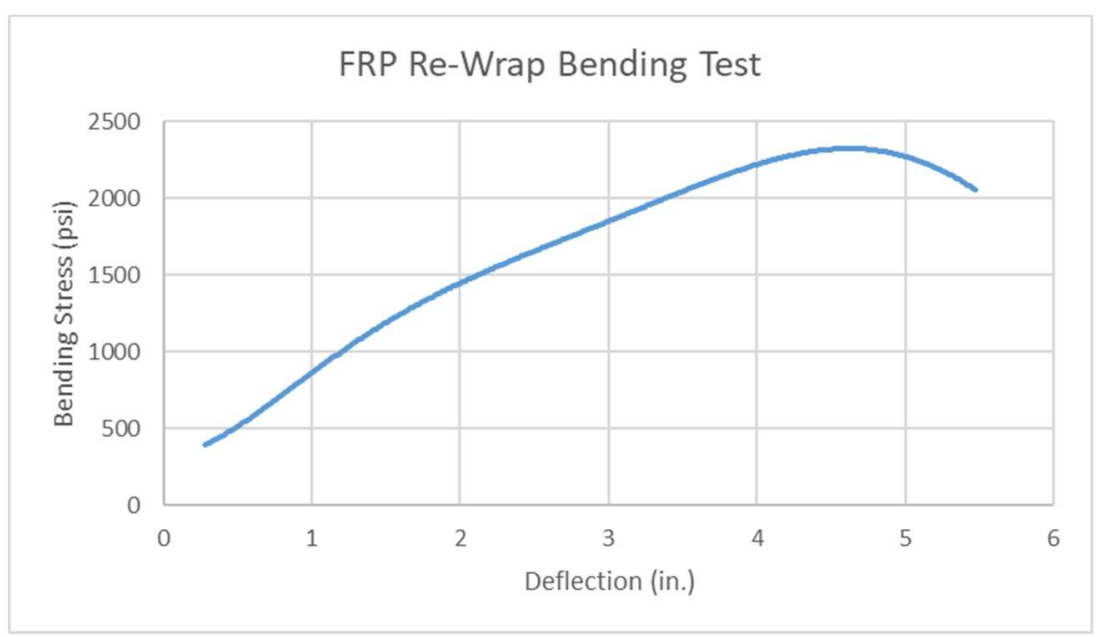

Figure 3-4 - FRP Re-Wrap Bending Stress vs Deflection 
The bending stress versus deflection plot for the six-layer pristine FRP wrap splice design is provided in Figure 3-5. The change in slope at 1800psi in the stress versus deflection plot indicates that de-bond may have occurred during this test. This de-bond was likely the result of inconsistency in wrapping during the hand-layup assembly of the FRP splice. It was also noted that the resin mix for this splice was of higher viscosity than usual, which can result in inconsistent soaking of resin in the fabric causing higher void content and weaker bond. Although these inconsistencies may be present, overall capacity and stiffness was still higher than that of the original FRP wrap test specimens (Table 2-7).

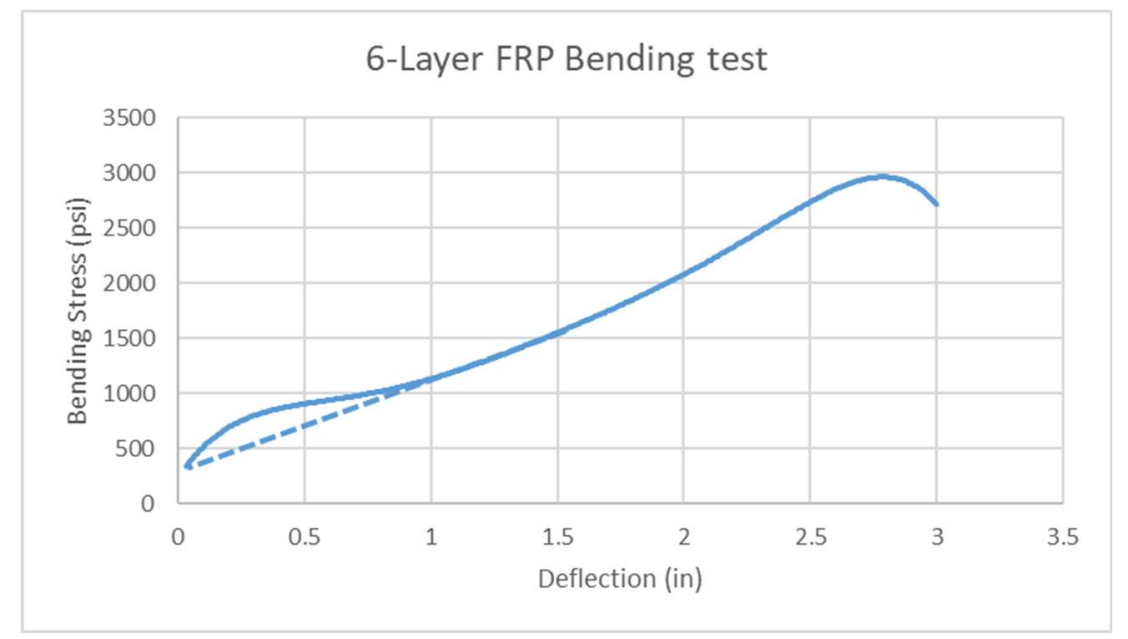

Figure 3-5 - Pristine 6-Layer FRP Bending Stress vs Deflection

\subsubsection{Summary and Failure Modes}

Performance of the re-wrapped (already failed and repaired) specimen provides slight increase (6\%) in bending stress capacity from the original design and provides larger deflection at ultimate stress. It was concluded that the remaining and already failed original splice did not contribute any bending resistance to the system. This means that once FRP splice fails; it no longer provides any extra bending capacity. The capacity of the re-wrap specimen was entirely dependent on the three new layers of FRP wrap that were added to the splice in the hoop direction only. Visual failure 
modes observed during the testing of the re-wrapped specimen supports this conclusion. The main visual failure mode observed was the splitting of fabric between fibers in the hoop direction, lacking adequate reinforcement in the longitudinal direction of the pile (Figure 3-6).

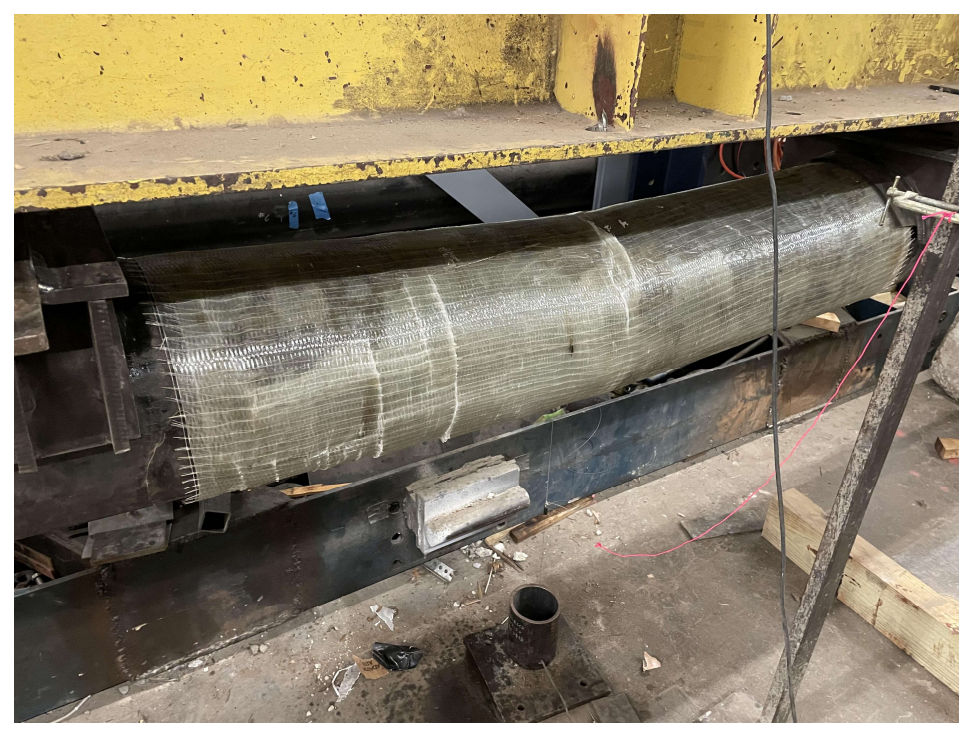

Figure 3-6 - Splitting of Fabric in Re-Wrap Test

Results from the pristine six-layer FRP wrap splice test specimen reveal that additional layers of wrap do help in increasing the strength capacity of the system. Inconsistencies, such as the higher than usual viscosity of the resin, were noticed during wrapping and testing of this specimen. Visual failure modes confirm these inconsistencies as they differ from other testing of FRP wrap splicing. The main failure mode was de-bonding of layers and buckling of the FRP splice (Figure 3-7). This indicates areas of voids (and de-bond) within the FRP splice zone. Even with these inconsistencies, performance has improved from the original three-layer FRP design by about $36 \%$. To prevent these inconsistencies, extra care must be exerted during the hand-layup wrapping, making sure that the resin mixture is not overly viscous and complete soaking is achieved. 


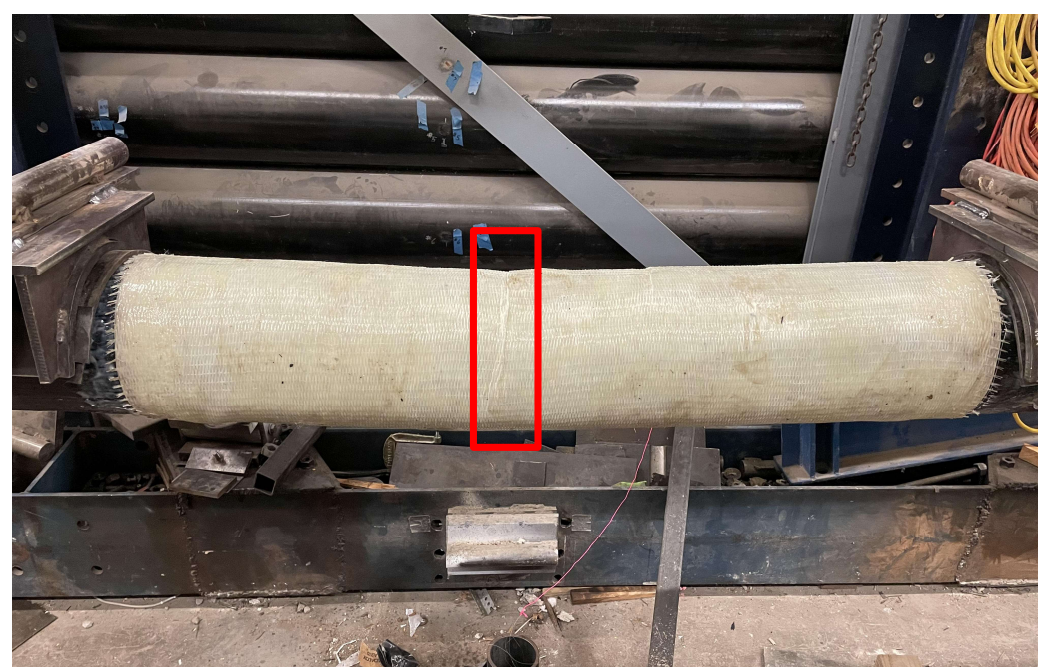

Figure 3-7 - Crumbling of FRP during 6-Layer Bending Test

\subsection{Conclusions from Improved FRP Splice}

Adding extra layers of FRP wrap to the original three-layer splice design increased both the shear and bending strengths of the pile system. Table 3-3 provides a comparison of results from the shear tests of the new six-layer FRP splice design and the original three-layer FRP splice. The new six-layer FRP design showed a significant increase in shear stress capacity from the original three-layer design (61\%). Deflection for the six-layer shear testing (2 in.) was higher than the recorded deflections during the shear testing of the original three-layer FRP splice specimens ( 0.9 in. average). The higher deflection is attributed to the additional movement in the splice after initial failure (at $1 \mathrm{in}$. deflection) and due to $61 \%$ higher stress to failure contributed by extra layers of wrap material. Table 3-4 provides a comparison of results from bending testing of the new sixlayer FRP splice design and the original three-layer FRP splice. The re-wrap bending specimen shows a slight increase in bending stress (6\%) at the cost of a larger deflection. The six-layer design under bending provides a significant increase $(36 \%)$ in bending capacity and a higher system 
stiffness. When the FRP splice mechanism fails, it is better to completely replace the FRP splice with a new splice, noting that re-wrapping does not help increase bending capacity.

Table 3-3 - FRP Splice Shear Test Comparisons

\begin{tabular}{|l|c|c|}
\hline Test & 6-Layer & 3-Layer AVG \\
\hline Maximum Shear Stress (psi) & 987 & 613 \\
\hline Deflection at Maximum Stress (in) & 2.0 & 0.9 \\
\hline Percent Increse in Stress (\%) & 61.04 & - \\
\hline
\end{tabular}

Table 3-4 - FRP Splice Bending Test Comparisons

\begin{tabular}{|l|c|c|c|}
\hline Test & Re-Wrap & 6-Layer & 3-Layer Avg \\
\hline Maximum Modulus of Rupture (psi) & 2321 & 2974 & 2188 \\
\hline Deflection at Maximum Stress (in) & 5.0 & 2.7 & 3.6 \\
\hline Percent Increse in Stress (\%) & 6.08 & 35.94 & - \\
\hline
\end{tabular}




\section{CHAPTER 4 BENDING CAPACITY OF TIMBER PILES}

\subsection{Virgin Timber Pile under Bending}

Repairing a timber pile specimen using splicing can decrease the bending capacity of the pile as mentioned briefly in 1.1.4. The goal of this section is to determine the bending capacity decrease due to cutting and splicing a pile using various splicing repair methods, as discussed in this report by comparing bending capacities of the various splicing methods to the bending capacity of a virgin (uncut) timber pile. The performance of a virgin timber pile (pile without splicing mechanism) was compared to the four splicing methods discussed in this report and analyzed for maximum bending stress capacity versus deflection.

\subsection{Bending Analysis of Virgin Pile}

Test procedures and analysis methods remained the same as the methods used in 2.3 .3 and 2.4.2. A $16 \mathrm{ft}$. long virgin timber pile, in good condition, was selected for testing. Table 4-1 provides the maximum bending stress and corresponding deflection values recorded during this test. Figure 4-1 shows bending stress versus deflection plot for virgin timber pile.

Table 4-1 - Virgin Pile Maximum Bending Stress and Corresponding Deflection

\begin{tabular}{|l|c|}
\hline \multicolumn{2}{|c|}{ Virgin Pile Bending Test } \\
\hline Maximum Modulus of Rupture (psi) & 5714 \\
\hline Deflection at Maximum Stress (in) & 3.2 \\
\hline
\end{tabular}




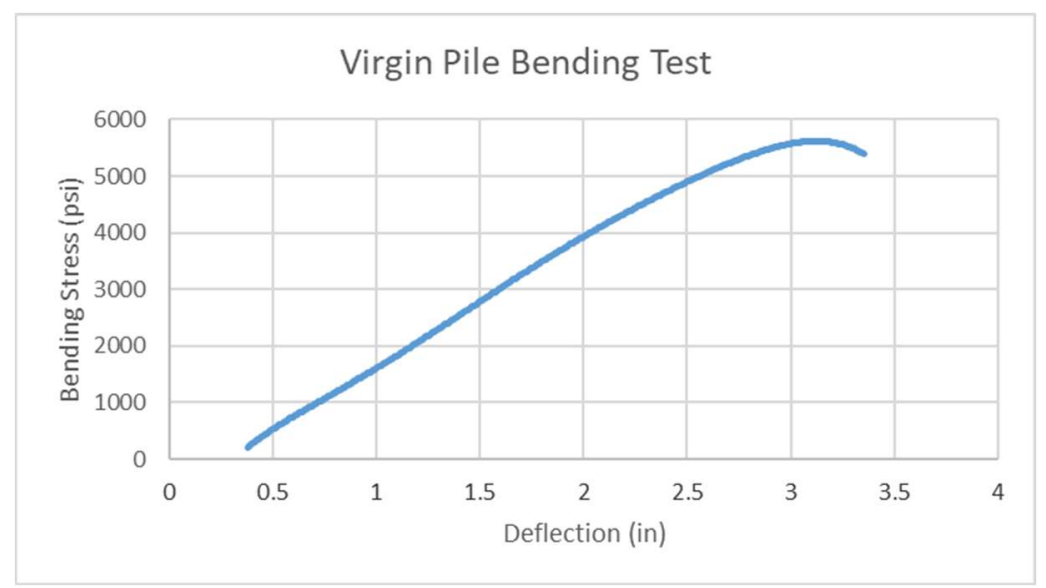

Figure 4-1 - Bending Stress vs Deflection Plot for Virgin Pile (No Splice)

\subsubsection{Discussion of Failure Modes in Virgin Pile}

Ultimate failure in the virgin pile occurred suddenly on the bottom or tensile side (opposite of applied load) of the pile specimen. Failure caused the pile to rupture because of tensile stress concentrations at the center of the span. Rupture did not occur at the center span, it occurred $2 \mathrm{ft}$. from the center, which is attributed to natural flaws in the timber pile, perhaps resulting in localized stress concentration. Figure 4-2 provides an image of the point rupture in the virgin pile specimen, which resulted in partial section loss.

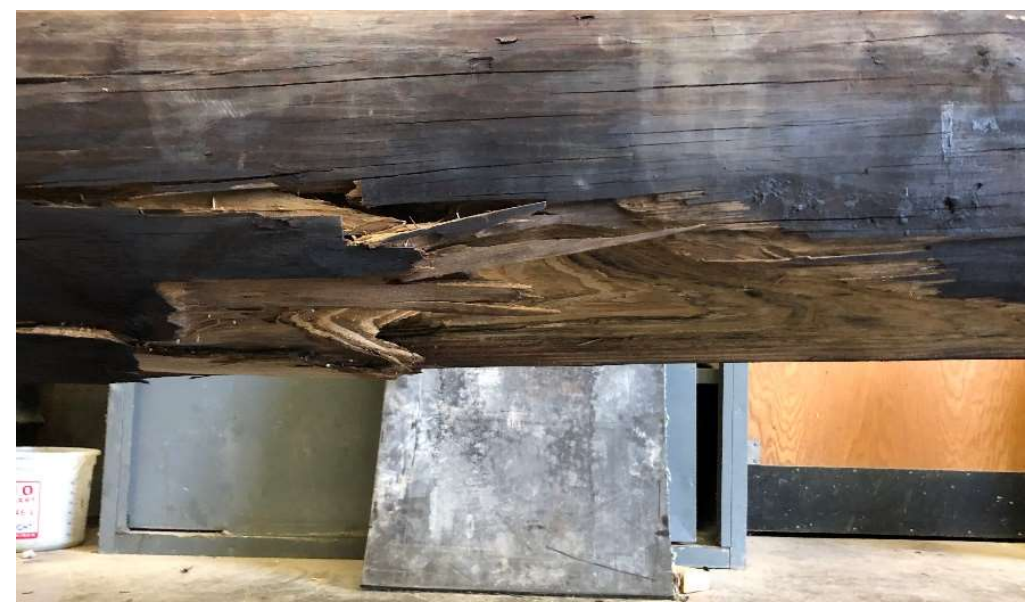

Figure 4-2 - Section Loss due to Rupture in Virgin Pile 


\subsection{Summary for Virgin Timber Pile Bending Analysis}

Maximum bending stress, recorded in the four-point bending test of the virgin timber pile, exceeded the maximum bending stress for each of the splicing methods previously discussed. Table 4-2 provides a comparison of maximum stress and corresponding deflection for the virgin timber pile and various splicing methods. Table 4-2 proves that splicing a pile creates a reduction in the overall bending stress capacity of the pile system. The three-layer FRP wrap splicing provides the largest decrease in bending stress capacity (62\%). The six-layer FRP wrap splicing provides a slightly lower decrease in bending stress (48\%) compared to three-layer FRP case, however it still has a greater capacity decrease than the three traditional splicing methods. The addition of splicing mechanisms to a pile system greatly increases the amount of deflection recorded at maximum bending stress. Both of the FRP wrap splice designs provide maximum deflections comparable to the maximum deflection of the virgin pile. Traditional splicing methods provide much higher deflection than the virgin pile, which is attributed to movement under initial loading of splicing methods that do not bond to the pile specimen. The bending stress versus deflection plot for the virgin pile (Figure 4-1) provides a consistent slope to failure, unlike that of piles spliced using traditional methods for the same reason of movement within the splicing mechanism.

Table 4-2 - Comparison of Bending Stress and Deflection between Virgin Pile and Spliced Piles

\begin{tabular}{|l|c|c|c|c|c|c|}
\hline Splice Mechanism & Virgin Pile & Steel Plate & C-Channel & Wood Plate & FRP (3-Layer) & FRP (6-Layer) \\
\hline Maximum Modulus of Rupture (psi) & 5714 & 3532 & 3778 & 3962 & 2188 & 2974 \\
\hline Deflection at Maximum Stress (in) & 3.2 & 10.1 & 9.6 & 6.5 & 3.6 & 2.7 \\
\hline Percent Stress Loss (\%) & - & 38.2 & 33.9 & 30.7 & 61.7 & 47.9 \\
\hline
\end{tabular}




\section{CHAPTER 5 THEORETICAL ANALYSIS OF FRP SPLICE}

Theoretical equations were developed to allow for ease in design with FRP wrap splice mechanisms. Variation between theoretical and experimental data was also calculated to determine the reliability of this theoretical analysis. Design examples are provided to replicate real-world application of design equations.

\subsection{Shear Capacity of FRP Spliced Piles}

Shear capacity in timber piles with FRP wrap splicing mechanism relies entirely on the strength of the FRP material, the timber has no shear capacity due to the gap between pile halves. Equation (5) provides the shear load capacity $\left(P_{v}\right)$ for timber piles with FRP wrap splice mechanisms. Shear stress capacity can then be calculated using Equation (6).

$$
\begin{gathered}
P_{v}=\frac{3}{2} f_{f v} \pi d t \\
\tau=\frac{4 P_{v}}{3 \pi r^{2}}
\end{gathered}
$$

$\mathrm{d}$ - Diameter of the pile cross section

$r$ - Radius of the pile cross section

$\mathrm{t}$ - Thickness of FRP wrap

$f_{f v}$ - Ultimate shear strength of FRP

\subsubsection{Shear Capacity with Three Layers of FRP Wrap}

For shear capacity calculation the thickness of three layers of FRP wrap (t) is $0.15 \mathrm{in}$. (measured with calipers from the wrap retrieved from lab test specimens) and the ultimate shear 
strength of the Sika glass/epoxy composite $\left(\mathrm{f}_{\mathrm{fv}}\right)$ is 5800 psi given by the manufacturer. Theoretical stress capacity was calculated for each of the three FRP wrap specimens tested under shear loading, shown in Table 5-1. Comparisons between theoretical and experimental data are shown in the form of theoretical/experimental ratio. For the three-layer FRP wrap spliced specimens tested under shear loading, theoretical stress capacity was very close to the experimental capacity for two of the test specimens. For the third test specimen, results varied by roughly 45 percent, this is attributed to inconsistencies derived from the hand-layup assembly of the FRP splice mechanism and strength variation of wood in this specimen.

Table 5-1 - Shear Capacity Theoretical VS Experimental (3 Layers)

\begin{tabular}{|l|c|c|c|}
\hline Test & $\mathbf{1}$ & $\mathbf{2}$ & $\mathbf{3}$ \\
\hline Diameter (in) & 11 & 11 & 8.875 \\
\hline Experimental Stress Max (psi) & 657 & 643 & 539 \\
\hline Theoretical Stress Capacity (psi) & 633 & 633 & 784 \\
\hline$\tau_{\mathrm{th}} / \tau_{\exp }$ & 0.96 & 0.98 & 1.45 \\
\hline
\end{tabular}

\subsubsection{Shear Capacity with Six Layers of FRP Wrap}

For shear capacity calculation using six layers of FRP wrap, the thickness of six layers of FRP wrap (t) is 0.3 in. and the ultimate shear strength of the Sika glass/epoxy composite $\left(f_{f v}\right)$ is 5800 psi given by the manufacturer. Theoretical shear stress capacity of the six-layer pile tested in shear was calculated (Table 5-2). For this test experimental load capacity exceeded theoretical capacity by about 22 percent. This means that the splice mechanism performed well and exceeded expectation for this test specimen.

Table 5-2 - Shear Capacity Theoretical VS Experimental (6 Layers)

\begin{tabular}{|l|c|}
\hline Test & 6-Layer \\
\hline Diameter (in) & 9 \\
\hline Experimental Stress Max (psi) & 987 \\
\hline Theoretical Stress Capacity (psi) & 773 \\
\hline$\tau_{\text {th }} / \tau_{\exp }$ & 0.78 \\
\hline
\end{tabular}




\subsubsection{Conclusions from Theoretical Shear Analysis}

Experimental data from laboratory testing shows minimum variation from theoretical calculations in shear capacity. Some variation is to be expected due to inconsistencies in the glass/epoxy composite that come from the hand-layup installation of the splice mechanism. Inconsistencies in the timber can also influence experimental results. Even with inconsistencies Equations (5) and (6) prove to be valid in determining shear stress in timber piles repaired with a FRP splice mechanism.

\subsection{Bending Capacity of FRP Spliced Piles}

Timber piles with FRP wrap splicing have a bending capacity that relies entirely on the strength of the FRP splice material used, the timber does not attribute to the bending strength of the system because of the gap between pile halves. Equation (7) provides the bending capacity $\mathrm{P}_{b}$ for timber piles with FRP wrap splice mechanism under 4-point bending load conditions. Once load capacity is determined, bending stress capacity $\left(\sigma_{\mathrm{b}}\right)$ can then be calculated using Equation (8). For Equation (8) four-point bending condition is taken into account.

$$
P_{b}=\frac{f_{f u} \pi t d^{2}}{2 L}
$$

$d$-Diameter of the pile cross section

$\mathrm{t}$ - Thickness of FRP wrap

$f_{f u}$ - Ultimate tensile strength of FRP

$\mathrm{L}$ - Length of span

$$
\sigma_{b}=\frac{P_{b} L\left(\frac{d}{2}+t\right)}{6\left(I_{t}+n I_{f}\right)}
$$

$I_{t}-$ Moment of inertia of timber 
If - Moment of inertia of FRP $\left(I_{f}=\left(\frac{\pi}{64}\right)\left[(d+t)^{4}-d^{4}\right]\right.$, for hollow cylindrical section $)$

$\mathrm{n}-$ Modular ratio $n=\frac{E_{f}}{E_{t}}$

$E_{f}-$ Modulus of elasticity of FRP

$E_{t}-$ Modulus of elasticity of timber

\subsubsection{Bending Capacity with Three Layers of FRP Wrap}

For three-layer FRP wrap stiffened timber pile, bending capacity calculation of lab tested specimens are based on geometrical properties as: span length (L) is $15 \mathrm{ft}$. (or $180 \mathrm{in}$.), the thickness of three layers of FRP wrap (t) is 0.15 in, the tensile strength of the Sika glass/epoxy composite ( $f_{\text {fu }}$ ) is $61.7 \mathrm{ksi}$ (given by manufacturer), and the modular ratio (n) is 4.3 given the modulus of elasticity for FRP $\left(E_{f}\right)$ is $3.4 \times 10^{6}$ and the modulus of elasticity for timber of $\left(E_{t}\right)$ is $0.8 \times 10^{6}$. Moment of Inertias were calculated for each individual specimen after measuring the pile diameter for each test specimen. Theoretical bending stress capacity values were calculated for each of the three FRP wrap specimens tested under bending, shown in Table 5-3. Comparisons between theoretical and experimental data are shown in the form of theoretical/experimental ratio.

Table 5-3 - Bending Capacity Theoretical VS Experimental (3 Layers)

\begin{tabular}{|l|c|c|c|}
\hline Test & $\mathbf{1}$ & $\mathbf{2}$ & $\mathbf{3}$ \\
\hline Diameter (in.) & 11.5 & 11.375 & 10.25 \\
\hline Experimental Stress Max (psi) & 2032 & 2402 & 2129 \\
\hline Theoretical Stress Capacity (psi) & 2121 & 2144 & 2377 \\
\hline$\sigma_{\mathrm{th}} / \sigma_{\exp }$ & 1.04 & 0.89 & 1.12 \\
\hline
\end{tabular}

\subsubsection{Bending Capacity with Six Layers of FRP Wrap}

For six-layer bending capacity calculation thickness of composite (t) is 0.3 in. and all other variables remain the same as in section 5.2.1. Theoretical bending capacities of the two six-layer piles tested in 4-point bending were calculated (Table 5-4). For the re-wrap specimen an effective 
fabric thickness of 0.15 in. is taken as only the outer three layers of FRP are effectively carrying load. Variation is small between theoretical and experimental data for the re-wrap specimen, proving the assumption that only the three new layers of FRP have load carrying capacity. The pristine six-layer FRP wrap splice has large variation in theoretical versus experimental data. This variation in theoretical to experimental data is attributed to inconsistencies in this pile specimen. The inconsistencies are attributed to hand-layup assembly of the pile as discusses in Section 3.4. Because of high viscosity of the resin which prevented proper soaking of the fabric; thus hindering the strength capacity of the system.

Table 5-4 - Bending Capacity Theoretical VS Experimental (6 Layers)

\begin{tabular}{|l|c|c|}
\hline Test & Re-Wrap & 6-Layer \\
\hline Diameter (in.) & 11 & 9.5 \\
\hline Experimental Stress Max (psi) & 2321 & 2974 \\
\hline Theoretical Stress Capacity (psi) & 1785 & 4130 \\
\hline$\sigma_{\mathrm{th}} / \sigma_{\exp }$ & 0.77 & 1.39 \\
\hline
\end{tabular}

\subsubsection{Conclusions from Theoretical Bending Analysis}

The three-layer FRP wrap specimens data compared well with the theory, having low variation in theoretical to experimental data (less than 15\%). A small amount of variation is expected as property variability in timbers is common. The re-wrap specimen had slightly lower variation under the assumption that only the new layers of wrap contributed to the capacity of the system (using thickness of 0.15 inches in calculations). The six-layer FRP wrap specimen had a large variation between theoretical and experimental data, indicating failure was not conventional due to inconsistencies in the hand lay-up assembly of the pile system. The resin was unable to completely soak the fabric leaving areas of insufficient bond, greatly reducing the strength capacity of the system. 


\subsection{Axial Capacity of FRP Spliced Piles - Compression Failure}

The axial compression capacity of FRP spliced timber piles depends on the capacity of the FRP wrap as well as the axial capacity of the timber and bond strength between FRP and wood substrate. Equation (9) is used to find the axial compression load capacity $\left(\mathrm{P}_{\mathrm{c}}\right)$ of timber piles spliced using FRP wrap. This equation assumes that the failure mode of a FRP wrapped pile is in compression. Load capacity can be converted to axial stress capacity $\left(\sigma_{c}\right)$ using Equation (10).

$$
P_{c}=f_{t c} \pi r^{2}+f_{f c} 2 \pi r t
$$

$f_{t c}-$ Ultimate compressive stress of timber

$\mathrm{f}_{\mathrm{fc}}$ - Ultimate compressive stress of FRP wrap

$r$ - Radius of pile cross section

$\mathrm{t}$ - Thickness of FRP wrap

$$
\sigma_{c}=\frac{P_{c}}{A}
$$

A - Area of cross section including area of timber and FRP

\subsubsection{Axial Capacity of FRP Wrapped Piles - Compression Failure}

All test specimens under axial compression used the three-layer FRP wrap splice design. For this calculation ultimate compressive stress of southern pine timber $\left(\mathrm{f}_{\mathrm{tc}}\right)$ is assumed to be 1200 psi, ultimate compressive stress of FRP $\left(f_{\mathrm{fc}}\right)$ is $40 \mathrm{ksi}$ (given by manufacturer due to hand layup manufacturing), the thickness of wrap ( $\mathrm{t}$ ) is 0.15 in., and the radius of cross section is taken from each specimen tested. Table 5-5 shows the comparison between theoretic and experimental values for each of the three FRP wrap specimens tested in axial compression loading, assuming the failure mode is compression in FRP. The theoretical axial compressive stress capacity is 
much larger than the experimental value indicating that failure mode of the FRP was not in compression. Failure mode is likely from buckling of FRP wrap followed by de-bond.

Table 5-5 - Axial Capacity Theoretical VS Experimental (Compression Failure)

\begin{tabular}{|l|c|c|c|}
\hline Test & $\mathbf{1}$ & $\mathbf{2}$ & $\mathbf{3}$ \\
\hline Diameter (in) & 9.25 & 10.75 & 10.25 \\
\hline Experimental Load Max (lb) & 90015 & 161205 & 176818 \\
\hline Theoretical Load Capacity (lb) & 254999 & 311548 & 292227 \\
\hline Fth/Fexp & 2.83 & 1.93 & 1.65 \\
\hline
\end{tabular}

\subsubsection{Conclusion from Theoretical Axial Analysis - Compression Failure}

From this comparison of theoretical and experimental data corresponding to each of the specimens, it is found that specimens failed in a non-compression mode of failure. Further analysis must be performed to accurately calculate theoretical axial load capacity assuming a noncompression failure mode in calculation. Failure mode observed during testing was buckling caused by de-bond of FRP wrap.

\subsection{Axial Capacity of FRP Spliced Piles - Non-Compression Failure}

Since failure mode is buckling of the FRP wrap, which is a follow up of de-bond, a new equation was developed to determine what percentage of FRP capacity and what percentage of timber capacity contribute to the overall capacity of the system. The following assumptions are made to develop accurate theoretical equations and computations: 1) perfect bond between FRP and timber substrate until interface de-bond between FRP wrap and pile which is followed by buckling of FRP wrap occurs, 2) there are no kinks in the timber pile. A step-by-step calculation to determine axial capacity based on non-compression failure of FRP is provided: 
1) Determine critical load for buckling in FRP based on Euler's Equation: $P_{c r}=\frac{\pi^{2} E_{f} I}{L_{e f f}^{2}}$. Where moment of inertia for the location of initial failure is: $I=\frac{b d^{3}}{12}$. In this calculation (b) is the width of the buckled area of the composite and (d) is the depth or thickness of the composite. Based on the assumption of fixed conditions which appears very close to the observed failure: $L_{e f f}=2 L$, where $\mathrm{L}$ is the length of buckled FRP wrap after debonding from pile L can be estimated from laboratory test data between 1 to 1.5 inches.

2) Strain in FRP composite can then be computed: $\varepsilon_{f}=\frac{P_{f}}{A_{f} E_{f}}$. Substitute $\mathrm{P}_{\mathrm{cr}}$ for $\mathrm{P}_{\mathrm{f}}$ since the failure mode in FRP is buckling: $\varepsilon_{f}=\frac{\pi^{2} E_{f} I}{A_{f} E_{f} L_{e f f}^{2}}=\frac{\pi^{2} I}{A_{f} L_{e f f}^{2}}=\frac{\pi^{2}\left(\frac{1}{12}\right) b t^{3}}{b t L_{e f f}^{2}}=\frac{\pi^{2} t^{2}}{12 L_{e f f}^{2}}$. In this calculation width (b) is assumed of FRP in buckling failure of a rectangular area, which is cancelled while computing buckling strain to failure.

3) After computing strain to failure under buckling failure mode, stress at buckling failure can be calculated: $f_{f b}=\varepsilon_{f} E_{f}$

4) Load of the composite to induce buckling failure is computed: $P_{f b}=f_{f b} 2 \pi r t$

5) The overall load capacity of the system is a sum of the load resisted by the FRP and the load resisted by timber: $P_{\text {total }}=P_{t}+P_{f b}$.

6) Using an assumed failure load based on experimental data, $P_{t}$ can be solved for: $P_{t}=P_{\text {total }}-P_{f b}$

7) FRP contribution $\left(R_{f}\right)$ and timber contribution $\left(R_{t}\right)$ to the overall load capacity of the system are calculated as: $R_{f}=\frac{P_{f b}}{P_{\text {total }}}$ and $R_{t}=\frac{P_{t}}{P_{\text {total }}}$ 
8) Equation (9) can be rewritten using factors to adjust the load capacity contributed by the timber and the FRP. This new equation that is used for bond failure is given in Equation (11).

$$
P_{c}=\left(R_{t}\right) f_{t c} \pi r^{2}+\left(R_{f}\right) f_{f c} 2 \pi r t
$$

Note: Equation (11) is valid only for de-bond of interface between FRP wrap and pile substrate; does not account for failure within the timber pile due to aging, rotting, or splitting.

\subsubsection{Axial Capacity of FRP Wrapped Piles - Non-Compression Failure}

To find FRP and timber contribution factors the step-by-step process discussed in the previous section is utilized. For computations: ultimate compressive stress of southern pine timber $\left(\mathrm{f}_{\mathrm{tc}}\right)$ is $1200 \mathrm{psi}$, ultimate compressive stress of FRP $\left(\mathrm{f}_{\mathrm{fc}}\right)$ is $40 \mathrm{ksi}$ (given by manufacturer due to hand layup manufacturing), the compressive modulus of FRP $\left(\mathrm{E}_{\mathrm{f}}\right)$ is $3.9 \times 10^{6}$ psi (given by manufacturer), the thickness of wrap ( $\mathrm{t}$ ) is 0.15 in., and the radius of cross section is taken from each specimen tested. The effective buckling length ( $\mathrm{L}_{\text {eff }}$ ) is assumed to be $3 \mathrm{in}$. for test 1 and 2 in. for Tests 2 and 3, based on observations of crack formation in specimens during laboratory testing.

For stress in FRP to induce buckling of specimen $1\left(\mathrm{~L}_{\mathrm{eff}}=3 \mathrm{in}.\right)$ :

$$
\begin{gathered}
\varepsilon_{f}=\frac{\pi^{2} t^{2}}{12 L_{e f f}^{2}}=\frac{\pi^{2}(0.15)^{2}}{12(3)^{2}}=2.056 \times 10^{-3} \\
f_{f b}=\varepsilon_{f} E_{f}=\left(2.056 \times 10^{-3}\right)\left(3.9 \times 10^{6}\right)=8019 p s i
\end{gathered}
$$

For stress in FRP to induce buckling of specimens 2 and 3 ( $\mathrm{L}_{\mathrm{eff}}=2$ in.):

$$
\begin{gathered}
\varepsilon_{f}=\frac{\pi^{2} t^{2}}{12 L_{e f f}^{2}}=\frac{\pi^{2}(0.15)^{2}}{12(2)^{2}}=4.626 \times 10^{-3} \\
f_{f b}=\varepsilon_{f} E_{f}=\left(2.056 \times 10^{-3}\right)\left(3.9 \times 10^{6}\right)=18043 p s i
\end{gathered}
$$


These stress in FRP values were used to complete the step-by-step calculation process. Table 5-6 shows the timber and FRP contribution calculations gained from the step-by-step process and a comparison between theoretic and experimental values for each of the three FRP wrap specimens tested under axial compression loading, assuming the failure mode is buckling in FRP.

Table 5-6 - Axial Capacity Theoretical VS Experimental (Non-Compression Failure)

\begin{tabular}{|l|c|c|c|}
\hline Test & $\mathbf{1}$ & $\mathbf{2}$ & $\mathbf{3}$ \\
\hline Diameter (in) & 9.25 & 10.75 & 10.25 \\
\hline $\mathrm{P}_{\mathrm{t}}(\mathrm{lb})$ & 55060 & 69803 & 89666 \\
\hline $\mathrm{P}_{\mathrm{fb}}(\mathrm{lb})$ & 34954 & 91403 & 87151 \\
\hline $\mathrm{R}_{\mathrm{t}}$ & 0.61 & 0.43 & 0.51 \\
\hline $\mathrm{R}_{\mathrm{f}}$ & 0.39 & 0.57 & 0.49 \\
\hline Experimental Load Max (lb) & 90015 & 161205 & 176818 \\
\hline Theoretical Load Capacity (lb) & 117033 & 162053 & 145444 \\
\hline Experimental Stress Max (psi) & 1339 & 1776 & 2143 \\
\hline Theoretical Stress Capacity (psi) & 1742 & 1785 & 1763 \\
\hline$\sigma_{\mathrm{th}} / \sigma_{\exp }$ & 1.30 & 1.01 & 0.82 \\
\hline
\end{tabular}

\subsubsection{Conclusions from Theoretical Axial Analysis - Non-Compression Failure}

Theoretical values are much closer to experimental values when assuming buckling in FRP is the controlling failure mode. Test 1 has the largest variation in theoretical vs experimental data, this could be due to inconsistencies in timber such as surface flaws that caused greater de-bond and buckling area between the FRP and timber substrate. All the specimens tested failed by buckling between the timber substrate and FRP. Slight variation in data is expected due to assumptions made in calculation that may not be entirely true during testing, such as

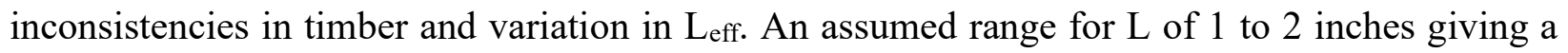
$\mathrm{L}_{\mathrm{eff}}$ range between 2 to 4 inches was used for calculations purposes. More testing should be completed to validate this solution process and allow for more accurate assumptions. 


\subsection{Design Example}

Theoretical capacity equations developed in this chapter are utilized in this design example to determine the capacity of the example pile given. The Allowable Stress Design (ASD) method is adopted herein for rating timber bridge piles that are repaired using a FRP wrap splice. Ultimate stress values in this example are based on material properties in FRP resulting from the hand layup assembly process. These values vary based on manufacturer, manufacturing method, and type of resin and fabric used.

Determine the a) axial, b) shear, and c) bending load and corresponding stress capacities of a timber pile repaired with a FRP splice mechanism. For axial capacity assume buckling failure with $\mathrm{L}_{\mathrm{eff}}$ of 3.5 inches and an assumption failure load of 200 kips. The timber pile has a diameter of 10 inches and a length of 16 feet. The FRP wrap has ultimate stresses: $\mathrm{f}_{\mathrm{fu}}=40 \mathrm{ksi}, \mathrm{f}_{\mathrm{fv}}=4.5 \mathrm{ksi}$, and $\mathrm{f}_{\mathrm{fc}}=55$ ksi; with total fabric thickness $t=0.2$ in. The timber is southern pine with ultimate compressive stress: $\mathrm{f}_{\mathrm{tc}}=1200 \mathrm{psi}$. For bending stress calculation assume a modular ratio (n) of 4.3 based on elastic modulus of FRP $\left(E_{\mathrm{f}}\right)$ of $3.4 \times 10^{6}$ psi and elastic modulus of timber $\left(E_{\mathfrak{t}}\right)$ of $0.8 \times 10^{6}$ psi.

Table 5-7 - Design Example 1 Properties

\begin{tabular}{|c|c|c|}
\hline Diameter & $\mathrm{d}$ & $10 \mathrm{in}$ \\
\hline Length & $\mathrm{L}$ & $16 \mathrm{ft}$ \\
\hline Thickness of FRP & $\mathrm{t}$ & $0.2 \mathrm{in}$ \\
\hline Tensile Strength of FRP & $\mathrm{f}_{\mathrm{fu}}$ & $40 \mathrm{ksi}$ \\
\hline Shear Strength of FRP & $\mathrm{f}_{\mathrm{fv}}$ & $4.5 \mathrm{ksi}$ \\
\hline Compressive Strength of FRP & $\mathrm{f}_{\mathrm{fc}}$ & $55 \mathrm{ksi}$ \\
\hline Compressive Strength of Timber & $\mathrm{f}_{\mathrm{tc}}$ & $1200 \mathrm{psi}=1.2 \mathrm{ksi}$ \\
\hline Effective Length & Leff & $3.5 \mathrm{in}$. \\
\hline
\end{tabular}




\begin{tabular}{|c|c|c|}
\hline Assumed Failure Load & $\mathrm{P}_{\text {total }}$ & $200 \mathrm{ksi}$ \\
\hline Elastic Modulus of FRP & $\mathrm{E}_{\mathrm{f}}$ & $3.4 \times 10^{6}$ \\
\hline Modular Ratio & $\mathrm{n}$ & 4.3 \\
\hline
\end{tabular}

\section{a) Axial Capacity}

Axial capacity in a pile is most important as axial stress is the controlling force that carries the load from the superstructure to the foundation and is responsible for a large majority of stresses present in the system (roughly 90\%). Since axial failure is assumed to be buckling the step-by-step process discussed in Section 5.4 must be followed to determine the timber and FRP contribution factors. These factors are utilized to determine the overall strength capacity of the pile system.

Determine the strain in FRP:

$\varepsilon_{f}=\frac{\pi^{2} t^{2}}{12 L_{e f f}^{2}}=\frac{\pi^{2}(0.2)^{2}}{12(3.5)^{2}}=2.679 \times 10^{-3}$

Determine stress in FRP from strain:

$f_{f b}=\varepsilon_{f} E_{f}=\left(2.679 \times 10^{-3}\right)\left(3.4 \times 10^{6}\right)=9131 p s i$

Determine the load that will induce buckling failure in the FRP:

$P_{f b}=f_{f b} 2 \pi r t=(9131)(2)(\pi)\left(\frac{10}{2}\right)(0.2)=57372 l b=57.4 k i p s$

Determine timber and FRP contribution factors:

$P_{t}=P_{\text {total }}-P_{f b}=200-57.4=142.6$

$R_{f}=\frac{P_{f b}}{P_{\text {total }}}=\frac{57.4}{200}=0.29, R_{t}=\frac{P_{t}}{P_{\text {total }}}=\frac{142.6}{200}=0.71$

Plug contribution factors into Equation (11) and solve for load capacity:

$P_{c}=(0.71) f_{t c} \pi r^{2}+(0.29) f_{f c} 2 \pi r t$ 
$P_{c}=\left((0.71)(1.2)(\pi)\left(\frac{10}{2}\right)^{2}\right)+\left((0.29)(55)(\pi)\left(\frac{10}{2}\right)(0.2)\right)=117$ kips

Axial force is then converted to axial stress using Equation (10):

$\sigma_{c}=\frac{P_{c}}{A}=\frac{P_{c}}{\left(\frac{\pi d^{2}}{4}\right)}=\frac{117(1000)}{\left(\frac{\pi\left(10^{2}\right)}{4}\right)}=1489.7 p s i$

b) Shear Capacity

Shear stresses in pile members are a result of eccentric loading. Shear stresses experienced in piles are often a small portion of the overall stress experienced, however they must still be accounted for.

Equation (5) is utilized to determine the shear load capacity of the pile system:

$P_{v}=\frac{3}{2} f_{f v} \pi d t=\frac{3}{2}(4.5)(\pi)(10)(0.2)=42.4$ kips

Shear load is converted to shear stress using Equation (6) to get the shear stress capacity:

$\tau=\frac{4 P_{v}}{3 \pi r^{2}}=\frac{4(42.4)(1000)}{3 \pi\left(\frac{10}{2}\right)^{2}}=719.8 p s i$

c) Bending Capacity

Like shear stresses in piles, bending stresses are also a result of eccentric loading. Bending stresses exerted on piles are often a small portion of overall stress experienced but must still be accounted for.

Using Equation (7) for bending capacity we get:

$P_{b}=\frac{f_{f u} \pi t d^{2}}{2 L}=\frac{(40) \pi(0.2)\left(10^{2}\right)}{2(16)(12)}$

$P_{b}=6.5$ kips

To convert bending load to stress using Equation (8) we must first solve for moments of inertia. The moment of inertia of the circular timber portion is: 
$I_{t}=\frac{\pi d^{4}}{64}=\frac{\pi(10)^{4}}{64}=490.9 \mathrm{in}^{4}$

The moment of inertia for the FRP section is calculated based on its hollow cylindrical geometry:

$I_{f}=\left(\frac{\pi}{64}\right)\left[(d+t)^{4}-d^{4}\right]=\left(\frac{\pi}{64}\right)\left[(10+0.2)^{4}-10^{4}\right]=40.464 i n^{4}$

Equation (8) is used to convert bending load to bending stress capacity:

$\sigma_{b}=\frac{P_{b} L\left(\frac{d}{2}+t\right)}{6\left(I_{t}+n I_{f}\right)}=\frac{(6.5)(1000)(16)(12)\left(\frac{10}{2}+0.2\right)}{6(490.9+(4.3)(40.464)}=1627 p s i$

This design example provided a process to determine the axial shear and bending strength capacity of timber piles with FRP warp splice mechanisms. These capacities can then be adapted to load rating of these such systems by adapting reduction factors in a similar manner to the load rating of timber piles. Theoretical calculations prove to be valid as capacities gained through theoretical analysis and this design example are similar in magnitude to those gained through experimentation performed in the WVU-CFC laboratory. 


\section{CONCLUSIONS}

- Of the traditional splicing methods, the steel C-channel splicing provides the maximum resistance under shear, bending and axial forces because of its high stiffness and material strength.

- Based on laboratory and field experiences, traditional (legacy) splicing methods are more cumbersome to rehabilitate than FRP wrapping techniques.

- Traditional splicing methods cause larger movement in the pile system under loading due to loose connections caused by the bolted splice mechanism; however FRP wrap splicing has no movement under loading due to $100 \%$ bond between the wrap and the substrate (timber).

- Three-layer unidirectional FRP wrap spliced piles performed well under axial loading, which had higher strength than the three traditional methods that were employed under this research program.

- Three-layer unidirectional FRP wrap spliced piles failed by unzipping of fabric between lateral fibers, additional reinforcement is needed in the hoop direction to prevent this failure mode.

- Adding three additional fabric layers (six layers in total) to reinforce the hoop direction improved the shear stress capacity by $61 \%$ and the bending capacity by $36 \%$ compared to the three-layer FRP splice design. The shear capacity of six-layer FRP splice design exceeded the shear capacity of all the three traditional splicing methods, where the bending capacity of six-layer FRP wrap was still lower than the three traditional methods.

- When a FRP wrap splice reaches ultimate failure it no longer has any load carrying capacity. 
- Splicing a timber pile with splice mechanisms tested in this program decreases the bending capacity of the system, which connects two individual timber components in relation to uncut continuous timber pile. FRP wrap splicing provided the largest decrease $(62 \%$ stress capacity loss) in bending capacity from a virgin (uncut) timber pile.

- Traditional splicing methods are more expensive than the FRP wrap splicing technique in terms of material, transportation, and labor costs.

- FRP wrap splicing provides a strong, cost efficient, and long-lasting solution as compared to traditional (legacy) splicing methods; additional improvements in strength and stiffness can be made by changing fiber type, orientation, and number of wraps.

- Assumptions provide adequate response scenarios to develop design equation for the capacity of timber piles repaired using a FRP splice mechanism. 


\section{RECOMMENDATIONS}

- Additional testing should be performed on timber piles repaired with FRP splice mechanisms to determine the reliability of design equations, especially under wet-dry cycles due to water level fluctuations.

- Both traditional and FRP splicing mechanisms methods should be tested under combined loading scenarios to further evaluate strength and deflection limits.

- Field evaluations of FRP wrap spliced timber piles should be conducted to establish the durability of the proposed method and to nondestructively evaluate for any potential voids behind the FRP wraps.

- Develop design and field splicing specifications, and field inspection methods for FRP wrap splicing to rehabilitate deteriorated timber piles.

- Develop a training program for construction workers on installation of FRP wrap systems for timber piles. 


\section{REFERENCES}

[1] W. Eslyn and J. Clark, Wood Bridges - Decay Inspection and Control, Madison: Agricultural Handbook NO. 557, 1979.

[2] S. R. Duwadi and M. Ritter, "Timber Bridges In The United States," Public Roads, vol. 60, no. 3, pp. 32-40, 1997.

[3] Pilejax, Rapid Repair Systems - Timber Pile Repair http://www.joinlox.com/wpcontent/uploads/2016/07/PILEJAX_Timber-White-Paper_FINAL_TW.pdf.

[4] R. S. Burrow, "Fuzzy Wood andd Coastal Piles," Structural Rehabilitation, pp. 20-21, 2020.

[5] alphafoundations.com, "Timber Pile Repair in Florida and Georgia Image," https://www.alphafoundations.com/photo-gallery.

[6] G. Zelada-Tumialin, W. Konicki, P. Westover and M. Vatovec, "Untreated Submerged Timber Pile Foundations," Structure Magazine, pp. 9-11, 2013.

[7] MnDOT, "Bridge Inspection For Decay and Other Deterioration," in Timber Bridges: Design, Construction, Inspection, and Maintenance, p. Chapter 13.

[8] Substructure.com, "Wood structures are subject to varios types of damage in the marine environment, mostly biological," https://www.substructure.com/about/marine-servicesinformation/marine-corrosion/wood-corrosion.

[9] A. Azizinamini, A. Mohammadi, J. Gull and R. Taghinezhad, "Assesment and Evaluation of Timber Piles Used in Nebraska for Retrofit and Rating," Nebraska Department of Transportation Research, 2014. 
[10] B. Phares, J. Dahlberg and W. Klaiber, "Cost-Effective Timber Bridge Repairs: Manual for Repairs of Timber Bridges in Minnesota," Minnesota Department of Transportation, 2015.

[11] J. Dahlberg, B. Phares, J. Bigelow and F. W. Klaiber, "Timber Abutment Piling and Back Wall Rehabilitation and Repair," Bridge Engineering Center, 2012.

[12] F. W. Klaiber, D. J. White, T. J. Wipf, M. Mekkaway and J. Koskie, "Investigation of Steel Stringer Bridges: Superstructures and Substructures," Bridge Engineering Center, 2007.

[13] T. J. Wipf, F. S. Fanous, F. W. Klaiber and A. S. Eapen, "Evaluation of Appropriate Maintenance, Repair and Rehabilitation Methods for Iowa Bridges," Iowa Department of Transportation, 2003.

[14] Army and Air Force, "Bridge Inspection, Maintenance, and Repair (TM 5-600/AFJPAM 321088)," Joint Departments of Army and Air, Washington, DC, 1994.

[15] P. K. Mallick, Fiber-Reinforced Composites: Materials, Manufacturing and Design, Boca Raton: CRC Press, Taylor and Francis Group, 2007.

[16] H. V. S. GangaRao, N. Taly and P. V. Vijay, Reinforced Concrete Design With FRP Composites, Boca Raton: CRC Press, Taylor and Francis Group.

[17] T. Alkhrdaji, "Strengthening of Concrete Structures Using FRP Composites," Structure Magazine, pp. 18-20, 2015.

[18] B. DuBose, "Gas Plant Uses Carbon Fiber-Reinforced Polymer Wrap to Strengthen Concrete Columns," Materials Performance, 2014.

[19] A. Ilki, O. Peker, E. Karamuk, C. Demir and N. Kumbasar, "FRP Retrofit of Low and Medium Strength Circular and Rectangular Reinforced Concrete Columns," Journal of Materials in Civil Engineering, ASCE, vol. 20, no. 2, pp. 169-188, 2008. 
[20] D. Baggio, K. Soudki and M. Noel, "Strengthening of Shear Critical RC Beams with Various FRP Systems," Construction and Building Materials, vol. 66, pp. 634-644, 2014.

[21] P. d. 1. R. Garcia, A. C. Escamilla and M. N. G. Garcia, Bending Reinforcement of Timber Beams with Composite Carbon Fiber and Basalt Fiber Materials, Madrid, Spain: Polytechnic University of Madrid.

[22] L. Li, S. Yuan, J. Dong and Q. Wang, "An Experimental Study on the Axial Compressive Behavior of Timber Columns Strengthened by FRP Sheets with Different Wrapping Methods," Applied Mechanics and Materials, Vols. 351-352, pp. 1419-1422, 2013.

[23] S. Petro, H. V. S. GangaRao, U. Halabe, S. Aluri, A. Smith, B. King, W. Steele and A. Vasudevan, "Carbon Fiber Reinforced Polymer Composites Used to Repair and Rehabilitate Wood Railroad Bridges," West Virginia Department of Transportation, Charleston, WV, 2007.

[24] A. Smith, "Rehabilitation of Timber Railroad Bridges using Glass Fiber Reinforced Polymer Composite Wraps," Graduate Thesis Dissertations and Problem Reports, 2004.

[25] P. Vijay, H. GangaRao, R. Liang and M. Skidmore, "Rapid Restoration of Rail Raod Timber Bridges Using Polymer Composites," ANTEC, 2011.

[26] ASTM International, "ASTM D7565: Standard Test Method for Determining Tensile Properties of Fiber Reinforced Polymer Matrix Composites Used for Strengthening of Civil Structures," ASTM, West Conshohocken, PA, 2017.

[27] ASTM International, "ASTM D3039: Standard Test Method for Tensile Properties of Polymer Matrix Composite Materials," ASTM, West Conshohocken, PA, 2017. 
[28] H. V. S. GangaRao, R. K. Gupta, P. Vijay, R. Liang, U. Halabe, M. Skidmore, R. Creese and M. Pavlick, "RP270: Phase One: Determine Structures Where FRPP Wraps Would Be Beneficial," West Virginia University Constructed Facilities Center, Morgantown, WV, 2013.

[29] J. Brown and H. R. Hamilton, "Quantitative Infrared Thermography inspection for FRP Applied to Concrete Using Single Pixel Analysis," Construction and Building Materials, vol. $38,2013$.

[30] R. M. Joshi, "Nondestructive evaluation of FRP composite bridge componenets using infrared thermography and digital tap testing," The Research Repository at WVU, Graduate Theses, Dissertations, and Problem Reports, 2018.

[31] ASTM International, "ASTM D198: Static Flexural Testing of Lumber in Structural Sizes," ASTM, West Conshohocken, PA, 2015.

[32] R. Younes, A. Hallal and F. F. F. H. Chehade, "Comparative Review Study on Elastic Properties Modeling for Unidirectional Composite Materials," intechopen.com, 2012.

[33] FHWA, Bridge Inspector's Reference Manual, Arlington: Federal Highway Administration - National Highway Institute, 2012.

[34] C. L. C. Hing and U. B. Halabe, "Nondestructive Testing of GFRP Bridge Decks Using Ground Penetrating Radar and Infrared Thermography," Journal of Bridge Engineering, $A S C E$, vol. 15, no. 4, pp. 391-398, 2010. 


\section{APPENDIX A - COST ANALYSIS}

A cost analysis is performed to determine the cost of each of the four splice mechanisms employed in this program. This is entirely based on material cost to construct one of each of the four splice mechanisms. Material costs are based on the cost of each individual part that was purchased through WVU-CFC. Costs for each individual part used for the four splice mechanisms are provided in Table 5-8. The cost per splice was calculated and included in Table 5-9.

Table 5-8 - Splice Individual Part Costs

\begin{tabular}{|c|c|}
\hline Material & Price for Single Part \\
\hline 18 " Bolt & $\$ 4.91$ \\
\hline $24 "$ Bolt & $\$ 6.11$ \\
\hline Hex Nut & $\$ 0.56$ \\
\hline Washer & $\$ 0.51$ \\
\hline Flat Steel Plate & $\$ 46.75$ \\
\hline Steel C-Channel & $\$ 90.65$ \\
\hline 4"x6"x12' Timber & $\$ 21.77$ \\
\hline 50"x150' Glass Fabric & $\$ 1,390.00$ \\
\hline Epoxy Resin Kit & $\$ 325.35$ \\
\hline
\end{tabular}

Table 5-9 - Cost Per Splice Mechanism

\begin{tabular}{|c|c|c|c|c|c|c|}
\hline & Bolts & Washers/Nuts & Plates & Wrap & Resin & Total \\
\hline Flat Steel Plate & $\$ 58.92$ & $\$ 12.84$ & $\$ 187.00$ & - & - & $\$ 258.76$ \\
\hline C-Channel & $\$ 58.92$ & $\$ 12.84$ & $\$ 362.60$ & - & - & $\$ 434.36$ \\
\hline Wood Plate & $\$ 73.32$ & $\$ 12.84$ & $\$ 43.54$ & - & - & $\$ 129.70$ \\
\hline FRP Wrap & - & - & - & $\$ 74.13$ & $\$ 68.73$ & $\$ 142.86$ \\
\hline
\end{tabular}

Based solely on material cost the wooden plate splice mechanism is the cheapest and the steel C-channel splice mechanism is the most expensive. The FRP wrap splice is relatively cheap compared to the two steel mechanisms utilized in this program. The FRP wrap splice is inexpensive however material for only one mechanism cannot be purchased as the fabric is sold in 150' rolls. The FRP splice is cost effective if multiple piles need to be repaired with this mechanism. Shipping costs are not calculated in this cost analysis however the FRP splice mechanism will have the lowest shipping cost due to its low weight in comparison to the other 
splice mechanisms. Labor costs for the FRP wrap splice will also be lower as assembly time is quicker for this mechanism. In assembly of the four various splice mechanisms in the WVUCFC laboratory the three traditional (legacy) bolted splice mechanisms took on average 3.5 hours to assemble a single pile. In 3.5 hours up to four piles were assembled using the FRP wrap splice mechanism. Overall the FRP wrap splice mechanism is assumed to be the most cost effective of the four mechanisms utilized in this program. 